R.B. Miller et al.

Pragmatic Case Studies in Psychotherapy, http://pcsp.libraries.rutgers.edu/

Volume 17, Module 2, Article 2, pp. 129-209, 08-04-21[copyright by authors]

\title{
Further Developments in the Panel of Psychological Inquiry Method of Case Study Research:: The Case of "Ronan"
}

\author{
RONALD B. MILLER, ${ }^{\text {a,k }}$ BRIAN ASHLEY, ${ }^{\text {b }}$ KRISTIN MOUNT, ${ }^{\mathrm{c}}$ SAMANTHA \\ TUEPKER, ${ }^{\mathrm{d}}$ THOMAS POWELL, ${ }^{\mathrm{e}}$ DAVID O'LEARY, ${ }^{\mathrm{b}}$ MICHELE FOUTS, ${ }^{\mathrm{f}}$ \\ KIMBERLY ALLSHOUSE, ${ }^{\mathrm{g}}$ JACOB RUSCZEK, ${ }^{\mathrm{h}}$ KELSY HENNEBARROWS, ${ }^{\text {i }}$ \& \\ AMANDA DOMBROSKI ${ }^{\mathrm{j}}$

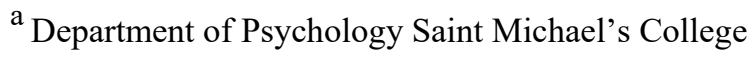 \\ $\mathrm{b}$ Private Practice, Burlington, VT \\ ${ }^{\mathrm{c}}$ Howard Center Children and Adult Outpatient Services, Burlington, VT \\ ${ }^{\mathrm{d}}$ Centerpoint Community Services, South Burlington, VT \\ ${ }^{\mathrm{e}}$ Vermont Forensic Psychology Associates \\ f Department of Psychology, Flagler College \\ $\mathrm{g}$ Private Practice, Montpelier, VT \\ h Faculty Master's Program in Clinical Psychology, Saint Michael's College, \\ and Private Practice, Montpelier, VT \\ i Wellness Center, Saint Michael's College \\ ${ }^{j}$ Graduate Assistant, Master's Program in Clinical Psychology, Saint Michael's College \\ ${ }^{\mathrm{k}}$ Correspondence regarding this article should be sent to: Ronald B. Miller, Department of Psychology, St. \\ Michael's College, One Winooski Park, Colchester, VT 05439 \\ Email: rmiller@smcvt.edu
}

\begin{abstract}
In 2011 our research group published a pilot study - the Case of "Anna"-employing the Panel of Psychological Inquiry (PPI) Clinical Case Study Method. The present study - the Case of "Ronan"-is a second example of the PPI method in action. The Case of Ronan has a number of modifications in method compared to the Case of Anna. First, the Case of Ronan involves the evaluation of a more complex and controversial written case study of a 20-month old boy who was diagnosed with moderate to severe autism spectrum disorder (ASD), and who was treated in a comprehensive therapeutic daycare center program where the core approach was based upon Greenspan's (2009) "Developmental, Individual-differences, Relationship-based" ("DIR"/ "Floortime") model. DIR/Floortime was originally developed for use by parents in their own homes, and the Case of Ronan demonstrates how a therapeutic pre-school environment can use DIR/Floortime as a model for most adult-child interactions in a pre-school therapeutic environment. In addition to the application of the PPI model to a radically different clinical diagnosis, there were modifications to the methodology itself including: (a) reduction in the number of judges from five to three; (b) having a key witness in the case testify remotely before
\end{abstract}


R.B. Miller et al.

Pragmatic Case Studies in Psychotherapy, http://pcsp.libraries.rutgers.edu/

Volume 17, Module 2, Article 2, pp. 129-209, 08-04-21[copyright by authors]

the Panel; (c) the writing of a much more detailed judges' opinion on the aspects of the case that most influenced their decisions; and (d) a further development of the logic of a quasi-judicial approach to clinical case studies in psychology. By examining how the civil law's basic framework for proving causality in cases of personal injury (who did what harm to whom), the process by which knowledge claims that emerge out of clinical practice (who provided what benefit to whom) is further explicated.

Keywords: clinical case study validity; quasi-judicial methodology; autism spectrum child; clinical case study; case study

\section{INTRODUCTION}

Early work on the methodology of a quasi-judicial or adjudication approach to clinical case study research began with Bromley (1986), in the United Kingdom. This was followed with work by Miller (1999, 2004, 2011, 2018); Bohart and Humphreys (2000); Bohart, Tallman, Byock, and Mackrill (2011a); Bohart, Berry, and Wicks (2011b); Bohart, 2018; and Elliott $(2002,2009,2015)$. This work on the quasi-judicial approach also coincided with the broader call for a return to pragmatic or systematic case studies in psychotherapy (and community psychology) by Fishman (1999); Dattilio, Edwards, and Fishman (2010); and Fishman, Messer, Edwards, and Dattilio (2017). An experimental psychologist specializing in the study of the impacts of ageing on the human mind, Bromley developed a view that the manner in which Anglo-American law constructs arguments and evidence in matters of the civil law cases would be far preferable to the way most clinical case studies are written in psychology and related disciplines. The logic of this position was based upon the realization that many of the areas of civil law-like breach of contracts, divorce, and personal injury-involve themes that constitute or parallel the presenting problems in many clinical psychological or mental health settings. Feelings of betrayal, abandonment, emotional (and sometimes physical) injury, and harm inflicted (whether intentional or unintentional) are common themes that are presented or emerge in the clients who seek out psychotherapy (Miller, 1998, 2004).

In Bromley's model the author of the case study assembles the information available about a case they have worked on. He strongly encourages the clinician to consider the quality of the evidence in a case study, and what would be the best evidence in support of a specific factual claim. Following the work on rhetoric and argumentation of the philosopher of science Toulmin (1959), Bromley urges the case study author to search for evidence in the records of the case that might support one possible explanation over the other available ones, and reach a conclusion based upon that evidence. There is an expectation that the case study author will be guided by respected theories of psychological explanation in doing and describing their clinical work. However, he challenges the clinician to consider whether the facts of the case actually support their theoretical assumptions, and to consider alternative interpretations of the facts of the case and how other theoretical assumptions might be relevant. 
R.B. Miller et al.

Pragmatic Case Studies in Psychotherapy, http://pcsp.libraries.rutgers.edu/

Volume 17, Module 2, Article 2, pp. 129-209, 08-04-21[copyright by authors]

Generally, in the civil law the concern is about establishing the responsibility of one person for the harm caused by their actions to another person. What Bromley saw was that the same process of building a case in law could be used to show that the actions of one person (e.g., a clinical psychologist or mental health worker) might be responsible for the benefit that accrued to a second person (the client or patient) in a therapeutic relationship. Bromley did not carry forward these critical insights about the nature of clinical reasoning in case studies into developing a formal procedure and mechanism for evaluating controversial cases that challenge the prevailing wisdom in a field. This is the reason for the development of the PPI approach to evaluating clinical case studies.

\section{THE PANEL OF PSYCHOLOGICAL INQUIRY (PPI) PROCESS}

In the initial pilot study of this methodology (Miller, 2011) seven components are identified, and these were implemented in this second pilot study, which took place over a period of four months:

(1) Standards of evidence which are adapted from the Federal Rules of Evidence (cf. Weissenberger \& Duane, 2007) that can be used to evaluate the truth of clinical claims. A prime example is the "hearsay rule" that permits conversations between doctors and patients to be introduced into evidence by the doctor over objections that such reports be considered hearsay.

(2) Descriptions of the participants, including: the panel administrator/convenor (the lead author); a three-judge panel; the case advocate; the case critic; and witnesses to the case, namely the therapist and clinical supervisor.

(3) A pre-hearing review of the written case study by all concerned.

(4) The development by the advocate and the critic of specific claims and counterclaims about the case to be proven before the Panel, which are shared these with one another and the judges prior to the PPI hearing. During this period both the advocate and critic have the opportunity to interview the witnesses (the clinician and the clinical supervisor) at their discretion, and to prepare their case outlines and strategy for the hearing. In this instance one of the witnesses was living at some distance from the site of the hearing and was able to be interviewed over the telephone or, during the PPI hearing, over Zoom. The Zoom technology made it possible to produce a video recording of the entire hearing.

(5) A 3.5 hour hearing process divided into a series of presentations by both the case advocate and the case critic of oral testimony and written evidence before the Panel, divided into five segments. This was one hour shorter than the first PPI, in part because there were fewer judges asking questions, but also due to the busy schedules of the judges and the limits to their working pro bono. 
R.B. Miller et al.

Pragmatic Case Studies in Psychotherapy, http://pcsp.libraries.rutgers.edu/

Volume 17, Module 2, Article 2, pp. 129-209, 08-04-21[copyright by authors]

(6) After a period of several weeks of individual reflection, the issuance of the judges' opinions through the feedback forms and a subsequent phone conference. (The write-up of the final judges' opinion took much longer than the four-month period of the basic process).

(7) Possible appeal of the findings. This has not occurred in the two pilot studies, but the model requires it in keeping with the model of the civil law.

Saint Michael's College in Vermont served as the host to the Panel in keeping with the PPI model that a non-profit organization devoted to promoting the knowledge base of clinical practice in psychology organize the Panels of Psychological Inquiry as a public service. Ultimately, the goal is for local and regional independent non-profit organizations to be established to support the development of "case law" in the clinical practice of psychology. This "case law" would be a body of validated clinical practice knowledge in psychology. Such a PPI organization would ultimately appoint the judges and case advocates and case critics for individual cases and publish the findings of the Panels. The clinician whose work is being evaluated would voluntarily submit a written case study to the PPI organization with permission from the client in the case. The clinician would select the case advocate they wish to work with from a list of case advocates approved by the PPI organization. The PPI organization would also maintain a roster of case critics who could be recruited to participate in specific Panels of Psychological Inquiry.

\section{Creating a PPI for this Second Pilot Study}

\section{Selecting a Case.}

While the PPI model envisions a day when this process will be initiated by a clinician (a) who wishes to have their work known to a larger audience, and (b) who is aware of how often case studies are dismissed as anecdotal clinical accounts of little value due to concerns about biased reporting and other self-serving biases that distort the clinician's accounts of their own work. Such a clinician would see the value in having their work reviewed by a PPI and potentially independently validated by a Panel of highly respected clinicians in their local community.

However, in this pilot study as in the last, the process was initiated by the lead author in order to further develop the PPI model. In this instance, a case study master's thesis by Kristen Mount (2016) was selected by the lead author based upon the severity of the diagnosis, the nature of the treatment - as explained below, the case did not employ the accepted therapy model for autism of Applied Behavior Analysis - and the thoroughness of the thesis paper. The case involved a two-year old boy who had been given the pseudonym "Ronan" in the thesis, and who had been diagnosed prior to treatment by an independent state agency and been found to be suffering from moderate to severe autism spectrum disorder. Ronan had been treated not primarily with the Applied Behavior Analysis (ABA) approach so widely regarded as the treatment of choice for such cases, but instead with a modified version of Greenspan's (2009) 
R.B. Miller et al.

Pragmatic Case Studies in Psychotherapy, http://pcsp.libraries.rutgers.edu/

Volume 17, Module 2, Article 2, pp. 129-209, 08-04-21[copyright by authors]

DIR/Floortime method in a therapeutic daycare center (referred to as the Center hereafter) created by a licensed psychologist, Michele Fouts, MA. Mount had been supervised in her graduate practicum and internship by Fouts, and Mount wrote her master's thesis on the experience of working as a staff member with Ronan at the Center.

Both Mount and Fouts agreed to participate in the PPI. For Mount this meant giving permission for her master's thesis case study (previously defended before a thesis committee) to be subjected to review by an independent panel of judges, and for her to be called as the lead witness in the PPI hearing in order to testify under oath. As her clinical supervisor at the Center, Fouts agreed to be a second witness before the Panel testifying to her own work with Ronan as Center director, and the validity of Mount's account of the treatment center and her own work with Ronan. Fouts agreed to facilitate the process of having Ronan's adoptive mother sign a release for the Center's records of clinical work with Ronan to be evaluated by the Panel, and in the process his mother happily reported and agreed to disclose to the Panel follow-up information on Ronan's current developmental status at the time of the Panel being organized, several years after Mount's thesis was written.

\section{The Particular Need for a Rigorous Case Study Methodology in the Treatment of ASD}

It should be noted that the first PPI pilot study, the Case of Anna (Miller, 2010), was of a young woman seen at a college counseling center whose symptoms were not unlike many college students struggling with their identity and adjustment to college. While certainly important work, the level of difficulty of the problems encountered by Ronan were of a different order of magnitude, and the treatment milieu as well as the individual work of the clinical graduate student were highly integrated.

In addition, the case presents a clinical diagnosis where there is a strong tradition of case study research that is deemed scientific, namely, single-subject experimental designs from Applied Behavioral Analysis (ABA). While there has also been a good deal of group design studies, they tend to be done in the face of serious obstacles that limit the ability to do full scale randomized controlled trials (RCT's). These obstacles appear to be particular to the subject of the treatment of ASD in young children. Most experts believe in the importance of early intervention for developmental disorders; however, the diagnosis of children prior to age one year is very difficult (Antonio, Costanza, Paolo, Umberto \& Filippo, 2014). In addition, these authors identify the following obstacles to doing RCT research on ASD in young children:

There are a plethora of issues making it difficult to carry out an RCT in autism. First, the parents are very informed about the various treatments they think to be most useful for their children and therefore many parents operate their own choices giving a deaf ear to the suggestions of clinicians....Secondly, many studies on autism interventions are made with very little funding compared to those necessary to conduct an RCT. Thirdly, a control group "without treatment" poses ethical problems because there is strong evidence that providing a treatment is better than providing none. (p. 5). 
R.B. Miller et al.

Pragmatic Case Studies in Psychotherapy, http://pcsp.libraries.rutgers.edu/

Volume 17, Module 2, Article 2, pp. 129-209, 08-04-21[copyright by authors]

Despite this acknowledgement of the threats to internal and external validity of RCT research on autism treatment, Antonio et al. list DIR/Floortime as one of the twelve most popular non-pharmacological treatments for ASD. Their review of the literature focuses on rating the scientific quality of research on these approaches, ranging from a rating of 1 indicating an RCT that measures both IQ and adaptive functioning and finds significant differences in favor of one approach over another on both measures; to a rating of 4 indicating only significant general improvement. Using these ratings, DIR/Floortime was rated in the bottom 22 percent of autism treatment studies in terms of quality of the research design.

Odom, Boyd, Hall and Hume (2010) did a literature review of 30 comprehensive treatment programs for individuals with autism spectrum disorders in order to establish which programs demonstrated treatment efficacy. They excluded focused intervention treatment approaches, which they argue have already established evidence of efficacy. Comprehensive programs are identified by having goals that include broader learning or developmental impact on core deficits. DIR/Floortime was one of the 30 programs examined. Each program's publications were evaluated over six categories, on a scale of 0 to 5 , with 5 being the highest rating. The DIR/Floortime program received a total rating of 19/30. The better known Denver program scored only slightly higher at $21 / 30$. The three highest rated programs were all based upon Applied Behavior Analysis, including the Lovaas Institute Los Angeles, 27/30; the May Institute, Randolph, Massachusetts, 25/30; and the LEAP program in Denver, Colorado 25/30.

Wagner, Wallace, and Roger's (2014) chapter on "Developmental Approaches to Treatment of Young Children with Autism Spectrum Disorder" ranks studies into six types with RCT's rated the highest (Type 1) and studies with "significant methodological flaws" including no control group or retrospective studies rated as Type 3. Case studies are rated type 6 and not included in the literature review at all. They found one study on DIR/Floortime that was an RCT and rated Type 1 (Pajareya and Nopmaneejumruslers, 2011) and two Type 3 studies.

Though this is not very encouraging for proponents of DIR/Floortime, Wagner, Wallace and Rogers (2014) make a number of observations on the research literature as a whole that are indirectly encouraging to those interested in the DIR/Floortime method. First, they call for a better integration of ABA approaches to treatment and the relational/developmental models as a whole as it is clear that developmental research in general is identifying the critical importance in healthy development for young children of mutually rewarding play and social interactions with parents and peers. Second, they acknowledge the generally disappointing state of the research literature they reviewed, commenting,

In terms of strength of evidence, we have very few high-quality efficacy trials of these developmental approaches to early autism. While behaviorally based interventions for early ASD also have few high-quality group efficacy studies, there are a plethora of high quality single-subject designs demonstrating behavioral control of the dependent variables in the behavioral literature (pp. 535). 
R.B. Miller et al.

Pragmatic Case Studies in Psychotherapy, http://pcsp.libraries.rutgers.edu/

Volume 17, Module 2, Article 2, pp. 129-209, 08-04-21[copyright by authors]

Finally, while noting the great difficulty in executing RCT studies with parents and children when children are identified with ASD at very young ages (echoing the concerns of Antonio et al. (2014) above), the review suggests that developmental researchers adopt "high quality single-subject designs" that "would add considerably to the accumulation of evidence of the efficacy of developmental approaches." Granted these authors are suggesting that developmental researchers find easily measurable behavioral indicators used in developmental psychology rather than the narrative data of a quasi-judicial method. However, the logic of their argument is quite parallel to that which led to the development of the model described here. RCT's are not very useful in determining the appropriate treatment in the complexity of the lives of individual children, just as they aren't in finding the right treatment for older psychotherapy clients. Both ABA single subject designs and the narrative case study of Ronan can be rigorous, and can allow for the kind of individualized treatments needed in the real world of clinical practice. The real question is this: Are the standards of evidence and rules of procedure for determining the responsibility for the outcomes of important human interactions that were developed over 500 years in Anglo-American civil law at least as reliable in determining the truth about human behavior as are the single-subject experimental research designs used in ABA research that were originally created 80 years ago for the study of pigeons and rats in laboratory settings?

\section{Recruiting the Advocate and the Critic.}

As in the first pilot study (Miller, 2010), the advocate and critic were appointed by the lead author. They were chosen on the basis of being outstanding graduate students and classroom discussion leaders in the lead author's MA program in clinical psychology, and because they were finishing their degrees and would understand well their freedom to decline the invitation. They were given copies of Mount's master's thesis on the treatment of Ronan and both students read it and the article on the PPI process (Miller, 2010) prior to agreeing to participate. They each had about six weeks to prepare their case for presentation to the PPI judges. About two weeks before the PPI hearing, the judges received a pre-hearing outline of the arguments that would be presented by the advocate and the critic.

The lead author introduced both the case advocate and case critic to the PPI process and their roles in it. He suggested that the case advocate limit herself to identifying three or four key claims in the written case study, and suggested to the case critic that in addition to attempting to rebut the advocates claims he consider having at least one of his own counterclaims. Both the advocate and critic were actively supported to the extent that they requested guidance. Opinions were offered when requested, but the final choice of claims, arguments, and evidence introduced were at the discretion of the participants.

\section{$\underline{\text { Recruiting the Judges }}$}

In the initial PPI, there were five judges, in order to obtain a broad cross-section of feedback on the PPI hearing process. Their feedback was very useful, and it seemed given their viewpoints, that a panel of three judges might be sufficient for a second pilot. Departing from the 
R.B. Miller et al.

Pragmatic Case Studies in Psychotherapy, http://pcsp.libraries.rutgers.edu/

Volume 17, Module 2, Article 2, pp. 129-209, 08-04-21[copyright by authors]

original PPI process, the Vermont Psychological Association (VPA) and the Vermont Association for Psychoanalytic Studies (VAPS) were each asked to nominate a judge for the process. VAPS nominated their research coordinator, Jacob Rusczek, PhD, and the VPA declined as they did not have a research coordinator. The lead author appointed the two other judges, Thomas Powell, PhD, a well-known, highly experienced forensic psychologist in Vermont, and Kim Allshouse, MSW, MA, who has extensive training and experience as both a clinical social worker and as licensed psychologist-master's in Vermont. Ms. Allshouse has many years of clinical experience working with adults with disabilities including autism spectrum disorder. ( Both Judge Powell and Judge Allshouse had received master's degree's in clinical psychology from the host institution decades before the convening of this PPI, and had only intermittent contact with the lead author in the intervening years.)

As noted earlier, the judges were given the master's thesis case study by Kristin Mount on the case of Ronan to read prior to deciding if they wished to be on the Panel, and were also provided with outlines of the cases to be presented by the advocate and critic two weeks before the actual hearing. They were given a judge's opinion form to be filled out after the hearing where they were asked to vote for against each of the four claims and one counterclaim, and to give a detailed explanation of their reasons for each of the four decisions. After their decisions were received, a phone conference was convened to explore where their opinions were divided, and to elicit additional feedback on the process.

\section{The Witnesses}

As noted above, the case study author, Kristin Mount and her supervisor at the Center, Michele Fouts, were the witnesses at the PPI hearing. During the PPI process participants other than the judges were addressed on a first names basis.

\section{Confidentiality}

All participants in the PPI process who had access to the original case study, the advocate and critic's prepared outlines of their positions, and any of the case records from the Center introduced into evidence at the PPI hearing, were given a summary of the American Psychological Association Code of Ethics sections (APA, 2017) that relate to protecting confidentiality of clinical material and records which had to be signed and returned to the first author prior to the day of the PPI hearing. This confidentiality pledge, which is presented in Table 1, was read at the beginning of the PPI hearing by the first author who presided over the hearing as a reminder of what each participant had agreed to regarding confidentiality and the severe penalties for violating the pledge.

\section{Documents Submitted into Evidence}

The advocate introduced into evidence the original report from a State agency of an independent diagnosis of Ronan with moderate to severe autism at age two years, as well as a 
R.B. Miller et al.

Pragmatic Case Studies in Psychotherapy, http://pcsp.libraries.rutgers.edu/

Volume 17, Module 2, Article 2, pp. 129-209, 08-04-21[copyright by authors]

letter from Ronan's adoptive mother about the progress he has made at home and school in the last two years prior to the PPI hearing.

\section{The PPI Hearing Timetable}

9:00 am. Chair of the Panel: Introductions of participants and relevant APA Ethics Code principles (APA, 2017) that require the honest reporting of data, and responsible handling of clinical information to protect the privacy and confidentiality of clients.

9:05 am. Opening Arguments:

Opening argument by the case advocate who presented the basic claims being made about the case and outlining the evidence that will be presented (10 minutes).

Opening argument by the case critic who presented perceived weaknesses in the claims being made about the case by the advocate. (10 minutes).

9:30: Questioning of the Therapist to Establish Case Claims:

Advocate questioned the therapist to establish the evidence for the claims being made about the case. (30 minutes).

The case critic questioned the therapist by (20 minutes).

Follow-up questions to the therapist by the case advocate (5 minutes).

Panel members question the therapist/advocate/critic (10 minutes).

10:35 Break

10: 45 Questioning of the Supervisor to Establish Claims

The case advocate questions the supervisor by (20 minutes).

The case critic questions the supervisor by (15 minutes).

The advocate asks follow-up questions of the supervisor by (5 minutes).

11:05 Panel questions the supervisor/advocate/critic (10 minutes).

11:15 Questioning of Therapist/Supervisor to Establish Counter-Claims

Case critic questions therapist/supervisor on counter-claims (20 minutes).

Case Advocate questions therapist/supervisor ( 15 minutes).

Follow-up questions by case critic (10 minutes).

Panel questions the therapist/supervisor/advocate/critic (10 minutes).

12:10 Lunch Break

1:00 Closing Case Summaries

Case Advocate (10 minutes).

Case Critic (10 minutes). 
R.B. Miller et al.

Pragmatic Case Studies in Psychotherapy, http://pcsp.libraries.rutgers.edu/

Volume 17, Module 2, Article 2, pp. 129-209, 08-04-21[copyright by authors]

\section{The Claims and Counterclaim: The Burden of Proof and Standards of Proof}

In the civil law, as in experimental research in psychology, it is necessary for the advocate of a position or research hypothesis to provide evidence in support of their assertions. In the absence of good evidence, critics need only refute the credibility of the evidence offered, and the case or research hypothesis fails to be confirmed. A critic or critical researcher may also choose to claim that there is evidence in the case or data set that has been overlooked, and that would support a very different view of the case. In addition, a critic of a case study or a research project could also introduce evidence from other clinical cases studies or experimental research programs that contradicts the claims being made in the original paper. When either of these last two strategies is undertaken by a critic, the burden of proof shifts on to the critic to now prove their new assertions.

It is important to note that in civil law there is a very different standard of proof than in the criminal law. The well-known phrase from criminal law that the defendant must be found guilty "beyond a reasonable doubt" is a very high standard indeed. It is justified on the basis of the result, for if one is found guilty one may lose one's individual liberty or even one's life. In the civil law, one risks losing one's personal property often in the form of monetary damages. In such circumstances civil courts have three increasingly more difficult standards of proof that may be invoked by the presiding judge: in the typical case the plaintiff or injured party must prove their case with a preponderance of evidence $(51 \%$ of the evidence and argument favoring their side). In cases where the damage done to another person's financial position is more egregious, it is required that the evidence and arguments be "clear and convincing." It is often suggested that the numerical equivalent of this standard is that the likelihood of the plaintiff's position being true is $70-80 \%$. In the rare cases where the civil law invokes the standard of "beyond a reasonable doubt" that the quantitative translation is greater than an $80 \%$ likelihood that the plaintiff's accusation is true. These numerical estimates are of course metaphorical, as there is no process for counting the strength of evidence. It is a matter of subjective judgment based upon the narrative force of the case made by the two opposing sides. In this PPI the standard of proof that is employed is "by a preponderance of evidence" - the most commonly used standard in civil trials.

In the case of Ronan, the case critic, David O'Leary, chose to both question the advocate's evidence, and then highlighted aspects of the original case that actually refuted part of the advocates third claim.

\section{The Four Claims of the Advocate}

Advocate Samantha Tuepker assumed the burden of proof for these four claims:

1. At time of treatment, "Ronan" met the criteria for Autism Spectrum Disorder, v moderate to severe.

2. Kristin implemented a relationship-based model of therapy in the context of the treatment center's therapeutic milieu. 
R.B. Miller et al.

Pragmatic Case Studies in Psychotherapy, http://pcsp.libraries.rutgers.edu/

Volume 17, Module 2, Article 2, pp. 129-209, 08-04-21[copyright by authors]

3. This treatment improved Ronan's outcomes (in social, emotional and cognitive areas).

4. There is a subset of children with moderate to severe Autism Spectrum

Disorder for whom this treatment is likely to be helpful.

Case Critic David O'Leary Offers a Counterclaim

for Which He Assumed the Burden of Proof

Since two years have passed between the end of treatment and follow-up, and since other one-to-one caregivers have been involved at home and in school, outcomes at follow-up cannot be attributed to Kristin's work at the treatment center.

\section{The Advocate's and the Critic's Case Outlines (Provided to the Judges Prior to the PPI Hearing)}

\section{$\underline{\text { Samantha Tuepker's Outline of the Advocate's Case }}$}

Claim 1: At the time of treatment, Ronan had Autism Spectrum Disorder, given this evidence:

(a) State Child Development Office Report

Two different assessments were conducted by the State

Development Center: The Bayley Scales of Infant and

Toddler Development-3rd Edition (Bayley-3); and the Autism

Diagnostic Observation Scale-2 (ADOS-2).

The Bayley assesses children between 1 month and 42 months of age and assesses child development across 5 domains: cognitive, language, motor, social-emotional, and adaptive. Ronan's age at assessment was 25 months. Cognitive skills were at a developmental level of 17 months, receptive language skills at 7 months, expressive language skills as 9 months, fine motor skills at 17 months, and gross motor skills at 18 months.

The ADOS is a play-based evaluation that includes makebelieve play, joint attention, response to name, and task completion. Ronan received a score of 19 on the ADOS-2, placing him in the range of moderate-to-severe concern for autism.

(b) Ronan also met criteria for a DSM-5 diagnosis of Autism Spectrum Disorder 299.00 (F84.0). He showed deficits in social-emotional reciprocity; deficits in nonverbal communicative behaviors used for social interaction; deficits in developing, maintaining, and 
R.B. Miller et al.

Pragmatic Case Studies in Psychotherapy, http://pcsp.libraries.rutgers.edu/

Volume 17, Module 2, Article 2, pp. 129-209, 08-04-21[copyright by authors]

understanding relationships; stereotyped or repetitive movements in the use of objects, or speech; and hyper- or hypo-reactivity to sensory input or unusual interest in sensory aspects of the environment.

(c) The Center Treatment Plan (1/19/15)

Michele's notes pertaining to Ronan's presentation: Ronan did not make eye contact; did not seek proximity to care giver; repeatedly opened and closed cabinets and doors; did not babble or use single words; did not point to shared interests or make requests; did not respond to name; did not explore/use toys in developmentally typical fashion; and made no attempts to engage socially.

(d) Kristin's Mount's description of Ronan in the case study

Throughout the case study, Kristin gave observations of Ronan's behavior. She described that he only spoke a few words; would barely acknowledge that he had heard his name; would barely register pain; showed a lack of eye contact; showed little initiation in interactions with adults or peers; and had extreme difficulty managing his emotions.

(e) Witnesses:

1. Michele: Discuss State Development Center report and Treatment Plans.

2. Kristin: Describe day-to-day with Ronan, observations of his behavior.

Claim 2: Kristin implemented a relationship-based model of therapy in the context of the Center's therapeutic milieu, given this evidence:

(a) Interview with Michele

The interview with Michele will discuss the general aims/goals/values of the therapeutic model offered at the Daycare Center. This includes goals such as having staff achieve co-regulation with each child in order to ultimately increase each child's intrinsic motivation to engage with others (as opposed to using behavioral or external motivators, such as giving a reinforcer when a task is accomplished).

She will explain opening and closing circles of communication. She will explain the model's emphasis on the 
R.B. Miller et al.

Pragmatic Case Studies in Psychotherapy, http://pcsp.libraries.rutgers.edu/

Volume 17, Module 2, Article 2, pp. 129-209, 08-04-21[copyright by authors]

relationship between staff and child: once a strong relationship has been established, the staff can push the boundaries in small, meaningful ways to help the child master new skills. She will explain this model's emphasis on the process of relationships, rather than the product. Michele will discuss the differences between her Center and other daycare centers.

(b) Interview with Kristin

The interview with Kristin, that will take place at the PPI, will continue to discuss interventions used at the Center. Kristin will discuss how she applied this treatment model with Ronan or with other kids, and what it looked like. She will discuss why she considers this model to be an integrative model: specifically, expectations around eating at the table, the use of behavioral strategies if a child is too unsafe or disruptive such that co-regulation cannot occur.

(c) Witnesses

1. Michele: Discuss the model used at the Daycare Center in depth.

2. Kristin: Discuss examples of how she used this model with children at the Daycare Center.

Claim 3: Kristin's application of relationship-based therapy, in the context of Center's therapeutic milieu, improved Ronan's outcomes, given this evidence:

(a) There are many examples that Kristin wrote about in her case study that will be discussed as evidence for this claim.

We will discuss Kristin's observations leading up to these interactions, her method of joining/co-regulating with Ronan, the outcome of the co-regulation, and how this interaction led to more improvement in Ronan's abilities. Interactions that will be used: the door example (p. 195 of Kristen's case study [see Appendix A]); the bubble example (p. 204); the nap example (p. 204); and the teasing example (p. 205). These instances will create a timeline of improvement.

(b) Kristin will also discuss why she believes Ronan's growth has, in large part, come from the support provided to him at the Daycare Center, rather than simply the passage of time, or having a safe stable home. 
R.B. Miller et al.

Pragmatic Case Studies in Psychotherapy, http://pcsp.libraries.rutgers.edu/

Volume 17, Module 2, Article 2, pp. 129-209, 08-04-21[copyright by authors]

(c) Progress Reports from the Daycare Center: Michele reported progress using the Greenspan Social-Emotional Growth Chart on four different occasions $(2 / 2015,5 / 2015,10 / 2015,3 / 2016)$. These progress reports show steady progress on social-emotional milestones while at the Center.

Treatment plans also documented progress on items such as problem solving, communication attempts, social engagement, and joint attention $(4 / 29 / 15 /, 7 / 30 / 15,10 / 1 / 15,1 / 15 / 16)$

(d) School: The school conducted many assessments, including Teaching Strategies GOLD, informal progress reports, the Reynolds Intellectual the Assessment Scales, the SLP Goldman-Fristoe Test of Articulation, the Preschool Language Scales, and the Wechsler Individual Achievement Test.

Outcomes of these tests showed "very average range" on composite intelligence, "borderline of the average range" for "receptive language performance," scores for "total language and expressive communication fell within the lower half of the average range." Overall, the reports state that Ronan "performed well on tasks measuring verbal reasoning abilities... On measures of academic testing, [Ronan] demonstrated slightly less developed early reading and math skills." Preschool language scales administered in 2017 show "tremendous progress" since he was tested in 2014 at the age of 20 months. He was in the $1^{\text {st }}$ percentile at 20 months of age for all language scores (receptive, expressive, and total) and now falls within the lower end of the average range.

(e) Michele's follow-up observation of Ronan.

(f) Follow-up letter from aunt (January 2018).

(g) Witnesses. Kristin: Specific examples of interactions that she had with Ronan that highlight the relationship-based therapy of the Daycare Center. Michele: Progress reports throughout his time at the Daycare Center; follow-up observation of Ronan; and follow-up letter from aunt.

Claim 4: This treatment model can show similar outcomes for other children with autism, given this evidence:

(a) In a formal interview, Michele will provide evidence for the generalizability of this case to other cases of autism. She will outline and discuss similar cases at the Daycare Center, showing that Ronan's 
R.B. Miller et al.

Pragmatic Case Studies in Psychotherapy, http://pcsp.libraries.rutgers.edu/

Volume 17, Module 2, Article 2, pp. 129-209, 08-04-21[copyright by authors]

case is not exceptional or unique. She will explain cases with similar backgrounds to Ronan (those with extreme trauma/neglect). She will also describe other cases that showed more progress and improvement and will give her opinion as to why more progress was made (more caregiver involvement).

(b) Witnesses: Michele and Kristin will describe day-to-day with Ronan, including observations of his behavior.

\section{David O'Leary's Outline of the Critic's Case}

Claim 1: At the time of treatment, Ronan had Autism Spectrum Disorder:

(a) The case critic does not necessarily disagree with the diagnosis of Autism Spectrum Disorder, but has questions about the seemingly transient nature of Ronin's diagnosis. Certainly, when viewing the case in its entirety, the overwhelming marked improvement in cognitive, language, social-emotional, and adaptive domains over a relatively short amount of time at the Daycare Center is noteworthy to say the least. Additionally, the notion of a traumatic infancy is referenced early on in Ronin's case study, but due to limiting information, this is not referenced further.

(b) I wish to ask more questions about this aspect of the case; chief among them, was the lack of relevant information about the potential trauma Ronan experienced taken into consideration at the time the assessment process was conducted by the State Office of Development?

(c) Witnesses: Michele - to ascertain the continuum of information sharing amongst the assessment team and the Daycare Center.

Claim 2: Kristin implemented a relationship-based model of therapy in the context of the Daycare Center's therapeutic milieu:

(a) I wish to know more about the day-to-day interactions between Kristin and Ronin, specifically around any situations, when applied to a more traditional Applied Behavioral Analysis, would have called for more traditional application of reinforcers upon task completion. In essence, how did Kristin communicate to Ronin that the completion of a task was indeed a good thing to be replicated without traditional reinforcers. I therefore wish to ask Michele, as Kristin's supervisor, how she guided Kristin through such dilemmas and what substitutes, if any, were in place of more traditional approaches. 
R.B. Miller et al.

Pragmatic Case Studies in Psychotherapy, http://pcsp.libraries.rutgers.edu/

Volume 17, Module 2, Article 2, pp. 129-209, 08-04-21[copyright by authors]

(b) Second, the therapeutic model offered at the Daycare Center was quite different from more traditional ABA models of intervention. I am curious as to what degree Kristin was familiar with these methods, especially in her previous capacity as a developmental psychologist, and whether or not these two worlds crossed over in a way that would "dilute" the Daycare Center's method of intervention.

(c) Witnesses:

Kristin: I wish to explore the potential that Kristin's previous experience in developmental psychology may have biased her against ABA and biased her in favor of a less traditional model of therapy for the Daycare Center.

Michele: I wish to determine how supervision was implemented for Kristin to ensure that her methodology was consistent with that of the Daycare Center's.

Claim 3: Kristin's application of relationship-based therapy, in the context of the Center's therapeutic milieu, improved Ronan's outcomes:

(a) Kristin's case study briefly assesses the limitations of ABA in regards to relationship building with others. I wish to pursue a line of questioning that will clear up exactly how much time each day was spent with Ronin on relationship-based therapy and how much was spent in the areas that ultimately led to Ronan's symptomatic improvements across cognitive and adaptive domains, especially as one of the school assessors stated that "on measures of academic testing, Ronan demonstrated slightly less developed early reading and math skills."

I wish to know more about how the relational approach addressed these areas of progress. My reasoning for this approach stems from my question as to what degree the Center's relational approach applies to these domains, and what that mechanism of change looked like on a day to day basis with Ronan.

(b) Ronan was unable to continue working with his team at the Center, and over time, the methods used by Michele were transferred to other care givers. I would like to know to what degree these care givers adhere to the Day Care model on an ongoing basis with Ronin, and if that work is in some way monitored to ensure that the essential tenets of the model are adhered to.

(c) Witnesses: Kristin: Specific examples of how this method of intervention bettered traditional ABA techniques, especially in regards 
R.B. Miller et al.

Pragmatic Case Studies in Psychotherapy, http://pcsp.libraries.rutgers.edu/

Volume 17, Module 2, Article 2, pp. 129-209, 08-04-21[copyright by authors]

....? Michele: I wish to know more about her training techniques for other providers who have taken up Ronan's care after his time at the Center ended.

Claim 4: It is likely that there is at least a subset of children with moderate to severe autism spectrum disorder for whom this treatment is likely to be helpful.

(a) In the formal interview, I wish to know more about the similarities between Ronan's case presentation and that of other children Michele has worked with. For example, to what degree does the relational model work with traumatized children versus non-traumatized children? Is the "subset" of children to which this treatment may apply only involve trauma?

(b) In her case study of Ronan (Appendix A) Kristin writes of other cases in the literature that are similar to Ronan's. In Lydia's case (Appendix A, p. 195), the effects of the treatment are less impressive than Joey's (Appendix A, p. 196), and far less noticeable than Ronan's. If the intention is to attempt this type of therapy with other clients with autism, to what degree can outcomes be predicted?

(c) Witnesses: Michele: Comparison case studies from the Daycare Center. Kristin: Comparison studies from the literature.

\section{Counter-Claim:}

I have one central counter-claim in this case, and that relates directly to claim number 3. My counter-claim is: It cannot be adequately proven that Ronan's ultimate outcomes, based on Michelle's most recent observations at his home, can be directly attributed to Kristin's intervention. This conclusion is based in large part on the amount of time passed between the last time Michele and Kristen worked together, and the lack of supervision in that interim for the one-toone caregiving that took over the work that Kristin began.

Ronan's outcomes in the cognitive, language, motor, social-emotional, and adaptive domains are certainly impressive, but to what degree can this Panel be assured that the techniques used by Kristin and the Daycare Center were adhered to by both primary and additional caregivers upon Ronan leaving the Center? A training session in these techniques was offered by Michele, but I wish to know how one may ascertain the degree to which the essential tenets of the technique were adhered to in the time period between Kristin ending therapy with Ronan and Michele's follow-up visit in two years later. 
R.B. Miller et al.

Pragmatic Case Studies in Psychotherapy, http://pcsp.libraries.rutgers.edu/

Volume 17, Module 2, Article 2, pp. 129-209, 08-04-21[copyright by authors]

Witnesses: Michele will be asked about levels of supervision for additional caregivers. Kristin will be asked more about the training she received from Michele in this technique, and to what degree she believes ongoing supervision to have been integral to incorporating this technique in a way that was effective for the client.

\section{THE OUTCOME OF THE PPI: OVERVIEW}

The PPI hearing was a collegial event as had been the first pilot study. The judges used their allotted time for questioning of the witnesses liberally, digging deep into the details of the case with the two witnesses and questioning ambiguities in their testimony. At the same time the judges expressed their enthusiasm for the work of both the case study author, Kristin Mount, and the Center director Michele Fouts, and the jobs done by the advocate and critic in their roles in the process.

One of the key differences in this PPI as compared to the first pilot study was the expectation this time that the judges would provide very detailed answers to the questions on their rating form. They were asked not only whether they accepted each of the claims and counterclaim but exactly what it was about the PPI process that most influenced their decisions. In addition, once they had make their decisions, they agreed that the first author would write up their opinion citing the specific sections of the hearing they were referring to in their response forms. We made a transcript of the entire 3.5 hours of the PPI hearing, and were able to identify and quote passages of the testimony that substantiated their findings.

This documentation is important in that it shows how the witnesses impacted the outcome of the judges' decisions in different ways and at different times. Given the different clinical backgrounds of the three judges, it is remarkable how consistent their views were with one another on the key claims investigated by the PPI. At the same time they did have their own perceptions of the witnesses, advocate, and critic and did not hold back their honest judgments about the case and its presentation in the PPI.

This is a critical aspect of the PPI As in the civil law, it is the judges that make the law by their decisions. They determine whether a clinical observation seems valid or whether a clinical treatment is effective. In this model the ultimate principles and guidelines of accepted clinical practice would ultimately be decided by a historical tradition of judges' decisions. (As with the civil law there may be divergences of opinion among local judges that might ultimately require the development of regional Appeal Panels who would decide the more controversial cases.)

To some extent, there are already de facto local clinical knowledge communities that have grown up around various psychotherapy training institutes in major metropolitan areas. Furthermore, there are elite university clinical psychology research centers that establish the local, regional, or national standards for knowledge claims related to clinical practice (i.e., standards of evidence-based treatments). These communities are very often highly critical of the 
R.B. Miller et al.

Pragmatic Case Studies in Psychotherapy, http://pcsp.libraries.rutgers.edu/

Volume 17, Module 2, Article 2, pp. 129-209, 08-04-21[copyright by authors]

standards set by the other. For this reason the judges' decisions on the four claims and the counter-claim are detailed and comprehensive. The goal of the PPI model is to develop a rigorous methodology that can evaluate clinical knowledge claims using rules of evidence and hearing procedures that are can be accepted by both the scientist-practitioner community and the local knowledge communities of clinical practitioners that exist wherever psychotherapy is practiced.

\section{THE OUTCOME OF THE PPI: THE JUDGES' OPINIONS ON THE FOUR CLAIMS AND COUNTER-CLAIMS}

\section{Claim \#1: At the Time of Treatment, Ronan Had Autism Spectrum Disorder (ASD)}

\section{The Advocate's Arguments}

The advocate supplemented the case study the judges had the opportunity to read before the PPI hearing with testimony from both the therapist, Kristin Mount, and the treatment center's director, Michele Fouts. One fact to support this claim includes the report conducted by the State Development Center which diagnosed Ronan with Autism Spectrum Disorder (ASD) through three means of assessment: The Bayley Scales of Infant and Toddler Development-3, the Autism Diagnosis Observation Scale-2, and a review of the Diagnostic and Statistical Manual of Mental Disorders-5. These reports were included in the panel for the judges to read.

Another fact to support the advocate's claim is indicated in the therapist's written thesis (Appendix A), which describes Ronan's distinct characteristics that are associated with ASD. This thesis included the case study of Ronan and was read by the judges before the hearing.

The third fact supporting the advocate's claim is the Daycare Center's treatment plan for Ronan created by the supervisor. The notes on Ronan's presentation and treatment needs indicate characteristics of ASD. The critic did not offer any contradictory evidence to dispute this claim, though he did question whether factors other than ASD, such as Ronan's possible trauma history, may be involved in his symptomology.

The hearing produced a detailed discussion about the facts of this claim. To begin, the advocate briefly reviewed the case materials, including the State Child Development Center report for the judges. The written report was also provided to the judges to review. After her introduction, the advocate called Ms. Kristin Mount, the child's therapist, as witness and asked her to describe her perceptions about Ronan:

Advocate: Can you tell us some of your initial impressions of Ronan?

Therapist: He didn't seem to have any social interest. He didn't look anyone in the eye, there was little that could catch his attention, he wouldn't look over when other kids were giggling, and adults had a tendency to get "big" in their 
R.B. Miller et al.

Pragmatic Case Studies in Psychotherapy, http://pcsp.libraries.rutgers.edu/

Volume 17, Module 2, Article 2, pp. 129-209, 08-04-21[copyright by authors]

movements to catch the attention of children like Ronan who did not work with them.

He also had big reactions to being told "no" or being redirected when he was doing something unsafe, such as climbing on the counter. He would immediately have a meltdown or tantrum and fall on the floor into a "puddle."

After both the advocate and the critic had time to question the therapist, they moved on to the supervisor.

Advocate: Michele, can you tell us what this document is?

Supervisor: That is the Diagnostic Assessment and Report from the State Child Development Center for Ronan.

Advocate: I'll submit this for evidence. Can you tell us why this was conducted?

Supervisor: Ronan's aunt had many concerns about developmental delays and she had questions about autism when she first brought him into her care. She wanted to have him assessed so that he could receive a diagnosis and start receiving intervention services quickly.

Advocate: Thank you. In this report, there are two tests conducted: the ADOS-2 and the Bayley-3. Can you briefly outline what those tests do and why they are conducted?

Supervisor: Those are standardized diagnostic assessment tools used by the State Child Development Center as well as others who assess young children. The ADOS is considered one of the best diagnostic tools for determining whether or not a child has autism, and to some degree there are some severity classifications to categorize the autism as very severe or not as severe. The ADOS looks specifically for the symptoms of autism using both questionnaires from the caregivers and direct interactions between the diagnostician and the child.

The Bayley Infant Scales are well regarded and broadly used assessment tools for assessing a child's level of development across several different domains.

Advocate: Can you tell us the findings from this report?

Supervisor: Ronan was given a diagnosis of autism as well as a developmental and speech delay. 
R.B. Miller et al.

Pragmatic Case Studies in Psychotherapy, http://pcsp.libraries.rutgers.edu/

Volume 17, Module 2, Article 2, pp. 129-209, 08-04-21[copyright by authors]

This line of questioning continued as they identified other documents, including supervisor Michele's early progress notes about Ronan during his time at the Daycare Center. Next, the advocate asked the supervisor to describe some of her perceptions of Ronan:

Advocate: What were your initial impressions of Ronan?

Supervisor: My impressions were very similar to what Kristin said. He had some connection with his Aunt but didn't seem interested in interacting with her or with the staff. He appeared very listless and showed a lack of curiosity - even for objects (many kids on the spectrum will show interest in objects despite a lack of interest in social interaction) - so Ronan generally lacked interest in everything. He also lacked a level of physical development: a sense of body, a sense of balance, sense of control of body.

He was kind of a "lump" or "blob," he just frequently sat in one place and did not seem focused on anything. He also had absolute zero tolerance for frustration and he had zero ability to self-regulate when upset. If we had to tell him no, move him because he's unsafe, or force him to wash his hands, he would immediately collapse, cry, and flail about and would not accept any comforting from the staff. I think his aunt had some ability to comfort him physically by holding him, but he was unable to make use of any of the staff members in the beginning for any sense of relief. It seemed like no matter what we did, he was on his own. We simply had to wait until the tantrum passed and then he would go back into his listless state.

These descriptions led to discussions around the treatment provided to Ronan at the Daycare Center. The advocate explains that many children with ASD exemplify repetitive, selfstimulatory behavior as an effort to soothe themselves, but need support in learning to selfregulate their bodies and emotions in a more helpful way. The advocate asks about this support in her initial interview with Kristin:

Advocate: In your case study you talked about the skill of co-regulation and implementing it with each child at the Daycare Center. Could you give us an example of how you co-regulate with a child?

Therapist: Sure, he was surely fixated on opening and closing doors [when he initiated treatment]. At this point, we were simply trying to get him interested in human connection. When he's opening and closing doors, instead of trying to redirect him, I went over to him and sang a preschool song "open, shut, open, shut" with hand movements along to him as he did what he was doing anyway. The first time I did it, it was hard to know if he noticed me because he did not look at me, but later in the day as I was singing and making the hand movements "open, shut" with another child, Ronan got up and walked 
R.B. Miller et al.

Pragmatic Case Studies in Psychotherapy, http://pcsp.libraries.rutgers.edu/

Volume 17, Module 2, Article 2, pp. 129-209, 08-04-21[copyright by authors]

over to the door. He stood there without opening and shutting the door as if he might have been waiting for me. So, I went over and began to sing the song and Ronan proceeded to open and close the door. Again, he did not look at me, but it was very clear that there was a connection there.

This is just one of many examples the therapist provided where the Daycare Center staff assisted Ronan in creating meaningful relationships and sharing his regulatory needs. Creating relationships and encouraging co-regulation is a main facet of the treatment plan at this Center as it has been shown to help with ASD children.

\section{The Critic's Concerns}

The critic did not move to negate the claim that Ronan met the diagnostic criteria for ASD at the time of treatment. He did not dispute any facts provided by the advocate. Instead, he describes his position on the matter during his introductory remarks:

Critic: With regard to the claim that Ronan had ASD at the time of treatment, I don't necessarily disagree with this. My question is about the degree to which trauma may or may not have had a factor in this. What is there to realize about Ronan's earliest experiences? I'm trying to make the distinction between what would be a trauma-centered diagnosis versus an autistic presentation.

The critic brings up this distinction later when he interviews the supervisor. He asks:

Critic: Without having the specific knowledge of trauma during infancy, to what degree was this considered to both you and the assessors with regard to Ronan's ASD diagnosis?

Supervisor: We had some information because his Aunt was involved in his first few years but there were things she only speculated, such as the opening and closing of doors. Ronan's aunt believed that there was neglect, that he was often left alone in a room with the door closed and frequently heard doors opening and closing as people came and went, often loudly and possibly violently, so this area could possibly be a traumatic trigger for him. So we were mindful of this as it may relate to some trauma. But, I think your larger question is, "Did our lack of knowledge about his first two years make me question his autism diagnosis?" Is that what you mean?

Critic: No. I was wondering about how the missing link plays a role in intervention itself from a clinician's standpoint.

Supervisor: We did not want to do anything that would set him off in any way, but that was not a way for us to avoid those things. We did not look at him as 
R.B. Miller et al.

Pragmatic Case Studies in Psychotherapy, http://pcsp.libraries.rutgers.edu/

Volume 17, Module 2, Article 2, pp. 129-209, 08-04-21[copyright by authors]

though "this is a child with autism, autism is the explanation of everything he does, and thus will guide everything we do using our formula of these are the behaviors we want to reinforce, substitute, extinguish, etc."

A rule of thumb may be that a child with trauma history will have much, much more difficulty with self-regulation and they will fly off the handle much more easily and take much longer to bring them back to homeostasis than a child that does not have a traumatic history but also has autism. So there's an emotional difference in terms of how they express their distress.

Here, the supervisor explains how a child may have both ASD and a trauma history. Implicit in this conversation is an agreement that both characteristics of ASD and trauma can take form in an individual without one disproving the other. Therefore, the critic did not directly negate the first claim in this hearing.

Given the advocate's substantial evidence for Ronan's diagnosis of ASD at the time of treatment and the critic's lack of contradictory evidence, all three judges chose to accept the first claim in the hearing.

Judge Allshouse and Judge Powell indicated that they accepted the first claim due to the ample evidence provided to substantiate the diagnosis of ASD through the State Development Center report, the treatment plan, and the descriptions of Ronan at the beginning of treatment.

Judge Rusczek accepted the claim for the reasons listed by the other judges, but also indicated that the fact that the critic did not contest the claim encouraged his decision as well.

The judges voted 3-0 to accept this claim.

\section{Claim \#2: The Therapist Implemented a Relationship-Based Model of Therapy in the Context of the Center's Therapeutic Milieu}

\section{The Advocate's Arguments}

The advocate supplemented the case study (Appendix A) the judges had the opportunity to read before the PPI hearing with testimony from both the therapist, Kristin Mount, and the Daycare Center's director, Michele Fouts, in three areas: (1) a detailed description of a relationship-based model; (2) detailed examples of the therapist using this approach to treatment; and (3) a contrast between those interventions with the leading treatment for children with autism, Applied Behavioral Analysis (ABA).

In response, the case critic sought to clarify the interventions of the relationship-based model by questioning the therapist and supervisor about three possible threats to the fidelity of the implementation of a relationship-based approach: (1) the use of some ABA-like behavioral 
R.B. Miller et al.

Pragmatic Case Studies in Psychotherapy, http://pcsp.libraries.rutgers.edu/

Volume 17, Module 2, Article 2, pp. 129-209, 08-04-21[copyright by authors]

reinforcement methods at the Daycare Center in addition to the relationship-based approach even thought there was no formal use of ABA therapies; (2) the therapist's previous training as a research scientist in developmental psychology, suggesting a sympathy for the experimentalpsychology-related techniques of ABA; and (3) the lack of a description of how the Daycare Center director supervised the therapist's work on this case to assure that it was true to the proposed relationship-based treatment model.

The hearing produced a detailed discussion surrounding this claim, beginning first with a description of the relationship-based model in general. As noted above, though the therapeutic interventions in this model were outlined for the judges in the therapist's written case study (Appen dix A), the PPI hearing provided additional details and a more thorough description of the therapeutic environment and process. After the advocate's and critic's opening remarks, the advocate called as a witness, the child's therapist, Ms. Kristin Mount. The advocate asked the therapist to provide a description of the model to the judges:

Advocate: Could you talk a little bit about the Center's treatment model in general?

Therapist: We used a relationship-based model where the emphasis is placed on the relationship between each caregiver and each child. [The rationale is that] if the child becomes more intrinsically motivated to relate to others, that relationship can be used in all sorts of ways to help the child learn and grow.

Later, during the Advocate' s questioning of the supervisor about the ways a relationshipbased model is thought to help children on the spectrum:

Advocate: How do you think that relationship-based therapy helped in the areas of cognition, language, and other academic abilities?

Supervisor: So the way that I look at this approach is in terms of essential early attachment, attunement, co-regulatory relationships. So, the relationships and the experience of feeling felt and understanding another person, feeling that attunement - that contingency — in my mindset, that is the template and foundation that then allows so many other domains of development to flourish.

I feel very strongly in my experience that when a child has that central, coregulated attachment - the essential relationship of you having a very simple but fundamental relationship and over time it becomes more complex. So I believe quite strongly that that is the grounds which create so many neural networks and keeps the body from being overwhelmed by stress so that the brain and body are able to take in new stimulation without experiencing them as threatening, [enhancing the] ... ability to process and make sense of things. 
R.B. Miller et al.

Pragmatic Case Studies in Psychotherapy, http://pcsp.libraries.rutgers.edu/

Volume 17, Module 2, Article 2, pp. 129-209, 08-04-21[copyright by authors]

When that initial relationship is in place, the child is then able to assume many other things, [to be] open to [being] ... challenged, [to engage in] cognitive development and problem solving and persevering and developing episodic memory. [The child can learn to ...] look back on an experience and project into the future and start to look at [the other person's] ... behavior in a situation.

So I feel strongly that all of the areas of development are intertwined in that way - and when you don't have the foundation of that initial coregulation relationship where the child feels reflected and contained-all of those other domains will suffer.

Later during the advocate's further questioning of the supervisor, Michele Fouts, she is asked to explain more why there was so much flexibility with Ronan at the center on a day to day basis:

Advocate: You mentioned a lot of flexibility given to Kristin with regard to her work with Ronan. Why was so much flexibility granted? Was that a purposeful choice?

Supervisor: Yes! Most everything about this model was very deliberate. I made sure that the days were very flexible, and I made sure that each child's individual schedule was flexible within some broad parameters. Whether they did bubbles or blocks first thing in the morning did not matter, whether they played inside or outside at any given time did not matter, whether they played one on one or in a group play did not matter.

What was emphasized was that an adult should observe a child carefully every moment of every day. You have got to be able to assess where a kid is right now and you have got to be able to react to where that kid is. So just because yesterday he did complicated play does not mean that ... [this is] ... what you should be doing first thing the next morning.

Kids are coming [into the Daycare Center] ... in different places. It is deliberate that each staff person could be flexible with the goal that you want to be as connected and as sophisticated as a child is capable of in the moment. Whether that means you're inside, outside, working one on one, working small group, [or] doing activity "A" or "B," you get some choice in that matter because the goal is about you being connected, not what behavior they are doing. 
R.B. Miller et al.

Pragmatic Case Studies in Psychotherapy, http://pcsp.libraries.rutgers.edu/

Volume 17, Module 2, Article 2, pp. 129-209, 08-04-21[copyright by authors]

At other moments during the panel, the therapist and supervisor provided additional, discrete examples of therapeutic work in a relation-based model. As described in the written case study (Appendix A), coregulation is a critical part of therapeutic work, and the advocate asked the therapist to tell the panel about coregulating with Ronan during the original questioning of the therapist.

Advocate: Can you talk a bit about coregulating with a child?

Therapist: A relationship must first be established over a couple of weeks through following a child's lead, going wherever they want to go, and trying to understand the purpose of any given behavior. Knowing this child helps know how they attempt to regulate themselves. So, if a grown-up notices that a child is dysregulated, the adult can match their behavior in order to regulate together. You are following each other's leads.

Advocate: Can you give an example of coregulating with Ronan?

Therapist: Some kids do self-stimulatory behavior to regulate themselves, whether it is [to create] ... a distraction from the outside world or because it provides power and control. Ronan was fixated on opening and closing doors. When he's opening and closing doors, instead of trying to redirect him, I went over to him and sang a preschool song "open, shut, open, shut" with hand movements along to him as he did what he was doing anyway. [After two attempts at this,] it was very clear that there was a connection there.

Advocate: Do you have any other examples of coregulating with Ronan?

Therapist: One day after some months had passed, he was alone blowing bubbles into a cup of water with a straw and seemed content on his own, but I decided to get my own cup and straw to join him. I sat next to him and blew bubbles, but he did not seem interested in me. So after a few minutes I put the cup down. When I did that, he picked up the cup and handed it to me and looked at me expectantly. So, I blew bubbles again and he proceeded to blow bubbles again. Where he seemed perfectly content doing this on his own, he saw someone was willing to join him in this activity and took it in and enjoyed the connection. He took the initiative to include me in the play more so than he did with the door example.

Advocate: Sounds like a step in the right direction. You had a number of examples in your case study (Appendix a), can you give us one or two more examples of this coregulation and connection between you and Ronan building over time? 
R.B. Miller et al.

Pragmatic Case Studies in Psychotherapy, http://pcsp.libraries.rutgers.edu/

Volume 17, Module 2, Article 2, pp. 129-209, 08-04-21[copyright by authors]

Therapist: A big example was the day after the bubbles. I was settling him for his nap. He wasn't actually sleeping much at nap time, but he had begun to slow down and be calm for a while during nap time. I was sitting with him and he seemed particularly tired, so I tried harder to help him nap by rocking with him and singing songs to him. He was settled comfortably and I sat down next to him to sing him one last song, and as I did, he took my face in my hands and looked at me tenderly. He then went and kissed my cheek and signaled to kiss his cheek back. We did this a couple of times.

Going from a little connection of blowing bubbles to this shows how meaningful these things that [seem] ... so little are so important for Ronan. His tenderness for me at this moment, his wanting to show that, was pretty powerful.

Around the same time he began engaging in some teasing behaviors. He was about three years old at this time. He had been very possessive and protective about food for a long time. He would hover over his food if people came near as if to say "Don't touch my food." He offered a bite of his food to a staff member and let her eat off of the fork he held out to her. She was surprised but followed through. Ronan went to feed her a bite of food again, but this time pulled it away from her as she went to bite it in a joking manner. He ate the bite of food quickly in a "hahaha" kind of way.

Ronan did the same with me the next day, asking me to take off his shoe but then hiding it before I could get to it. When a child has the ability to tease, it shows their ability to recognize that they have one idea in their mind that is different from the idea someone else has in their mind; and [the child then] can use it to trick people and be funny. It shows the idea of the theory of mind which is usually challenging for a child on the spectrum.

\section{The Critic's Concerns about Fidelity to the Treatment Model}

In his opening remarks the critic offered these questions about the therapist's fidelity to the relationship-based treatment model:

Critic: I wish to know more about the differences between the more traditional ABA model of intervention and to what degree the therapist is familiar with these methods, especially from past experience, and whether or not these two worlds crossed over and may actually produce behavior change at the Daycare Center in addition to the relationship-based methods of the Center.

And second of all, I wish to know a little bit more about how, on a day-to-day basis, the interactions with the therapist and Ronan were 
R.B. Miller et al.

Pragmatic Case Studies in Psychotherapy, http://pcsp.libraries.rutgers.edu/

Volume 17, Module 2, Article 2, pp. 129-209, 08-04-21[copyright by authors]

applied in regards to traditional reinforcers that are more common in the ABA methodology, and to what degree this was used on a daily basis.

In his written outline about the claims of the case, the critic also wrote: "I wish to determine how supervision was implemented for the therapist to ensure that her methodology was consistent with that of the Center." The critic also investigates these questions when he questions the supervisor about her role in the daily activities of the Center:

Critic: I want to discuss the level of supervision you provided the therapist at the time. In terms of eyes on your staff when they interacted with the children, particularly the therapist with Ronan, what sort of supervision did you have on a day to day basis?

Supervisor: Pretty intensive! I was on the floor pretty much all the time with the kids and the staff. There may be a few moments where I was off in a room with a child but pretty much all the time I was circulating with the children and the staff.

But keep in mind that on average there were four kids and maybe four, five or six adults, so we are not talking about a huge group of people. The therapist had a lot of flexibility and space to make her own decisions about what to do and which child to interact with in which way but I was almost always around and watching and observing what she and the other staff and the kids were doing.

Again, at the beginning and end of every day, plus individual supervision, there was lots and lots and lots of processing. Occasionally, I would record one of the adults with one of the children and we would watch that video at the end of the day. Also, throughout the day, there were many opportunities to speak briefly with any of the adults in the room privately or in a group so the therapist had a lot of flexibility to do what she felt was right, but if I noticed there was a struggle or if she seemed to not know what to do with him next, I could step in immediately, in real time, and make a suggestion, or I could start engaging with the child with an activity that I had already created and allow her to take it over.

This happened much more in the beginning because [Kristen, like the other therapists was] ... learning and feeling her way with each kid in how to do this and to find which kid they connected with more than others.

Because that is a natural part of human behavior, some people connect more than others.

So I encouraged all of the adults to find the children that they 
R.B. Miller et al.

Pragmatic Case Studies in Psychotherapy, http://pcsp.libraries.rutgers.edu/

Volume 17, Module 2, Article 2, pp. 129-209, 08-04-21[copyright by authors]

clicked with so that we maximize our efforts and [the] relationship potential of each staff-child dyad. Or later, with small groups of children. Though Kristen had very intensive supervision, and as time went on, she needed less of that, she had a lot of independence on what to do and how to do it with the kids.

This dialogue endorses the idea that the therapist, along with all staff at the Center, received thorough supervision that kept them working in line with the relationship-based model.

Substantial discussion on ABA and its contrast to this model occurred throughout the panel. The judges had the opportunity to ask direct questions of the witnesses once the advocate and critic had completed their questioning of each witness.

Judge Powell: What is ABA?

Therapist: It is a reward based program used in a lot of schools. People who employ this technique usually want a child to complete the checklist of short term and long term goals with rewards when they are reached. It could be something as simple as picking up a pencil to hold.

It is very easy to track data to create empirical support because the therapist can check items off the list once they are achieved. There can be gains in a child's IQ through ABA. A good ABA provider will build a relationship with the kid and use the relationship to help motivate the child to practice skills, but the relationship is not the focus of what is the catalyst for change.

An M\&M can be rewarding, but in the case of Lydia [in the case study about her mentioned in my thesis (Appendix A)], she showed a number of behaviors that she had been asked to do but she was not doing it because she understood why she was doing it, she was doing it to get an M\&Ms.

So, I think the idea behind ABA is that children are doing what is expected of them, they are doing what they have to do to be successful in a classroom, but they are not necessarily internalizing what they are doing. The relationship-based programs try to encourage children to do things because they want to.

Later in the hearing the Critic questioned the supervisor, Michele Fouts, about the difference in her experience between the outcomes of ABA and a relationship based model.

Critic: I want to talk about outcomes. We are quite blessed to have someone who has both experience with more traditional interventions and the newer one we are 
R.B. Miller et al.

Pragmatic Case Studies in Psychotherapy, http://pcsp.libraries.rutgers.edu/

Volume 17, Module 2, Article 2, pp. 129-209, 08-04-21[copyright by authors]

discussing today. With that in mind, how do you think that an evidence-based practice such as ABA, which as the therapist mentioned earlier can increase IQ points, how do you think that would rank in a side-by-side analysis if that had been the preferred intervention with Ronan? And where would it have come up short?

Supervisor: So maybe I can answer that best by giving you an example of another child that I worked with where the intervention style was ABA using discrete trials and techniques. I had great success using ABA in the first ten years of my career.

I was given a checklist of skills that this child was supposed to master and it was my job to get [kids like this] ... to perform those skills. So to start with getting ready to learn, to make eye contact, to respond when their name is called, to make eye contact when they are tapped on the shoulder (or whatever the social cue was), to sit down in a chair and keep your body calm and upright, to have quiet hands (so not doing all the "stimming"), to "put your hands in your lap or on the table like I told you," or "now I want you to show me red, now I want you to show me the square, now I want you to show me the letter A," and so on. A long list of skills.

If you have a reasonably bright, reasonably regulated child with autism, you can sit them down at a table pretty quickly with M\&Ms or cookies and teach them these skills quickly and they will do it right and you can celebrate a "job well done." I spent years going through these lists and thinking I am a good teacher and my kids now have all these academic, getting-ready-to-learn skills, these functional-for-life skills and progress like using the bathroom and getting a haircuts.

But to this day those children want nothing to do with me. One child I remember literally fears me and looks away from me when he sees me around town. It breaks my heart because what he learned from me and all the other adults in his life is that we want something from him. "Here's what I want you to do, you jump through my hoops, great job, here's your reinforcer, we're done for the day."

You know what the biggest reinforcer was for these kids? To get away from me when I said "All done," and they got to get away from me! The reinforcement was "okay thanks lady, now I get to go home and lose myself in a video game or repeatedly watch the same video!"

[Through ABA], we teach kids that other human beings represent a demand, and other human beings are the arbiter of whether or not you did it 
R.B. Miller et al.

Pragmatic Case Studies in Psychotherapy, http://pcsp.libraries.rutgers.edu/

Volume 17, Module 2, Article 2, pp. 129-209, 08-04-21[copyright by authors]

properly. After years, this method teaches kids to jump through hoops so that they may leave you alone. When I came to terms with that, it was sad and scary and prompted me to find another way. My goal is to make a kid want to be with me: to feel like my presence is valuable and meaningful so that they may seek me out on their own.

The differences between ABA and relationship-based therapy were made frequently throughout the panel. Keeping in mind the critic's question of whether ABA, as the standard treatment model, may have inadvertently been confounded with the methods of the Center, the advocate asks the supervisor about the goals of the two models.

Advocate: Does this model emphasize the process of the relationship or the product of the relationship?

Supervisor: Absolutely the process. The product is important, but focus is the process. The goal is the process of how we got there. The question is, "Are we going somewhere together?" as opposed to "where are we going?"

In an ABA model the adult has a target behavior they are trying to get the child to do through a variety of strategies. But the adult already has a plan, "I want the child to do X behavior because I have decided that X behavior is necessary or relevant to this child's development."

Whereas, the relational approach is "Yes, we want to get to $\mathrm{X}$ behavior eventually, but how we get there is much more flexible." The focus is, "Are we connected? Are we attuned? Are we making meaning of each other?" Regardless of what behavior you are doing or what the outcome of the behavior is. So, process over product. Absolutely.

This dialogue emphasizes that the goals of this model are extremely different than those in ABA. Though not explicitly discussed, the content of these interviews undermines the critic's question about whether parts of an ABA model diluted the relationship-based intervention.

The judges voted 3-0 to accept the claim that the therapist implemented a relationshipbased model of therapy in the context of the Daycare Center's therapeutic milieu. Given the description of the model, the clear examples of the therapist's implementation with Ronan, and the close supervision provided by the Daycare Center director, the judges rejected the speculative claim made by the critic that some ABA methods must have been implemented by the therapist due to her prior education in experimental developmental psychology. 
R.B. Miller et al.

Pragmatic Case Studies in Psychotherapy, http://pcsp.libraries.rutgers.edu/

Volume 17, Module 2, Article 2, pp. 129-209, 08-04-21[copyright by authors]

\section{Claim \#3: Kristin's Application of Relationship-Based Therapy, in the Context of the Daycare Center's Therapeutic Milieu, Improved Ronan's Outcomes.}

\section{The Advocate's Arguments}

The advocate supplemented the written case study with regard to this claim in four ways: (1) Kristin's experiences with Ronan, (2) documented reports on Ronan's progress, (3) Michele's follow-up observations of Ronan, and (4) a follow-up letter written by Ronan's aunt. The use of and the rationale for the relationship-based therapy used at the Daycare Center was substantiated in the report from the previous Claim $\# 2$. Therefore the focus of this claim is to demonstrate improvements in Ronan's outcomes.

The advocate explored the gains Ronan made during the section of the panel where she questions the therapist. A long discussion about Ronan's gradual improvements were detailed in Kristin's report (Appendix A) on Claim \#2, but they can be summarized here with Kristin's response to the advocate's question:

Advocate: Can you speak about Ronan's improvements as a full picture from when he started to when he ended?

Therapist: Ronan went from having no meaningful human connection to being able to use people - plural - to figure out how to get what he wanted. Over 14 months he changed drastically. Going from a kid who was very concerned about food - only eating five foods and avoiding anything new - he was able to expand his palate exponentially. But Ronan was willing to try new foods and textures because our relationship with him was meaningful and he trusted us when we said, "I think you're going to like this." This is typically quite difficult for kids on the spectrum.

This interaction provides a brief look at Ronan's overall gains. Ronan's improvements were also demonstrated in progress reports from both the Center and his preschool. Ronan spent a few days a week at each center until ultimately moving to the preschool full time when the Early Intervention Center closed in 2016. Michele used the Greenspan Social-Emotional Growth Chart to periodically document Ronan's progress at the Center. This chart is a standardized questionnaire used to assess developmental levels in a child compared to the expectations of a typically developing child. When the advocate questioned the supervisor to establish claims, the advocate introduced the Greenspan reports to the panel and asked the supervisor to elaborate on them:

Advocate: Did Ronan make improvements over time [according to these documents]?

Supervisor: Yes. He made significant improvements from the time he started to the time he left. 
R.B. Miller et al.

Pragmatic Case Studies in Psychotherapy, http://pcsp.libraries.rutgers.edu/

Volume 17, Module 2, Article 2, pp. 129-209, 08-04-21[copyright by authors]

Advocate: Can you speak to how much improvement?

Supervisor: I remember he was at the bottom of the chart when he started and rose up several levels, I think he was at $5 \mathrm{~A}$ at the last assessment. The assessments go in stages that are correlated with stages in most typically developing children and are measured in a matter of months. He had gained, according to the chart, years of developmental progress.

Soon after this, the advocate introduced Ronan's developmental reports conducted by the preschool he had also been attending. These include the Teaching Strategies GOLD, the Reynolds Intellectual Assessment Scale, Wechsler Individual Achievement Test, the Preschool Language Scales, and more. The Preschool Language Scales were the only assessment conducted twice by the preschool: once when he began at the preschool in 2014 and had not yet started at the Daycare Center, and once following his treatment in 2017.

Advocate: According to the report in 2014, Ronan fell into the first percentile for all language scores, meaning that he only scored better than one percent of his same-age peers. In 2017, he was placed in the thirteenth percentile for receptive language, the twenty-seventh percentile for expressive language, and the eighteenth percentile for total language, placing him in the low-toaverage range for same-age peers. So he made significant jumps on this scale.

While these reports suggest significant developmental improvements for Ronan, Michele indicated that she personally perceived massive growth within him as well. After the Daycare Center closed in 2016 and treatment ceased, Michele paid the family a home visit in December 2017. She wrote a brief summary of the visit and documented the progress she perceived for Ronan.

Advocate: Can you tell us about this letter?

Supervisor: That was a write-up I made. I did a home visit [in December 2017] and I was able to visit Ronan at his home and see him with his now adopted parents and both of his siblings. So, I wrote this briefly about all the growth and progress that we started to see-all of the pieces coming together when the Daycare Center closed. Being able to see Ronan at home, in person, recently allowed me to say, "Yes, this growth is continuing." Ronan is continuing to grow and mature and is doing quite well.

During Michele's home visit, she mentioned to the aunt that there was a possibility of Ronan's case being used for this panel. The aunt felt it was important that her voice be heard in the hearing, so she wrote her own letter about Ronan's progress and gave it to Michele for submission. Immediately after the conversation above, the advocate read the last paragraph of the aunt's letter aloud: 
R.B. Miller et al.

Pragmatic Case Studies in Psychotherapy, http://pcsp.libraries.rutgers.edu/

Volume 17, Module 2, Article 2, pp. 129-209, 08-04-21[copyright by authors]

Advocate: It says, "Today, Ronan is very aware of his surroundings. He is learning to have control over his environment by using words to navigate the world around him. Is he still autistic? Of course, he is. But he's on his way to becoming a responsible, productive member of society because he is motivated to be a part of it. There is no doubt in my mind that this would not have happened except for Michele's relational therapy work directly and indirectly with him."

The Critic's Concerns About Fidelity to Ronan's Improvements

During his opening remarks, the critic posed these questions about the third claim:

Critic: I wish to know, based on this relational intervention, how Ronan was able to show improvements in areas of academic testing such as language and cognition.

In his written statement about the claims, the critic also writes: To what degree do current caregivers adhere to the relationship-based model with Ronan? Is this work monitored to ensure that the essential tenets of the model are adhered to?

The line of questioning posed by the critic does not negate the third claim that Ronan showed ultimate growth, and in fact, the critic never specifically asked these questions during the Panel. These subjects came up naturally through discussion, however, so the questions were partially answered despite the critic's degree of involvement. For example, during the section designated for counter-claims, the advocate asked Michele about concrete improvements seen in Ronan:

Critic: I would like to end with you talking about the actual product Ronan received as a direct result from his treatment and time at the Daycare Center.

Supervisor: He learned how to talk, how to make eye contact, how to initiate social interactions, how to play in a dynamic and creative and curious way (as opposed to repetitive, stereotyped, restricted way).

He learned how to be open to new experiences (instead of shutting down or withdrawing or having tantrum when something new presented itself whether it was a person, activity or place). He learned how to share a bit more!

He learned how to build a tower next to another child and take turns with others. I don't think he was toilet trained at the time he left the daycare Center, but he is now.

He learned that when he was frustrated, he did not need to fall apart. He did not need to shut down, shut out the world, and just become a puddle 
R.B. Miller et al.

Pragmatic Case Studies in Psychotherapy, http://pcsp.libraries.rutgers.edu/

Volume 17, Module 2, Article 2, pp. 129-209, 08-04-21[copyright by authors]

of chaos. He learned that when he was frustrated he could ask for help, sit in someone's lap, go take someone by the hand, stop what he's doing and walk away. He learned real, concrete skills to deal with frustration and how to use other people to help him feel more secure, more confident, and more regulated.

This dialogue exemplifies many concrete ways that Ronan developed over time, including academic areas such as language and cognition. Though the relationship-based model did not specifically seek to address language deficits, the overall development initiated with this model also established gains in these discrete cognitive areas.

The critic's question with regard to a continued provision of a relationship-based model was addressed during the critic's questioning of the supervisor to establish claims:

Critic: After the Center closed, Ronan went to a new center with a one-on-one provider. Do we have a way to measure this individual's use of a relationship-based model?

Supervisor: No, we don't. When the Center closed, he went into full time child care that he had already been familiar with. He had a one-on-one with him much of the time who was a person who had been an intern at the Sapphire Center and had been trained by me previously. But I had no formal, professional involvement.

While the critic was able to cast doubt on whether some of Ronan's improvement could be due to a provider using something other than the Center's relationship-based model, a different discussion indicated how regardless of later therapies, it was this therapeutic environment that "got the developmental ball rolling." When the advocate questions the supervisor again to rebut the counterclaim, she asks:

Advocate: When Ronan's treatment ended, do you believe that his "developmental ball" was rolling?

Supervisor: Yes, absolutely. His aunt was very nervous about him losing his gains because of the change when the program closed. However, he did not lose anything that he gained and he continued to make gains.

The dialogue here endorses that the interventions received following Ronan's end with the Center, regardless of whether they were relationship-based or not, do not negate the impact that was made during Ronan's time there.

Judges Powell and Allshouse voted to reject his claim. Despite some hesitation about the wording of the claim, Judge Rusczek voted to accept the claim that Kristin's application of relationship-based therapy, in the context of the Center's therapeutic milieu, improved Ronan's outcomes. The concern voiced by Judge Rusczek was that the claim attributed Ronan's improvement to the relationship- based treatment offered by Kristen, rather than attributing the 
R.B. Miller et al.

Pragmatic Case Studies in Psychotherapy, http://pcsp.libraries.rutgers.edu/

Volume 17, Module 2, Article 2, pp. 129-209, 08-04-21[copyright by authors]

improvement to the overall relationship-based treatment offered by the Center. He viewed this as an ambiguity in the claim and reasoned that the testimony so clearly showed the entire therapeutic milieu of the Center was responsible for the outcomes, and that it was clear that Kristen was only one part of that milieu. Judge Rusczek wanted to affirm the impact of the Center on Ronan's outcomes and thought a "No' vote would be a disservice to the work that had been accomplished. Judges Powell and Allshouse noted that there were issues in semantics for this claim which made it far too contingent on Kristin's specific intervention, but in the Judges Feedback Form Judge Rusczek wrote:

Proving that Kristin's application of the relationship-based therapy contributed to Ronan's improvement is a more difficult matter since causality can only be inferred. In my judgement, the claim that Kristin's application of relationship-based therapy improved Ronan's outcomes is supported by the high degree of "fit" between the rationale of the therapy, the case vignettes which showcased intervention and improvement, and the overall progress Ronan made. Additionally, there appears to be a good fit in terms of timeline. We know that prior to the treatment Ronan was relationship-deprived. He did not have emotionally present and responsive adults who provided him with the various kinds of interaction that are necessary for healthy development. At the Center and in his work with Kristin, Ronan was provided with the kind of attuned adult presence that had previously been scarce in his life. Both at the Center, and gradually in other areas of his life, such relationships constituted a major change in his life and coincide with his improvement.

Judge Allshouse made similar observations about the success of the treatment being the result of the work of the Center of which Kristin was a part, however, she felt that wording of the claim put too much emphasis on Kristin's work, and that she could not vote in favor of it for that reason, stating that though she supports the claim that Ronan showed incredible developmental improvements, they may not be attributed specifically to Kristin's intervention. She states that if the claim had been written "Kristin's work had contributed to the Center's treatment that produced positive outcomes," she would have supported the claim. Judge Powell indicated a similar concern about the wording of the claim and voted to deny the claim. He observed that it was clear Ronan's outcomes improved, but there were clear indications that the stabilization in home life that occurred after he was removed from his parents' custody, and this could not be ruled out as a key element in his improvement. Judge \# also thought that the therapeutic work of the Center in general, not just Kristin's work had an important impact on Ronan's outcomes.

\section{Claim \#4: It Is Likely That There is at Least a Subset of Children With Moderate to Severe Autism Spectrum Disorder for Whom This Treatment is Likely to be Helpful.}

\section{The Advocate's Arguments}

The advocate supported this claim by exploring two areas during the panel: (1) the two cases where children on the spectrum saw improved outcomes following a relationship-based intervention provided in locations outside of the Daycare Center that were included in Kristin's thesis case study (Appendix A); and (2) Michele Fout's testimony that other children improved 
R.B. Miller et al.

Pragmatic Case Studies in Psychotherapy, http://pcsp.libraries.rutgers.edu/

Volume 17, Module 2, Article 2, pp. 129-209, 08-04-21[copyright by authors]

similarly to Ronan at the Center, which indicates generalizability for this treatment model. The critic raised two questions that might undermine this claim: (1) Why do some children have more pronounced improvements than others? (2) To what degree does trauma history interact with ASD and subsequent treatment?

Following opening remarks, the advocate called Kristin as a witness. After a series of descriptions about the Daycare Center and a relationship-based model in general, the advocate asked Kristin about the cases included in her paper:

Advocate: In your case study you described two comparison case studies (Lydia and Joey] that were very similar and had outcomes similar to Ronan's. The first is Lydia, can you tell a little about how Lydia's case was similar to Ronan's?

Therapist: Both of the cases were from a book on the Rebecca school, a school in New York, that uses [Greenspan's] Floortime model. This is a relationshipbased model in an intensive program that focuses on building skills through a strong relationship with a caregiver.

[In the case of Lydia, she] ... made a lot of really big gains with the parents using the things that already intrinsically motivated her, such as playing games like "chase and tickle" and building on those. So, instead of just playing "chase and tickle," the parents could throw a curveball by being "stuck in the muck." This makes it so the child has to stop and think, "Well okay, what's she got in her mind that's different than what I have in my mind?" There are different things we would throw into the mix so that instead of just chasing and enjoying and it being the same, the child now had to figure out "why" I did what I did. Once the child has that connection with the parent and she's getting rewards from these connections, she's motivated on a more social level. The parents can use this connection that they've built to make other gains for her.

Advocate: Can you tell us a bit about Joey and how he is similar to Ronan?

Therapist: Joey was a bit older and he engaged in a lot of self-stimulatory behaviors before he started in the Floortime model. He had very few communication skills. I think he was about 4 or 5 when he started this program. His father was able to use their relationship.

Joey liked to be "flown" around the house, pretending that he was an airplane, then it became symbolic and once he was too big to be flown around, Joey would pick up toy airplanes and fly them around the house. They would have things like "mechanical problems" or problems with the "fuel," so Dad would stop the play and have Joey figure out what he needed to do to continue the play. What was really special about this case was that 
R.B. Miller et al.

Pragmatic Case Studies in Psychotherapy, http://pcsp.libraries.rutgers.edu/

Volume 17, Module 2, Article 2, pp. 129-209, 08-04-21[copyright by authors]

Joey started to use the airplane play symbolically, where he was able to work through some peer relationship problems with this airplane. So, to take this relationship with a special adult and make it into something that can help you solve problems later in life.

This dialogue establishes evidence that two children outside of the Center made gains with a relationship-based intervention. This provides support for the claim in that it indicates generalizability for the improvements this model can create in children on the autism spectrum in other programs. Later on, during the advocate's first opportunity to question the supervisor, they wrapped up the section with succinct dialogue about how this model helped many children other than Ronan:

Advocate: I want to talk about the generalizability of this case to other cases. Were there children with similar backgrounds to Ronan who made similar progress at the Daycare Center?

Supervisor: Yes.

Advocate: Were there children with different, less traumatic backgrounds to Ronan that made similar progress at the Daycare Center?

Supervisor: Yes.

Advocate: Do you believe that Ronan's progress was extraordinary or unique?

Supervisor: No.

Advocate: Were there children who made less progress than Ronan?

Supervisor: Yes.

Advocate: That's all I have. Thank you.

\section{The Critic's Concerns about the Generalizability of Outcomes}

The critic's question for this claim around why some children have more pronounced improvements than others was never addressed through an explicitly poised question. However, one clear example came when the critic questioned the supervisor for a second time towards the end of the hearing:

Critic: What happens in a situation where [safety and playfulness] is not present in the home?

Supervisor: Well we had those families at the Center! One family in particular had three children at the Center. Their home was not safe, predictable, or playful 
R.B. Miller et al.

Pragmatic Case Studies in Psychotherapy, http://pcsp.libraries.rutgers.edu/

Volume 17, Module 2, Article 2, pp. 129-209, 08-04-21[copyright by authors]

and those kids spent most of their time at home in front of the television. However, all three of those children made significant gains. At least two of them did not make gains close to what Ronan did. When they were calm, they were capable of being very engaged and using language and using complex play and social interactions, but most of the day was spent just trying to get the kids to a place where they regulated.

At the end of the day, there may have been meaningful co-regulated interactions, but they went home to a chaotic, unsafe environment and we had to start the process again in the morning. This progress was much slower and much harder, so I don't think they made as many gains. You can't just have a therapeutic center to see huge gains. You also have to have a safe, stable, responsive home.

While Ronan's substantial gains are not replicable in every child due to environmental constraints, there are still noticeable benefits this model provides to children involved, suggesting generalizability. The judges were aware of additional research that supports the generalizability exhibited with this model. Kristin's written thesis (Appendix A), read by all the judges, cited a great deal of work from Stanley Greenspan on relationship-based interventions for children on the autism spectrum. Greenspan helped to develop the Rebecca School that Joey and Lydia attended (2017). This school uses the developmental, individual-difference-tailored, relationship-based model of intervention. The DIR* Floortime method, where adults follow the child's lead and engage in rapid back and forth play, is a large part of this treatment (2006). Greenspan's works include a similar rationale for and application of a relationship-based model as Michele employed at the Center.

Note that although Joey and Lydia are two strong cases to exemplify improvements due to this model, the lead author (RBM) discovered an older study by Greenspan and Wieder (1997) that indicates even more generalizability for Greenspan's DIR/Floortime model in a study involving clinical case review research. Specifically, in a review of 200 charts of children with ASD, Greenspan and Wieder's findings suggest that a number of children with ASD are capable of empathy, affective reciprocity, creative thinking, and more with appropriate relationshipbased intervention.

\section{The Critic's Concerns about Trauma History with ASD}

The critic raised questions about the role of trauma in Ronan's symptoms suggesting that a dual diagnosis of both a trauma reaction and ASD might be appropriate, and that Ronan's improvement might be due to resolution of the trauma issues rather than effective treatment of ASD. In fact, in his written outline of his view of the case sent to the judges before the PPI hearing, the critic raised this question: 
R.B. Miller et al.

Pragmatic Case Studies in Psychotherapy, http://pcsp.libraries.rutgers.edu/

Volume 17, Module 2, Article 2, pp. 129-209, 08-04-21[copyright by authors]

Critic: To what degree does this work with traumatized children versus nontraumatized children? Is there a "subset" of children this treatment may apply to those with trauma only?

This line of questioning casts doubt on the utility of the relationship-based model for children with ASD by considering the presence of trauma for many children at the Center. Ronan experienced trauma and saw gains from the relationship-based model, so it is possible that the intervention treats the issues from trauma as opposed to issues from ASD. Though this was an interesting consideration, the Panel never fully discussed this question as the Critic chose not to raise it in the actual PPI hearing

All three judges accepted the claim that it is likely that there is at least a subset of children with moderate to severe ASD for whom this treatment is likely to be helpful. They indicated that the theoretical rationale behind a relationship-based model of treatment clearly suits the symptoms of ASD. This was exemplified by the distinct ways Ronan improved in communicating, self-regulating, playing dynamically, and desiring social connection. Judge Allshouse mentioned that the cases of Joey and Lydia were important contributions to the discussion. By exploring these improvements, Judge Alllshouse was able to support the generalizability of this model.

Judge Powell mentioned that he felt the guardian's (and eventual adoptive mother's) involvement described as part of the model was exceptionally powerful. At various times throughout the panel, the therapist and supervisor mentioned how and why parents are involved in the treatment. The goal of treatment is to not simply to create a relationship between a child and staff member in which a child can comfortably explore themselves, but for a child to become more deeply connected to their caregiver and form a meaningful relationship that can build across the lifespan. Both Judge Rusczek and Judge Allshouse critiqued the semantics of this claim (terms such as "subset of children" and "helpful") as being extremely vague which make it hard to accept or deny, but both ultimately accepted the claim based on the clinical improvements reported in each case.

\section{Critic's Counterclaim: Ronan's Improvement Cannot Be Attributed Kristin's Treatment}

The critic made the following counterclaim:

It cannot be adequately proven that Ronan's ultimate outcomes, based on Michelle's most recent observations at his home, can be directly attributed to Kristin's intervention, in large part due to the amount of time [that] passed between the last time they worked together and the lack of supervision in that interim for the one-toone caregivers that have taken over the work that Kristin began.

The critic offered his own perspective on Ronan's case in this counterclaim. While the critic indicated in the PPI hearing that he agreed that Ronan exhibited impressive outcomes, he 
R.B. Miller et al.

Pragmatic Case Studies in Psychotherapy, http://pcsp.libraries.rutgers.edu/

Volume 17, Module 2, Article 2, pp. 129-209, 08-04-21[copyright by authors]

questioned the degree to which the earlier work of Kristin and the Center helped Ronan during the two years following termination at the Center.

The critic asks: (1) To what degree did primary and additional caregivers utilize a relationship-based intervention after the center closed? (2) To what degree was Michele able to supervise these caregivers to ensure proper utilization of this method? In this line of questioning, the critic casts doubt on the effects from the relationship-based intervention and instead emphasizes the possibility that the growth Ronan exhibited may be due to non-relationship based interventions provided by his primary caregivers and professionals at his preschool.

In order to explore the ideas posed in the counterclaim, the critic asked Michele about the short-term training she provided to caregivers and other professionals in his section of interviewing the supervisor:

Critic: For a period of time in Ronan's life, you were able to supervise Kristin and other workers. Subsequently, when the Center was no longer a resource for Ronan, you then trained his aunt and some of the workers who would be working with him at his preschool. At that point, however, levels of supervision dropped off for obvious reasons. I'm wondering to what degree do we know that the tenets of this treatment are applied on an ongoing basis to Ronan? Since we don't have access to supervision at this point, can we say that there is a stringent adherence to this philosophy or do we have any way to measure that?

Supervisor: No, we don't. After the Center closed, Ronan went into full time childcare at the preschool he was already familiar with. He had a one-on-one with him much (but not all of) the time. This person had been an intern at the Center and had been trained by me previously. So, as Kristin stated, one of his aunt's greatest strengths was that she was very good at advocating and getting good people to help support him.

Somebody I had trained was working with him, but I was not actively supervising her, I did not access the site, there was no formal, professional involvement at that point in time. His aunt had learned and been able to implement some of the things that had started at Center, but to what degree she was doing that... No one can say for sure. She brought in some other staff later and they probably learned something from her about the model, but to what degree were they implementing it? We can't say.

Critic: Okay, thank you.

Here, Michele indicates that the closing of the center also terminated Ronan's time receiving a truly relationship-based intervention. While adults in his life were aware of and had some skill with these methods, they were no longer applied in a systematic way. Michele 
R.B. Miller et al.

Pragmatic Case Studies in Psychotherapy, http://pcsp.libraries.rutgers.edu/

Volume 17, Module 2, Article 2, pp. 129-209, 08-04-21[copyright by authors]

provided no active role in Ronan's care from the time the center closed, directly answering the critic's questions in his counterclaim.

The judges did not find Michele's lack of involvement critical to Ronan's outcomes. Judge Allshouse and Judge Rusczek indicated the Ronan's time at the Center got the "developmental ball rolling," and the details of the subsequent supports are not highly relevant to the claims of this case. Judge Powell voted to deny the counterclaim, writing in his Judge Decision Form:

Judge Powell: The passage of time and lack of supervision do not appear to have undermined or negated the evidence in support of the program's impact.

The judges voted 2 to 1 to reject the counterclaim. Judge Allshouse objected again to the idea that Ronan's outcomes are "directly attributed to Kristin's intervention" and reiterated that the Daycare Center in general likely had a more direct relationship with Ronan's improvements than Kristin as a sole provider. She also indicated that the long-term outcome might well have also been due to the aunt's continuing care provided to Ronan. This brings up again the problem of semantics in this claim as the advocate stated quite directly in her closing statement:

Advocate: I do want to make it clear that I'm not arguing that the Daycare Center or Kristin is the sole reason why Ronan made such vast improvements, but it's clearly a substantial reason, and that's the major point of these claims.

However, Judge Allshouse accepted this critic' counterclaim because she agreed with the critic in that Kristin could not receive total credit for Ronan's growth as literally written in the counterclaim. She wrote in her Judge Decision Form: "Certainly, as one of the number of individuals working with Ronan who used relationship-based interventions, the claim could be made that Kristin's interventions supported him to make developmental gains in social, emotional, and language goals."

If the wording had been different, Judge Allshouse would have voted to negate the counterclaim. Judge Rusczek also wrestled with this interpretive issue, but ultimately chose to deny the counterclaim because he noted the clear positive developments that arose in Ronan during his time at the Center were sufficient for him to argue that Kristin played a role in this outcome. He and Judge Powell identified exactly the same problem with attributing Ronan's continued improvement after the end of treatment at the Center to the work of Kristen. One chose to interpret the claim literally and voted in support of the counterclaim, but two of the judges voted to reject the counterclaim assuming that Kristen was a graduate student at the Center, and therefore, what was really being examined was the treatment program of the Center, which they viewed as powerful enough to produce a long term effect after nine months of treatment. So the counterclaim was rejected by a vote of 2 to 1 , but in their narratives, all three judges wished to object to the wording of claim \#3 that put too much emphasis on the graduate student's role in the treatment success rather than the success of the Center's overall treatment program. 
R.B. Miller et al.

Pragmatic Case Studies in Psychotherapy, http://pcsp.libraries.rutgers.edu/

Volume 17, Module 2, Article 2, pp. 129-209, 08-04-21[copyright by authors]

\section{DISCUSSION}

This Panel of Psychological Inquiry was instructive in revealing the central importance of a formal hearing into the reliability and validity of a written clinical case study. The process of having the case author and the clinical supervisor answering questions in an impromptu manner over the course of 3.5 hours created its own narrative about the case that was at times compelling. In all, the case advocate questioned the two witnesses for 80 minutes, the case critic questioned them for 70 minutes, and the judges questioned them for 35 minutes.

One of the surprises of the PPI hearing was the information provided by the supervisor, which was not in the original case study narrative written by the therapist. This information involved the supervisor's response to the case critic's question during the portion of the hearing devoted to establishing that there was implementation of a therapeutic daycare environment based upon Greenspan's model of treatment of ASD. The question from the critic was to clearly differentiate the Center's approach from ABA, widely accepted in the literature as the only empirically validated treatment for ASD. This interaction is captured on pages 157-158 above, and the testimony was riveting then and to others who have seen it since in the recording of the PPI hearing. It became clear that the supervisor had in fact been trained in and practiced ABA treatments of ASD for ten years before changing directions in her career and learning this new model which she experienced as much more personally meaningful and professionally satisfying.

This speaks to the core question that the reader of a clinical case study must ask, do I trust this clinician to report thoroughly, honestly, and openly the therapeutic process being undertaken with the client? The willingness to be scrutinized before a jury of one's professional peers which includes senior members of one's practice community that one may have never met before is a severe test of the validity of the clinician or supervisor's account of a clinical case.

By convening a PPI, a practice community comes together to consider and evaluate the work of one (or more) if its members, and draws on the community's collective wisdom that can emerge out of critical scrutiny of the clinical work that has been reported. The adversarial model taken from Anglo-American civil law assures that the clinician(s) are not alone in this process due to the role of the advocate and the presence of impartial judges, and also that assumptions about the case and interpretations of the meaning of symptoms and when and how these change or remit will be challenged in a manner that attempts to leave no stone unturned. In other words, the professional tendency to not challenge a colleague's effectiveness is put aside, by requiring at least one person in the hearing, the case critic, to make the best argument possible about the weaknesses in the case as reported in writing or in person at the hearing.

The PPI begins with a written case study, and as with other adjudication methods (cf. Bohart 2018, and Elliott, 2015) this is an invaluable starting place, but it does not end there. The written case study is examined and viewed from multiple perspectives (advocate, critic, and at least three judges) in order to answer the question, "What really happened in this clinical encounter between client and therapist?" 
R.B. Miller et al.

Pragmatic Case Studies in Psychotherapy, http://pcsp.libraries.rutgers.edu/

Volume 17, Module 2, Article 2, pp. 129-209, 08-04-21[copyright by authors]

It appears that the interactive component of the live hearing adds a critical dimension to the adjudication of a case for it allows the judges to do much more than review a written record of the advocate and critics analyses of the case and produces data that was available but not initially thought to be that relevant to the clinical record of the case. This process is as invaluable to judging the merits of a clinical therapeutic process as it is in the law in resolving conflicting accounts of interpersonal interactions that result in harm.

\section{The Limitations of a Master's Thesis Case Study}

As a second pilot study, a completed and defended case study was chosen as the focus of the hearing. The Case of Ronan was chosen due to the author's success in her graduate studies and her maturity and self-confidence in presenting her views in classes with the first author. The requirements of a case-study-style thesis in the graduate program emphasize focusing on the clinical setting where the internship occurred, the psychological problems addressed in the treatment, the theoretical framework or lens through which the graduate viewed the problems, and the kinds of therapeutic strategy or process they attempted to employ, as well as of course the outcome of the work. The graduate student is required to search the clinical case study literature in psychology to find several parallel cases and compare one's own work with that described by the case study authors in terms of diagnosis, treatment and outcomes.

It is natural for a graduate student to emphasize in their case study the actual clinical work they did with their client, and the supervision of that work or the training they received in their internship setting tends to be seen as secondary to the description of that work. This works very well in outpatient settings as the pedagogical need for an original paper, and the clinical task of working quite independently with supervision of course provided regularly as well as "as needed" are quite well suited to one another.

However, in the case of Ronan where the child was in a therapeutic Daycare Center six hours per day, and where the parents are encouraged to stay with the children for an hour of each day and also receive home visits from the director, the PPI hearing revealed to everyone present the powerful backdrop to the individual work being done by the case study author that was provided by other caregivers. Specifically, it became clear that the total therapeutic environment of the Center was a very important part of Ronan's treatment, including such components as: the contributions of all staff; the hands-on involvement of the Director, Michele Fouts, when difficulties emerged; and the offering of one-on one therapy by Director Fouts with the children attending the Center several times per week. This is something that we will need to pay more attention to from the beginning of the PPI process in cases involving day treatment or inpatient milieu therapy.

\section{The Crucial Role of the Advocate}

As anyone who has defended a thesis or submitted a paper for peer review understands it can be quite an intimidating process especially when one is challenging the received view on a 
R.B. Miller et al.

Pragmatic Case Studies in Psychotherapy, http://pcsp.libraries.rutgers.edu/

Volume 17, Module 2, Article 2, pp. 129-209, 08-04-21[copyright by authors]

topic. Imagine then the PPI hearing with a critic and three judges essentially saying, "Look me in the eye, and tell me that really happened!" One would need to be incredibly confident in one's work, one's interpretation of that work, and one's ability to express both in an articulate manner under that kind of scrutiny.

The PPI model would have little appeal to the talented and insightful therapist without an ally in the hearing room whose job it has been to prepare and coach such a therapist for a concerted attempt to undermine the credibility of the work and one's interpretation of it. The advocate can demonstrate their understanding of the clinical work, and the critical process of proving to the judges that it is more likely than not that what the therapist reports in terms of the client's problems, the therapist's clinical approach to those problems, and the clinical outcome are true. Yet, the advocate can also be dispassionate as it is not their own clinical work that is under scrutiny, and they are required by the APA Code of Ethics to present the information with honesty and integrity. With less personal emotional investment at stake, the advocate can tackle difficult subjects with the therapist in preparation for the hearing, and in the hearing their own clinical judgment or effectiveness is not being questioned.

Due to this separation of roles, it is more likely that the quality of the work done by the therapist will be presented more objectively than if the therapist was doing this for themselves. As an unfamiliar setting for most therapists, it is more likely they will feel protected and have a fair hearing of their case study.

\section{The Challenges of the Critics Role}

In this second pilot study of the PPI hearing model, as in the first pilot study, the difficulty of the critic's role stands out. Typically, a therapist is not in a position where other therapists are "publicly" permitted to question the accuracy or completeness of a lengthy case study of therapy one has written. In the context of both PPI pilot studies, the critics were in the same year of graduate school as the advocate, although in the present pilot study the critic did not actually attend classes with the therapist whose case study was under investigation. Still it was clear that while the critic (David O'Leary) was not averse to challenging the weaknesses he perceived in the four claims about the case in question, he was probably less critical of the narrative data than an ABA-trained therapist experienced with children diagnosed with ASD would have been. This is not a unique phenomenon as Bohart (2018) and Elliott (2015) have both noted a similar reticence in the role of what they refer to as the case "skeptic."

By using a model where the judges are permitted to ask the witnesses questions at the end of each segment of the PPI (three segments with 15 minutes of judge's questions in each segment), there is the opportunity for the judges to raise questions about the written case study or the oral arguments and evidence presented on each of the five claims. This helps to balance any lapses in the advocate or critic's performance in their roles, and we saw this in how two of the judges expressed concerns of the vagueness of the second claim concerning whether Kristin's 
R.B. Miller et al.

Pragmatic Case Studies in Psychotherapy, http://pcsp.libraries.rutgers.edu/

Volume 17, Module 2, Article 2, pp. 129-209, 08-04-21[copyright by authors]

intervention "in the context of the Center's programs" was responsible for Ronan's remarkable growth and development. This was not an issue that the critic had raised.

\section{The Process Generates Evidence in Itself}

It was indeed surprising how much evidence emerged as the result of the PPI process that augmented what appeared to be a very thorough case study thesis. Particularly noteworthy was the emergence of much more evidence about the nature of therapeutic setting - a therapeutic daycare - with high staff to client ratios, and a highly trained supervisor. Though the milieu nature of the therapeutic day care center was evident in the case study thesis narrative, the description of the complexity and structure of the therapeutic program that included individual therapy with the supervisor, the intense supervision of the staff by the supervisor, and the Center's use of outside consultants in speech and language therapy and physical therapy made for a much richer picture of the intensity of the treatment. This in turn made the degree of progress achieved in ten months all the more plausible.

The original intent behind asking that the supervisor be a witness in the PPI was to corroborate the therapist's work as an intern with Ronan as described in her case study master's thesis (Appendix A). It was not originally intended that all of the other features of the therapeutic Daycare Center program - the supervisor's role also as individual therapist to each child at the Center, and her degree of close supervision of staff throughout the day - would be topics discussed in the written case study; and these only emerged from the PPI process itself. The PPI becomes an impromptu though highly structured clinical case conference where a community of practitioners worked together to make sense out of what transpired in the child's therapeutic experience and the nature of the outcome. In this instance, the impact was to enhance the appreciation of all concerned with the child's (Ronan's) therapeutic progress.

\section{Establishing Responsibility for Improvement in Clinical Cases Parallels with the Civil Law}

Implicit in Bromley's (1986) quasi-judicial clinical case study method for psychology is the observation that Anglo-American civil case law is respected as the most reliable method yet invented for resolving disputes about personal responsibility and injury of one party by another. It does so by establishing in cases of personal or financial injury (1) who injured whom; (2) in what manner; and (3) to what degree. The PPI model of investigating the reliability and validity of clinical case studies takes this one crucial step further. It asserts that if the civil law can do this for matters of personal harm, then the PPI model can establish (1) who benefitted whom; (2) with what psychological intervention; and (3) to what degree.

The critical question in both formulations above is contained in (1). To harm or benefit another person means that one person is responsible for either the harm or benefit experiences by another person. Another way of saying this is, of course, that one person caused the harm or benefit experienced by another person. Now being a profession where scientific research is 
R.B. Miller et al.

Pragmatic Case Studies in Psychotherapy, http://pcsp.libraries.rutgers.edu/

Volume 17, Module 2, Article 2, pp. 129-209, 08-04-21[copyright by authors]

central to our training, we are wont to assume that the proof of (1) above in both formulations requires that one have scientific research using the most advanced experimental and statistical procedures to prove (1).

While it is true that in certain situations in the civil law (e.g., product safety; the logistics of mechanical failures of equipment or vehicles; contamination of food stuffs) there may be a need for that kind of proof of causation, but prior to that sort of information being invoked the law has established a way of looking at causation suited to specific individuals (not group averages) in individual or unique (as opposed to general) circumstances. Here are the five questions that the law requires be asked of the situation where there is a law suit over personal injury:

1. Did the defendant have a duty to protect others from unreasonable risk?

2. Did the defendant breach that duty by failing to do \#1?

3. Was there sufficient causal connection between that conduct and the injury to the plaintiff? (Sometimes referred to as a "cause-in-fact".)

4. Was there "proximate cause? (The law acknowledges that any event can have multiple causes. Determining exactly what part the defendant's actions played in producing the injury to the plaintiff is difficult. The defendant must have some direct relation to the injury.)

5. Did the plaintiff suffer a quantifiable loss in terms of material wealth, loss of employment, and/or pain and suffering. ( Bryson, 2018, pp. 317-318.)

These must be slightly reworded when considering responsibility for benefit:

1'. Did the clinician have a professional duty to provide services that were likely to be beneficial to the client?

2'. Did the clinician actually provide such a service that was deemed beneficial to the client?

3'. Is there cause-in-fact? (Is it plausible to conclude that the benefit gained by the client as direct result of the clinical services provided?)

4'. Was there proximate cause: Could the clinician have foreseen the benefit that resulted?

5'. Are there substantive changes in the client's psychological well-being clearly identifiable either in terms of affective experiences and/or changes in work or living arrangements, affluence, and other rewards of hard work? 
R.B. Miller et al.

Pragmatic Case Studies in Psychotherapy, http://pcsp.libraries.rutgers.edu/

Volume 17, Module 2, Article 2, pp. 129-209, 08-04-21[copyright by authors]

Another way that this has been explained by legal scholars and that is used to separate background causal forces or factors from those that should be seen as "proximate" factors is referred to as the "but for" test. One is responsible for the hardship caused another person when the injury to the plaintiff would not have occurred "but for" the injurious action by the defendant. (Bryson, 2016, pp. 319). Now how to translate this into the attempt to define causal factors in the improvement in a single client's life as a result of psychotherapy. We would say that "but for" the work with the client done by the therapist, the client would not have improved as much as described in the case study. Of course, when this is used in a PPI setting, the therapist and their advocate have also the burden of proof in this process. So they must show that it is more likely than not that the client in a therapeutic setting was positively impacted by working with the therapist.

If we use the concept of causality that has been a part of our civil legal system for five hundred years, then a clinician who (1) agrees to offer professional clinical services to a client; (2) actually offers those professional clinical service to the client that the clinician believes will be helpful; (3) achieves the desired therapeutic outcome (4) as foreseen by the clinician; and (5) but for the therapeutic services offered in (2), the outcome observed in (3) seems unlikely to have occurred; then by rights a clinician can claim to have caused the client's improvement. Notice the claim is about the therapist being the causal agent through the implementation of beneficial therapeutic strategies or techniques in this case. It remains for the reader to compare this case with the clients they encounter to see whether they can reproduce this result in their own practice.

One final important issue in discussing the legal model for allocating responsibility for harm that would also be important in allocating responsibility for acts that are beneficial to others:

The law is far from pure science and while it appears to be logical, law is not the product of pure logic... While consistency, predictability and analytic soundness are important for the law as other fields, other values have their claim in legal doctrines as well...it must respond to the community's sense of fundamental justice (Bryson, 2016, p. 339).

I take this to mean that we might encounter a hypothetical case like the following client, call her "Mary," with severe borderline personality disorder:

The therapist's efforts with Mary were highly responsible, supportive, and comprehensive, considering every possible traumatic experience or psychological process that might have resulted in the development of her severe borderline personality disorder. The therapy ended with Mary hospitalized after a very serious suicide attempt. She had been hospitalized many times before, and always stabilized but without any fundamental change to her level of functioning. 
R.B. Miller et al.

Pragmatic Case Studies in Psychotherapy, http://pcsp.libraries.rutgers.edu/

Volume 17, Module 2, Article 2, pp. 129-209, 08-04-21[copyright by authors]

The therapist's account of the work describes a therapeutic breakthrough just prior to the hospitalization. Mary agrees that even though the therapy triggered the latest suicide attempt, that it is not like her other such attempts, and that due to the therapy she was able to use the hospitalization in a much more productive manner, and feels that she is on the road to health. Mary says that after thirty years of therapy she finally found someone who really understood her and helped her to change.

During the PPI hearing on such a case like Mary's, the case critic might argue that the hospitalization records do not see the patient as improved, and that a hospitalization did not produce any fundamental change in her chronic condition. They see the therapist's and client's claims of a breakthrough as a "folie a deux." Were such a case brought before a PPI for review, it might be the result that the Panel would support the client's claim that her therapist did wonderful work that he deserves great credit for, and that the therapist's approach once documented through PPI would become an important step in a better understanding of how to do therapy with such a severe borderline personality disorder.

What should the Panel decide in the above case? Is it fair or just to ignore the therapist's and client's accounts of three years of intensive psychotherapy based upon an account of a 10 day hospitalization written by a hospital staff (several psychiatrists, a psychologist, psychiatric nurse and an occupational therapist at a prestigious medical school) wanting her to be referred to their preferred therapy mode of Dialectical Behavior Therapy and steering her away from her existential-psychoanalytic therapy? Typically, one would think that the outline of this case might argue against finding that the existential-psychoanalytic therapist had benefitted his client very much at all. What if the testimony at the hearing by both the therapist and the client were compelling, documenting changes that the medically- and behaviorally-trained hospital staff dismissed out of hand? Might not the judges in such a PPI find the fair and just conclusion be to credit the therapist and Mary with impressive work despite the more obvious evidence to the contrary.

\section{REFERENCES}

Antonio, N., Costanza, C., Paolo, F., Umberto B., Filippo, M. (2014). Non-pharmacological treatment in ASDs: An overview on early interventions for pre-schoolers. Current Clinical Pharmacology, pp. 2-11.

APA. (2017). Code of Ethics (Including 2010 and 2016 Amendments, effective date June 1, 2003 with amendments effective June 1, 2010 and January 1, 2017). Washington, DC: American Psychological Association.

Bohart, A.C., \& Humphreys, C. (2000, June). A qualitative "adjudicational" model for assessing psychotherapy outcome. Paper presented at the meeting of the International Society for Psychotherapy Research, Chicago, Illinois.

Bohart, A.C.; Tallman, K.L., Byock, G., \& Mackrill, T. (2011a). The "Research Jury Method": The application of the Jury Trial Model to evaluating the validity of descriptive and 
Further Developments in the Panel of Psychological Inquiry

Method of Case Study Research: The Case of "Ronan"

R.B. Miller et al.

Pragmatic Case Studies in Psychotherapy, http://pcsp.libraries.rutgers.edu/

Volume 17, Module 2, Article 2, pp. 129-209, 08-04-21[copyright by authors]

causal statements about psychotherapy process and outcome. Pragmatic Case Studies in Psychotherapy, 7(1), Article 8, 101-144. Available: https://pcsp.libraries.rutgers.edu/

Bohart, A.C., Berry, M., \& Wicks, C. (2011b). Developing a systematic framework from utilizing discrete types of qualitative data as therapy research evidence. Pragmatic Case Studies in Psychotherapy, 7(1), Article 9, 145-155. Available: https://pcsp.libraries.rutgers.edu/

Bohart, A. (2018). How can we identify therapeutic change from the case history data. Arthur Bohart (Chair) Using Qualitative Research Methods to Assess Quality and Outcome in Psychotherapy. 34th Annual Meeting of the Society for Exploration of Psychotherapy Integration, New York City.

Bromley, D.B. (1986). The case study method in psychology and related disciplines. Chichester: John Wiley \& Sons.

Bryson, W. C. (2016). Cause and consequence in the law. In R. Harre and F.M. Moghaddam (Eds.), Questioning causality: Scientific explorations of cause and consequence across social contexts. Santa Barbara, CA: Praeger

Dattilio, F.M., Edwards, D.J. and Fishman, D.B. (2010). Case studies within a mixed methods paradigm: Toward a resolution of the alienation between researcher and practitioner in psychotherapy research. Psychotherapy: Theory, Research, Practice and Training, 47, No. 4, 427-444.

Elliott, R. (2002). Hermeneutic single-case efficacy design. Psychotherapy Research, 12, 1-21.

Elliott, R., Partyaka, R., Alperin, R.,Dobrenski, R., Wagner, J., Messier, S. B., ...Castaonguay, L.G. (2009).An adjudicated hermeneutical single-case efficacy design study of experiential therapy for panic/phobia. Psychotherapy Research, 19, 543-557.

Elliott R. (2015). Hermeneutic single case efficacy design. In K.J. Schneider, J.F. Pierson, \& J.F.T. Bugental (Eds.), The handbook of humanistic psychology (2 ${ }^{\text {nd }}$ ed., pp. 351-360.). Thousand Oaks, CA: Sage.

Fishman, D.B. (1999). The case for pragmatic psychology. New York: New York University Press.

Fishman, Daniel B.; Messer, Stanley B.; Edwards, David J. A.; Dattilio, Frank M. (Eds.), (2017). Case studies within psychotherapy trials: Integrating qualitative and quantitative methods. New York: Oxford University Press; 2017.

Greenspan, S.I. \& Tippy, G. (2017). Respecting autism: The Rebecca school DIR casebook for parents and professionals. Hollywood, FL: Simon \& Brown.

Greenspan, S.I. \& Wieder, S. (1997). Developmental patterns and outcomes in infants and children with disorders in relating and communicating: A chart review of 200 cases of children with autistic spectrum diagnoses. The Journal of Developmental and Learning Disorders, 1(1), 1-38.

Greenspan, S.I. \& Wieder, S. (2006). Engaging autism: Using the floortime approach to help children relate, communicate, and think. New York: Da Capo Press.

Hilton, J. \& Seal, B. (2007). Brief report: Comparative ABA and DIR trials in twin brothers with Autism. Journal of Autism and Developmental Disorders, 37(6) 1197-1201. 
Further Developments in the Panel of Psychological Inquiry

Method of Case Study Research: The Case of "Ronan"

R.B. Miller et al.

Pragmatic Case Studies in Psychotherapy, http://pcsp.libraries.rutgers.edu/

Volume 17, Module 2, Article 2, pp. 129-209, 08-04-21[copyright by authors]

Mercer, J. (2017). Examining DIR/Floortime ${ }^{\mathrm{TM}}$ as a treatment for children with Autism Spectrum Disorders: A review of research and theory. Research on Social Work Practice, 27(5), 625-635.

Miller, R.B. (1998). Epistemology and psychotherapy: The unspeakable, unbearable, horrible truth. Clinical Psychology: Science and Practice, 5, 242-250.

Miller, R. B. (1999, August). Doing justice to the case study method. In R. Miller (Chair), Case study standards and the knowledge base of professional psychology. Symposium conducted at the $107^{\text {th }}$ Annual Convention of the American psychological Association, Boston.

Miller, R. B. (2004). Facing human suffering: psychology and psychotherapy as moral engagement. Washington, DC: American Psychological Association Books.

Miller, R. B. (2011). Real Clinical Trials $\left(\mathrm{RCT}^{1}\right)$ - Panels of psychological inquiry for transforming anecdotal data into clinical facts and validated judgments: Introduction to a pilot test with the case of "Anna." Pragmatic Case Studies in Psychotherapy, 7(1), Article 2, 6-36. Available: https://pcsp.libraries.rutgers.edu/

Miller, R. B. Kessler, M. Bauer, Howell, S., Kreiling, K. Miller, M. (2011). Findings of the Panel of Psychological Inquiry convened at Saint Michael's College, May 13, 2008: The case of “Anna." Pragmatic Case Studies in Psychotherapy, 7(1), Article 7, 95-100. Available: https://pcsp.libraries.rutgers.edu/

Miller, R.B., Ashley, B., Mount, K.,Tuepker S., O’Leary, D., Fouts, M., Allshouse, K., Rusczek, J., Powell, T. Hennebarrows, K. (2018). Further developments in the Panel of Psychological Inquiry: The case study of 'Ronan.' Arthur Bohart (Chair), Using Qualitative Research Methods to Assess Quality and Outcome in Psychotherapy. 34 ${ }^{\text {th }}$ Annual Meeting of the Society for the Exploration of psychotherapy Integration, New York City.

Mount, K. (2016). The Intricate connection between autism and trauma: A case study. (Unpublished master's thesis). Saint Michael's College, Colchester, Vermont.

Odom, S.L., Boyd, B.A., Hall, L.J., Hume, K ((2010). Evaluation of comprehensive treatment models for individuals with Autism Spectrum Disorders. Journal of Autism and Developmental Disorders, 40, 425-436.

Pajareya, K.\& Nopmaneejumruslers, K. A. (201) A pilot randomized controlled trial of DIR/Floortime ${ }^{\mathrm{TM}}$ Parent training intervention for pre-school children with autistic spectrum disorders. Autism, 15(5), 563-577.

Solomon, R., Necheles, J. Ferch, C. \& Bruckman, D. (2007) Pilot study of a parent training program for young children with autism: The PLAY Project Home Consultation program. Autism, 11(3), 205-224.

Toulmin, S. (1958). The uses of argument. Cambridge, England. Cambridge University Press. Wagner, A.L., Wallace, K.W., Rogers, S.J. (2014). Developmental approaches to treatment of young children with Autism Spectrum Disorder. In Tarbox, J., Dixon, D.R., Sturmey, P., \& Matson, J.L. (Eds.), Handbook of early intervention for autism spectrum disorder. New York: Springer.

Wieder, S. \& Greenspan, S.I. (2003). Climbing the symbolic ladder in the DIR Model through Floor Time/Interactive Play, Autism, 7 (425-435). 
R.B. Miller et al.

Pragmatic Case Studies in Psychotherapy, http://pcsp.libraries.rutgers.edu/

Volume 17, Module 2, Article 2, pp. 129-209, 08-04-21[copyright by authors]

Weissenberger, G. and Duane, J.J.(2007). Federal rules of evidence, rules, legislative history, commentary and authority, sixth edition. New York: LexisNexis.

Table 1. Relevant Sections of the APA (2017) Ethical Principles of Psychologists and Code of Conduct for Panels of Psychological Inquiry Participants

Note: The following are abbreviated and selected (due to copyright restrictions) sections of the APA Code of Conduct agreed to by participants.

Section 4: Privacy and Confidentiality

4.04 Minimizing Intrusions on Privacy

(b) Psychologists discuss confidential information obtained in their work only for appropriate scientific or professional purposes and only with persons clearly concerned with such matters.

4.07 Use of Confidential Information for Didactic or Other Purposes

Psychologists do not disclose in their writings, lectures, or other public media, confidential, personally identifiable information concerning their clients/patients..., unless (1) they take reasonable steps to disguise the person or organization, (2) the person or organization has consented in writing, or (3) there is legal authorization for doing so.

5.01 Avoidance of False or Deceptive Statements

(a) Psychologists do not knowingly make public statements that are false, deceptive, or fraudulent concerning their research, practice, or other work activities or those of persons or organizations with which they are affiliated.(Italics added)

Section 8: Research and Publication

8.10 Reporting Research Results

(a) Psychologists do not fabricate data. (See also Standard 5.01a, Avoidance of False or Deceptive Statements.)

I understand and specifically agree to abide by the above elements of the APA Code of Conduct as they pertain to my participation in all aspects of the Panel of Psychological Inquiry investigating the case study by Kristin Mount, The Intricate Connections between Autism and Trauma: A Case Study (2016),

Signature

Date:

(Please print your name) 
R.B. Miller et al.

Pragmatic Case Studies in Psychotherapy, http://pcsp.libraries.rutgers.edu/

Volume 17, Module 2, Article 2, pp. 129-209, 08-04-21[copyright by authors]

\title{
APPENDIX A: \\ The Intricate Connections between Autism and Trauma: A Case Study \\ KRISTIN MOUNT
}

(Note: This case study is a version of Kristin Mount's Masters Thesis [2016] that was reformatted to conform to the headings in a PCSP case study.)

\begin{abstract}
The effects of trauma in childhood are far-reaching and oft studied. The increase in incidence of autism in current years has sparked some research on the link of early trauma. There may be a biological or genetic predisposition for autism that has been activated by a traumatic event or series of events. This paper is a case study on a boy for whom it is particularly difficult to know if trauma or autism "came first". This case study will take an in depth look at the case of Ronan and how he progressed during his time at the Early Intervention Center, a specialized childcare for children with autism. Links between his trauma history and his autism diagnosis will be addressed within a psychodynamic frame with a focus on long-term outcomes for Ronan.
\end{abstract}

\section{CASE CONTEXT AND METHOD}

The Intricate Connections between Autism and Trauma: A Case Study (Mount, 2016) was originally written as my master's thesis. This case study documents the growth and change of a threeyear-old boy named Ronan, who was diagnosed with autism around 20-months of age, following a traumatic first two years of life. Ronan was engaged in programming at an Early Intervention Center that used a relational-based play therapy style. Ronan and his caretakers were invited to participate in this case study following a clinical evaluation that indicated that Ronan may have retreated into his internal world because of the early trauma he experienced.

\section{Early Intervention Center}

The Early Intervention Center that Ronan attended is an intensive childcare program with a high adult to child ratio that aims to engage with children on the autism spectrum in dynamic and meaningful ways. The director of the Center developed the integrative, dynamic approach to early intervention work described here.

The setting of the Center is in a converted house. The room design and toy selection was very deliberate. There are few distractions on the walls. Toys are not electronic or overstimulating, and are put behind a closed door when not in use. This reduces distractions, but also encourages communication 


\section{R.B. Miller et al.}

Pragmatic Case Studies in Psychotherapy, http://pcsp.libraries.rutgers.edu/

Volume 17, Module 2, Article 2, pp. 129-209, 08-04-21[copyright by authors]

for when a child wants to take something out. Symbolic play is encouraged with the use of puppets, dolls, stuffed animals, and costumes. There is a rhythm to the day, but not set schedule. The house is set on the top of a hill with a spacious meadow in the front and woods in the rear. Nearby is a dirt road leading to a river. Within a day, outdoor play, nature walks, or running through the field to climb on hay bales may ensue, depending on the needs and expressed desires of the children.

\section{A. THE CLIENT}

This paper explores the case of a boy for whom the literature reviewed is particularly relevant. Ronan is a three-year-old boy who had a traumatic beginning. He was born to drug-addicted parents who had difficulty meeting his needs. The extent of his parents' neglect of his needs is largely unknown, but there were reports that Ronan was often left in his high chair or crib with the television acting as a "babysitter" of sorts.

When Ronan was 20 months old, he went into custody of the Child Protective Services department within his state, and began to live with his aunt, Annette. In her care, he was evaluated by the Child Development Clinic to address his significant developmental delays. He was only speaking a few words, would barely acknowledge that he had heard his name, and had many behaviors that were rated "high" on a measure intended to catch early signs of autism. Indeed, he was diagnosed with autism and the Clinic doctor referred the family to the Early Intervention Center, a nearby specialized childcare for children on the autism spectrum. It is at the Early Intervention Center that the researcher came to meet Ronan when he began there at 25 months of age.

This case study details the case of Ronan's time at the Early Intervention Center. His name and other details of the case have been changed for the purpose of protecting confidentiality. Where there have been changes, every effort has been made to maintain the overall integrity of the case. The etiology of his diagnosed disorder is a case that may well be from the early trauma he experienced.

\section{B. THE THERAPIST}

I went to college knowing that I wanted to major in psychology, and I never wavered. I loved it to its core. I was not one of the many students who majored in it as a liberal arts degree, choosing it because it was inherently interesting but having no intention of taking it all the way. I wanted to go all the way. After graduation, I pursued a job in a psychological research lab, where we studied the stress levels of pregnant women and later, the developmental outcomes of their infants. I loved working with mothers and young children and chose a path of developmental psychology. The advisor I applied to work with for graduate school continued similar research. My Master's thesis was on the anxiety of twoand-a-half-year-olds and the sensitivity of the mother. However, I was in a research oriented doctoral program, and I left shortly after receiving my Master's to pursue more direct work with families.

Autism has also held my interest for many years. In the very first psychology class I took, during my senior year of high school, we watched a movie about the creators of the Son-Rise program, a highly intensive one-on-one method of joining the child with autism in their activities in an effort to draw them into a more social world (Kaufman, 1994). While working as a research assistant, I also worked (very) part time as a Son-Rise facilitator for a local boy with autism named Jake. I felt invigorated when Jake and I "connected", the many moments, some more fleeting than others, where he seemed to really see me. Three components of this intervention really stuck with me: reducing the number of distractions in the 


\section{R.B. Miller et al.}

Pragmatic Case Studies in Psychotherapy, http://pcsp.libraries.rutgers.edu/

Volume 17, Module 2, Article 2, pp. 129-209, 08-04-21[copyright by authors]

room (white walls, toys up on high shelves only available when asked for), the focus on enthusiasm for eye contact ("Great eyes!" and "I love it when you look at me!"), and the use of the connection between me and Jake to facilitate positive change. While I have come to place much less emphasis on verbally rewarding eye contact, I continue to see the benefit of removing distractions from the environment and using the connection between people as a vehicle for change in my current work. In many unexpected ways, this experience helped prepare me for my future.

During graduate school for Developmental Psychology, I began to conduct a preliminary research study on the sensitivity of mothers of children with autism, and I performed developmental assessments on the children. I had a period of time when I was interested in focusing my career on working with children with autism. I have gone back and forth on this.

During my work as a mental health clinician, I worked with several children who had trauma histories. One such child, Ruby, had gone straight from her birth room into foster care. Her mother regained custody of Ruby when she was six months old, but the mother admitted that she felt for a long time like Ruby was someone else's child and had a hard time bonding with her. I became acquainted with the family when Ruby was a three-year-old, at which time she was often socially withdrawn and would have frequent, unexplained tantrums over seemingly minor incidents. Her behaviors were similar in many ways to those of Jake, and yet there was a different feel to them. While Jake received a diagnosis of autism, Ruby was diagnosed with Reactive Attachment Disorder. My understanding at the time was that Jake had an organic disorder, while Ruby's came from a traumatic beginning of first leaving her birth mother and then at six months, leaving the family she had come to know.

After my three years working as a case manager for young (birth to six years) children and their parents, I left because I had a baby. I enjoyed being a mother every bit as much as I expected I would. My husband had a son from a previous relationship, and we spent a great deal of time and energy trying to get primary custody of him. Being a mother and stepmother has been my world. When I came back to graduate school, it was the families I did it for. I wanted to continue working with families who needed parenting help, and I wanted to do it in a more clinical way. During the first of my two years in the Clinical Psychology Master's program at a small, New England liberal arts college, I was assigned a practicum site to begin gaining clinical experience.

My practicum assignment was at an Early Intervention Center, run by a director with a degree and license in Clinical Psychology. The Center was an intensive childcare program with a high adult to child ratio that aimed to engage with children on the autism spectrum in dynamic and meaningful ways. This can look a lot of different ways, something I will explore in more detail later, but it is worth noting that it is a far cry from Applied Behavior Analysis, or ABA (discussed in a later section), which is often used for children with autism in academic settings. I continued at the Early Intervention Center for my internship during my second and final year in my Master's program.

During my practicum year at the Early Intervention Center, I reignited my former passion for children with autism. Seeing the way the staff at the Early Intervention Center engage children who otherwise had little interest in the social world was truly inspiring. In my Abnormal Psychology class during the first year of my clinical psychology program, it came up several times that children with trauma histories may at times seem like they have autism, and may thus be treated with behavioral intervention programs that are detrimental to their well-being. If a child has had a trauma history, the child may have learned not to trust the people around him or her. Some children have learned that the 
R.B. Miller et al.

Pragmatic Case Studies in Psychotherapy, http://pcsp.libraries.rutgers.edu/

Volume 17, Module 2, Article 2, pp. 129-209, 08-04-21[copyright by authors]

people they love most and are closest to can be unpredictable and even dangerous. If they then withdraw into an internal world because of this experience, the rigid training involved in programs focused primarily on behavior management may be an additional detriment. What these children needed was to build a trusting and supportive relationship with someone who can teach them what was and was not safe in the world.

I was a foster mother and a stepmother before I became what is traditionally referred to as "mom". Because of the somewhat complex nature of my relationships with these two very young boys and because of the education I had received as a student of developmental psychology, I spent a lot of time thinking about healthy attachments. I wanted to be sure I had healthy attachments with these boys because I knew how important it is to development. I also knew that both boys had had bumpy relationships with their biological mothers, making it even more important to me. Then I had my first biological son. I had every intention of going back to work after a 14-week leave. Every cell of my being felt like it was resisting my plan. Here was this tiny little human who relied on me for everything. We came to have a very loving, trusting relationship, and it was far from difficult to make the decision to cut our household income in order to nurture my son in the ways that I felt he needed most. We were very attached to one another in a most loving and natural way. A daughter was added to our family two and a half years later.

My children are typically developing and have a healthy, secure attachment to me, their mother. In the cases of my foster son and stepson, their lives lacked healthy attachments to their mothers. I came to writing this paper through years of living and breathing deep and intense experiences related to attachment. I came to these questions by way of working with children with autism and children who experienced trauma.

I chose to write this paper because I wanted more answers about whether or not some children receive a diagnosis of autism due to early traumatic experiences, leading them to withdraw into an internal world. In some treatment programs, such as the one at the Early Intervention Center that uses a relational-based play therapy style as an intervention, it may not matter much what the "root cause" of the child's autism symptoms were, because the treatment will cover any possible etiology. However, in programs that focus on shaping behavior rather than building relationships, it may make a huge difference. One primary observation of the leading clinicians in the field of autism is that there are some children with autism who seem primed for change through psychotherapy, and others who make little progress through psychotherapy (Reid, 1999). I wanted to know more about why that was.

\section{GUIDING CONCEPTION WITH RESEARCH AND CLINICAL EXPERIENCE SUPPORT}

\section{Autism Overview}

The term "Autism" was coined by Eugen Bleuler, coming from the latin autos, or self (Kerig, Lulow, \& Wenar, 2012). Bleuler noted delayed language development, echolalia, pronoun reversal, and extreme literalness. Leo Kanner continued this research in the 1940's, citing "extreme autistic aloneness", a pathological desire for sameness, and language problems. Also at that time, he noted that a distinct unifying characteristic was a lack of warmth in the child's mother, later referred to as the "refrigerator mother" (Kerig, Lulow, \& Wenar, 2012). Impairment of social relatedness is a core symptom of autism (Reid, 1999). Other common symptoms are deficits in communication and the 


\section{R.B. Miller et al.}

Pragmatic Case Studies in Psychotherapy, http://pcsp.libraries.rutgers.edu/

Volume 17, Module 2, Article 2, pp. 129-209, 08-04-21[copyright by authors]

presence of rigid behaviors and restricted interests (Lindgren \& Doobay, 2011). The cognitive and learning abilities of those with autism can vary from gifted to severely limited. It is at least four times more common in males than in females (Lindgren \& Doobay, 2011).

Over the years, the autism diagnosis has gone through an array of changes. Most notably, the most recent Diagnostic and Statistical Manual, Fifth Edition (DSM-5; American Psychiatric Association [APA], 2013), merged Autism, Asperger's Syndrome, Childhood Disintegrative Disorder, and Pervasive Developmental Disorder- Not Otherwise Specified into a single Autism Spectrum Disorders category. Another more puzzling change in the field has been the increase in incidence of autism over the recent decades (Rutter, 2005). In an article by Rutter (2005), the author reviewed the research and found that the definition of autism grew to include cases that would have formerly been excluded and that professionals became better at identifying cases. Research seeking a true rise in the number of autism cases has been inconclusive.

Signs of autism are often noted by 18 months of age. Common early signs include lack of or delay in spoken language, little or no eye contact, lack of interest in other children, lack of spontaneous or make-believe play, persistent fixation on parts of objects, poor response to his or her name, failure to imitate caregivers, motor mannerisms (e.g., hand-flapping), and failure to point or show joint attention (Lindgren \& Doobay, 2011). There is a large developmental range for what is considered "typical", and often children with autism fall behind many standard milestones. Other common characteristics are desire for routine or predictability and heightened or diminished sensitivity to sensory experiences, such as the texture of food or the feel of clothing on the skin.

Another common characteristic of children with autism is in the realm of sharing joint attention (Gutstein, 2009). This is a core symptom, and one that children with autism tend not to develop this skill at the pace of a neurotypical child. Joint attention refers to the communication between two people and the motivation to share such communication. For instance, a mother may point to an object as she says to her child, "Look at the ball over there!" The child would put the verbal and the non-verbal communications together and look. The mother and child are now sharing in the object that holds their attention. Here, the child has his or her own perspective, and also becomes interested in the perspective of the adult. The child is then able to use this information to develop a more complex understanding of the world (Gutstein, 2009). The delay in development of this skill for children with autism is key as joint attention is an integral part of social relatedness and perspective taking.

\section{Possible Etiologies of Autism}

There is some professional discord in the current understanding about what causes autism. In the relatively short history of autism research, some have believed in a strictly cognitive basis of disorder, rooted in genetic or other organic causation (Reid, 1999). This group believed that there was little opportunity to modify the condition, which led parents and professionals to give up on children with autism. Others believed autism was engaged as a "defensive avoidance" of the aloof, or "refrigerator" mother, which led to guilt on the part of the parents. The ensuing psychotherapy targeted the child's defenses but failed to acknowledge the developmental delays and other very real aspects of the disorder. Klauber (1999) pointed out that the theory of the refrigerator mother came from therapists who met families with a child with autism after the diagnosis had been established. These therapists failed to consider that the lack of warmth they observed on the part of the mother may actually have been in 


\section{R.B. Miller et al.}

Pragmatic Case Studies in Psychotherapy, http://pcsp.libraries.rutgers.edu/

Volume 17, Module 2, Article 2, pp. 129-209, 08-04-21[copyright by authors]

response to years of trauma and loss from parenting a child who seemed largely indifferent to her existence.

There is a subgroup of autism researchers and theorists who believe that the answers to what causes autism may lie in the parent-child relationship. The late Frances Tustin was a groundbreaking psychotherapist who worked primarily with children with autism. She described a subgroup of children with autism as coming to it "psychogenically", which means that it arises from a mental or emotional process, rather than biological (Tustin, 1992). Specifically, she believed that it came from the time when the child realizes he or she is separate from the mother.

When awareness of their separateness from the mother's body was suddenly experienced, it was as if they had lost a part of their own body.... Autism became an impenetrable protection which shut out the frustrating and terrifying awareness of bodily separateness. But this prevented the development of a sense of individual identity, since awareness of bodily separateness is a necessary precursor for that development. (Tustin, 1992, p. 11)

Tustin further goes on to describe a subgroup of mothers who inadvertently use their infant to fill a void, "a cork" to fill the emptiness and loneliness.

Birth [in situations such as these] was unusually traumatic for both mother and baby and precipitated a panic-stricken 'clinch' which, if not modified by subsequent nurturing, would result in the catastrophic consequences of feeling torn apart when awareness of bodily separateness could no longer be avoided. (Tustin, 1992, p. 15)

As such, Tustin believed that the development of autism was something of a protection that comes out of the traumatic stress of experiencing bodily separateness.

Tustin (1992) referred to autism as a type of psychosis, in that psychosis indicated a person who was extremely out of touch with reality. She further distinguished between children who had an organic condition, whereby the autism had an organic etiology such as neurological impairment or metabolic imbalance, and children whose autism was psychogenic in nature. Those who came to autism by way of a psychogenic manner could most be helped by engaging in psychotherapy. Tustin further noted that early interventions were most likely to succeed, as the "psychosis" would become a way of life impossible to modify if it went on too long. She further distinguished between childhood autism and schizophrenia by describing that the autistic child becomes somewhat encapsulated in his or her own body. The schizophrenic child, in contrast, is trapped in the body of another, leaving him or her confused and entangled with other people (Tustin, 1992).

The field of epigenetics is addressing this fragile balance between parenting and genetics. As it turns out, researchers were right to puzzle for so long over the nature versus nurture debate, because they are so delicately intertwined that there is really no separating the two (Champagne, 2015). As Daniel Siegel so simply put it, "Nature needs nurture," (2006). The human brain can change and adapt in response to experiences. An individual's DNA provides one layer of a person's genome, while the chemicals and proteins that control gene activity are the epigenetics. A relevant example would be the deprivation of warmth from a parent to an infant leading to a decrease in brain volume (Champagne, 2015). Similarly, research conducted by Roberts and colleagues (Roberts, Koenen, Lyall, Robinson, \& Weisskopf, 2015) showed that people with autism traits were at an increased risk for interpersonal 


\section{R.B. Miller et al.}

Pragmatic Case Studies in Psychotherapy, http://pcsp.libraries.rutgers.edu/

Volume 17, Module 2, Article 2, pp. 129-209, 08-04-21[copyright by authors]

victimization (e.g., sexual and physical abuse) and for developing Post-Traumatic Stress Syndrome after experiencing a trauma.

There are many possible pathways for the early relational experience to change the formation of parts of the brain that are linked to deficits in people with autism (Schore, 2014). In his 2013 and 2014 articles, Schore laid out different aspects of attachment that affect the development of the right hemisphere, which is the hemisphere of the brain that is predominantly developing between the last trimester of pregnancy and the first two years of life (Schore, 1994). The right hemisphere is connected to the innate drive for affiliation and social connection, and facilitates interconnectedness and emotion regulation (Hecht, 2014, as cited in Schore, 2014). If this growth is disrupted because the necessary social connections are not being made, or because trauma is occurring that engages the flight/fight/freeze response, thereby using neural energy that would otherwise be used to create new connections in the brain, the effects can be far-reaching (Perry, 2008). This can be related to the onset of autism in two ways: first, if the feeling of pleasurable connection is not established during this period, the child may give up on the need for social connectedness and may not find meaning in what are considered socially appropriate responses. For example, making eye contact and exchanging pleasantries come from a place of wanting to be socially connected to others (Gutstein, 2006). Second, this research can be relevant in the early intervention framework, whereby the brain is at its most plastic during the first two years of life in the areas that are most lacking for children with autism. If autism is identified early, this information can be used to provide interventions in areas that may assist in healthy brain development.

Finally, there are views from a very scientific perspective that blend the physiological perspective and the psychogenic one. Autism is traditionally viewed as a complex, lifelong neurodevelopmental disorder with onset most likely in the latter part of the first year-but maybe earlier (Schore, 2013). Abnormalities have been found in multiple areas of the autistic brain, such as atypical neural circuitry. Elevated stress during the prenatal and early postnatal period can set in motion modifications to the brain that have long-term developmental consequences (Schore, 2013). Among these consequences may be an increase in the risk for autism. The developing brain whose connections are not undergoing the usual refinement may result in the emergence of an ASD phenotype. This finding is a big update to the "strictly biological" model, and accounts for the interactive relational model.

\section{Trauma Overview}

The effects of trauma in childhood are far-reaching, oft studied, and have largely been around PostTraumatic Stress responses, anxiety, depression, and the adult onset of various personality disorders. However, with the increased incidence of autism in current years, an interest in its etiology has sparked some research on the potential link of early trauma (Schore, 2013). Some researchers believe that there is a subgroup of children who resorted to withdrawing internally after experiencing some sort of early trauma (Barrows, 2004). In essence, there may be a biological or genetic predisposition for autism that was activated by a traumatic event or series of events. There is also a possibility that there are children who have autism, and then those who appear in many ways to have autism but turned inward because the outside world appeared frightening or inconsistent.

In Levine and Kline's book Trauma Through a Child's Eyes (2007), the authors note that trauma can occur from the expected avenues such as being the victim of or witness to abuse, but also from common incidences such as medical procedures, a car accident, or falling out of bed. In his article calling for a new diagnostic category of Developmental Trauma Disorder, Bessel van der Kolk (2006) describes 


\section{R.B. Miller et al.}

Pragmatic Case Studies in Psychotherapy, http://pcsp.libraries.rutgers.edu/

Volume 17, Module 2, Article 2, pp. 129-209, 08-04-21[copyright by authors]

the trauma a child can experience when his or her parent is emotionally unavailable, inconsistent, intrusive, or neglectful. Additionally, there are potential subgroups of children with autism that Reid describes in her book (1999) as children who are typically sensitive and have very real trauma, but there are also children who are hypersensitive and have ordinary life experiences that are experienced as traumatizing. This is described as introjection, or the taking in and processing of experience. Taken together, along with the research on the brain by Allan Schore, these concepts suggest that there are children for whom a frequently misattuned parent can be experienced as traumatizing. For example, if a child's mother cannot recognize that her child is overstimulated, tired, or hungry, she will have difficulty meeting the needs the of the child. Over a period of time, some children may experience this pattern of not relating as traumatic.

\section{Attachment Overview}

Attachment is an important relationship established in early childhood between a child and his or her caregivers. Evolutionarily, humans are engineered to build this attachment bond with their primary caregivers. While a secure attachment relationship can pave the way for healthy adult relationships and a low incidence of psychopathology (Kerig, Ludlow, \& Wenar, 2012), insecure relationships can do the opposite. For the roughly $40 \%$ of children who are insecurely attached to their primary caregiver, there is an increased incidence of psychopathology (Wallin, 2007). A person's attachment style is a pattern. If a person who had an insecure attachment becomes a parent without working through some of the issues of their own childhood, they are likely to repeat the patterns of their parents. According to a meta-analysis conducted by van IJzendoorn (1995), there is a 75\% correspondence rate between a mother's attachment style and her children's. Further, attachment is more than an emotional springboard for the future. The type of attachment a child has can go so far as to change the brain (Schore, 2013). Attempts to heal from negative attachment patterns can be compounded by this biological component.

Bowlby originated the theory of attachment (Kerig et al., 2012). He theorized that it was adaptive for a helpless infant to remain in close proximity to his caregiver early in life, ensuring that needs for safety, food, and survival would be met. In the 1970's, Mary Ainsworth made advances in the study of attachment by observing patterns in parent-child relationships (as cited in Kerig et al., 2012). She identified three attachment categories: secure attachment, insecure-avoidant attachment, and insecureresistant (also called ambivalent) attachment.

A securely attached infant will explore the environment freely (while maintaining a social awareness and connection to the parent) and interact with unfamiliar adults when the primary caregiver is present. They express distress upon separation, and joy upon reunion. The caregiver responds to the infant's needs in a sensitive manner and with positive affect. A secure attachment can provide the basis needed for healthy cognitive, emotional, and social development (Kerig et al., 2012).

An insecure-avoidantly attached infant will appear very independent, lacking in reliance on the caregiver. These children react minimally upon separation (though research shows that cortisol levels spike at these moments regardless of their outward appearance (Wallin, 2007)), and avoid the parent upon reunion. Caregivers whose children express this pattern tend to be distant, lacking in a comforting presence, as well as reacting with anger and irritability. The avoidant response of the child is thought to be an attempt to cope with the parent's rejection (Kerig et al., 2012). Often times, these children receive more positive attention from their caregiver when they behave very independently but are rejected when they behave in a needy manner, as though the caregiver cannot tolerate the child's neediness (Wallin, 
R.B. Miller et al.

Pragmatic Case Studies in Psychotherapy, http://pcsp.libraries.rutgers.edu/

Volume 17, Module 2, Article 2, pp. 129-209, 08-04-21[copyright by authors]

2007).

An insecure-resistantly attached child acts clingy with the parent and avoids exploration (Kerig et al., 2012). These children are highly distressed upon separation and act angry and difficult to soothe upon reunion. Caregivers whose children express this pattern tend to be unpredictable, overly involved at times and unapproachable at others. The resistant response (e.g., the child expresses high need for the parent but also resists them at times-I want you/I don't want you - as if keeping the parent constantly in a cycle of intensity will keep them near and involved rather than risk losing their involvement altogether) is thought to be an attempt to catch the parent's attention, and the anger is a result of frustration with the parent's inconsistency (Kerig et al., 2012).

A fourth category was added after Ainsworth's initial study, called insecure-disorganized attachment. These children act in inconsistent or odd manners, wandering aimlessly or appearing fearful of their caregiver. They may approach their caregiver backwards or freeze when they are close. The caregivers tend to be confusing in their cues, such as offering a hug while backing away. This attachment style tends to come from the child being repeatedly placed in an unpredictable or frightening setting (Kerig et al., 2012), where the caregiver is both the source of fear and of comfort (Wallin, 2007).

Attachment theory states that, for the most part, the attachment style a child has with his or her primary attachment figure will follow that child throughout life via his or her interpersonal relationships (Prather \& Golden, 2009). If a child learns that the environment is unpredictable and at times scary (without consistent repair - all children will sometimes experience the world as scary and unpredictable, but usually parents will come along and make it better fairly quickly), the response may be to withdraw (Wallin, 2007). A parent, in turn, may become intrusive, trying harder to draw the child out, but instead simply reinforce the child's experience that the social world is unpleasant.

\section{Autism and Trauma: Early Brain Development}

Despite efforts to detach the disorder from the family unit altogether so that parents did not feel the need to bear the blame, which has the benefit of alleviating guilt that may otherwise be felt (which may further affect the mental health of the parents and the resulting parent-child attachment relationship), some of the biological data support autism etiology as related to the mother, either in utero or from the early attachment relationship (Schore, 2013). However, the question remains, how can a parent learn from his or her missteps if a pattern of misattunement is not identified? Beebe and colleagues (2012) researched disorganized attachment styles in children and the relationship with the mother. They found that mothers in the disorganized attachment group would close off their own facial expressions when the child was in distress, as if the mother was re-experiencing some past trauma and dissociating to avoid the pain. Children who have a disorganized attachment with their mothers would almost get stuck in a pattern of not touching. These mothers were inadvertently transmitting their own trauma histories to their children by making themselves unavailable for their children's emotional needs. This, coupled with much of the neuropsychology research that shows the rapid growth of the right hemisphere of the brain during the first two years of life, may pave the way for a path to autism that is more epigenetic than purely biological (Schore, 2013).

Allan Schore has researched the developing brain and how this development may play a role in the onset of autism. Specifically, Schore (2013) notes research that has shown the right brain to be in a period of rapid development from the last trimester of the mother's pregnancy through the age of two. 


\section{R.B. Miller et al.}

Pragmatic Case Studies in Psychotherapy, http://pcsp.libraries.rutgers.edu/

Volume 17, Module 2, Article 2, pp. 129-209, 08-04-21[copyright by authors]

The limbic system plays a critical role in the development of language and social skills and desires. If there is a trauma during this early period, the brain may send all of its resources to the trauma, rather than being allowed to focus its energy on the typical growth of that time.

Dr. Shore's research offers many areas in which the parent-child relationship does indeed change the developing infant brain, which may be related to the psychogenic onset of autism. In a 2014 paper, Schore stated that:

Early emotionally laden attachment experiences indelibly impact and alter the early developing right brain, which for the rest of the lifespan is dominant for the non-verbal, holistic, spontaneous (unconscious) processing of emotional information and social interactions, for enabling the organism to regulate affect and cope with stresses and challenges, and thereby for emotional resilience and emotional well-being in later stages of life. (p. 1)

The right hemisphere of the brain begins a growth spurt that goes from the third trimester of pregnancy through the second birthday. Attachment transactions can influence this programming.

The right hemisphere is the dominant hemisphere for the first two years of life. It influences the innate drive for affiliation and social connection, emotion regulation, and interdependence (Schore, 2013). It also lays the foundation for later emotional wellbeing. All of these are deeply connected to the attachment relationship and can be disrupted through trauma. The right hemisphere is also responsible for the internal representations of attachment figures (specifically, this occurs in the right orbitofrontal cortex, where implicit procedural memory lies.). In turn, the mother's right hemisphere is more involved than the left in processing emotional cues and mothering. Boiled down, attachment is a right brain-to-right brain system, interactively regulating affective arousal. There is a biological synchronicity (Schore, 2013).

Schore echoes other researchers in proposing an early childhood autism "phenotype", which, if identified early on, while the brain is still highly plastic, can lessen or even prevent the challenges associated with autism through attachment-focused changes. Regulation theory guides attachment episodes of spontaneous visual-facial, auditory-prosodic, and tactile-gestural affective communications. Through these, the caregiver interactively regulates an infant's internal states of peripheral and central arousal.

Schore (2013) discusses three different areas that serve the attachment relationship: first is visualfacial attachment. Mutual gaze is critical to early social development. During this critical stage, synaptic connections in the occipital cortex (modified by visual experiences) are activated when exposed to faces. This begins at two months and becomes increasingly selective to mother's face. Next is auditoryprosodic attachment. Here the caregiver's use of infant-directed speech activates the right temporal area in 4- to 6-month olds, which directly leads to the ability to read the emotional tone of the voice of others. Also, there is tactile-gestural attachment. Touch synchrony (affective touch) is related to the infant's vagal tone and cortisol (the stress hormone) reactivity. As the infant grows into toddlerhood, these attachment areas become integrated and allow for the emergence of a coherent right brain emotional and bodily individual sense of self (Schore, 2013).

Additionally, severe and ongoing dysregulation may lead to a psycho-physiological state called dissociation, used to conserve energy in the face of tremendous terror (Levine \& Kline, 2007). In their 


\section{R.B. Miller et al.}

Pragmatic Case Studies in Psychotherapy, http://pcsp.libraries.rutgers.edu/

Volume 17, Module 2, Article 2, pp. 129-209, 08-04-21[copyright by authors]

book, authors Levine and Kline (2007) note that children who lived in a state of fear may have become frozen in a defensive shell, and thus appeared to have autism to well-meaning professionals. In one such family case, the authors noted:

[The mother] began to realize that doing less was in fact the recipe for healing. As the family gave up their struggle and began to process their own grief, in a nurturing, fun, and warm environment, Forrest began to blossom. His tantrums became an opportunity for his parents to stop and center in the deepest, calmest place within. (p. 358)

The authors posit that Forrest's rapid recovery was because he had been misdiagnosed with autism, while his true diagnosis should have been Post-Traumatic Stress Disorder. They urge professionals to be sure to rule out Post-Traumatic Stress Disorder before diagnosing a child with autism. If a child who has PTSD is misdiagnosed with autism, the real problem is that the intervention may never address the trauma.

\section{Clinical Practice and Treatments}

Retrospective studies that looked at early home videos of children later diagnosed with autism found that infants $0-6$ months with autism show lower levels of enjoyment in social engagement, expression of affective states, and ability to attend and read the affective states of others. These children also have lower levels of social initiative, difficulties which progress as the child ages. Parents tend to become hyperstimulating, overstimulating their child in response to their inactivity. Schore (2013) suggests that the relational context may be the catalyst for the increase in the infant's dissociative withdrawal. Screenings in the first six months of life could identify some of these pairs, and result in parent-infant relationship training thereafter to potentially change the course of the developing brain.

Case examples of children with autism (e.g., Rhode, 2004) or with early signs of autism (e.g., Voran, 2013) discuss the importance of the parent - the mother, in particular - seeing the child for who the child actually is, rather than basing treatment of the child on who the parent would like him or her to be. This can lead to a lack of parental attunement to the child's needs. Dr. Miriam Voran is a psychotherapist who believes that there is a certain temperament that is more likely to withdraw internally when overstimulated (Voran, 2013). In her research and clinical work (and that of others), she has found that as babies tend to withdraw, parents tend to "get bigger", perhaps in an intrusive manner. This may lead to the baby withdrawing further, finding the social world to be too much and ultimately go into a permanent state of internalization.

Voran wrote a case study of a family with whom she worked in practice (2013). The family was referred to her for therapy because their six-month-old daughter was displaying some signs of autism and other courses of action had proved unfruitful. Dr. Voran observed the infant's autism-like symptoms and was able to help the family change the course of behavior by encouraging the mother to acknowledge and release some negative feelings she had, resulting from her parenting experience not being all that she had expected. The mother learned to recognize and reflect her daughter's emotions, to play in a relaxed manner, and was open to feedback regarding the overwhelming noise (from multiple music and television mediums, simultaneously) in the family home. As a result, the young girl righted the path to developing as a typical toddler. Dr. Voran (2013) wondered what would have happened had the little girl and the family been left to their own devices-would the young girl have continued to retreat into herself, and later been diagnosed with an autism spectrum disorder? 


\section{R.B. Miller et al.}

Pragmatic Case Studies in Psychotherapy, http://pcsp.libraries.rutgers.edu/

Volume 17, Module 2, Article 2, pp. 129-209, 08-04-21[copyright by authors]

In response to Voran's (2013) case study, Dr. Allan Schore wrote an article that described in great detail the many connections between the early months and years of a child's life and brain development (Schore, 2013). In particular, he noted the areas that are commonly thought to be impaired for children with autism, specifically related to the intersubjective deficits that are at the core of autism. Schore attempted to draw connections between clinical practice and the research to help those who are in the field to better help those who are affected and those who work in related clinical fields (Schore, 2013).

The concepts of autism and trauma have not had much of an empirical past together, but it is easy to see how they are intertwined. As Voran (2013) laid out in her case study, the parents held certain expectations about bringing a baby into the world and then the baby failed to meet those expectations. She was not warm and affectionate. She held her body in a rigid manner when her mother tried to hold her close. As relationships tend to do, this became transactional: as the daughter rejected the advances of the mother, the mother internalized the rejection and advanced less frequently, or with less enthusiasm. Because the family did not start work with Dr. Voran before their daughter exhibited signs of low social connectedness, it is not clear who began the pattern, but Dr. Voran suspected that the mother may have had some deep-seated emotions related to her own attachment with her parents that was making the warmth needed to reach her daughter more difficult. The mother was unwilling to delve into her past in any way that would have been meaningful for therapy. Nonetheless, she was able to take Dr. Voran's feedback and use it effectively. Now, if the mother did not start out with a negative childhood frame and had healthy attachments in her own life, but the child was still avoiding her gaze or otherwise averting her attention elsewhere, the mother could still, in a transactional way, begin to take this seeming slight personally and internalize it, allowing herself to believe that her child does not feel affectionately about her (Voran, 2013).

This work might be of some small benefit to the child alone, but ultimately the work would have to come from the child's primary caregivers. Parent-child interaction therapy or some sort of modified family therapy with an element of play would be ideal. As noted in Miriam Voran's case study of a sixmonth-old girl (2013), in which the parents were closed off to doing any work on themselves, an openness on the part of the parent is extremely beneficial, but not necessarily critical.

\section{Clinical Work in Practice}

The Tavistock Clinic is a psychotherapy center in the United Kingdom that has a team of associates who specialize in the psychodynamic treatment of autism. Anne Alvarez and Susan Reid from the Tavistock Clinic edited a book with many contributing authors, together compiling a volume that includes theory, guidelines for treatment, and case studies.

Reid (1999) describes families' experiences of having a child with autism. She noted that the overarching themes were that the child lives in their own separate and mysterious world, and that they, the parents, are not interesting to the child. This can leave the parents with feelings of despair and hopelessness. Regardless of the child's personal etiology of autism, the main characteristics, such as the lack of a desire for social engagement, leaves families suffering in their own right. Reid (1999) suggests assessing the child in the presence of the parents to open up communication within the family and to keep from being yet another expert that knows how to work with their child better than they feel they can. Reid believed that this could increase the feelings of helplessness that parents are already fraught with, and to widen the chasm between parents and child. 


\section{R.B. Miller et al.}

Pragmatic Case Studies in Psychotherapy, http://pcsp.libraries.rutgers.edu/

Volume 17, Module 2, Article 2, pp. 129-209, 08-04-21[copyright by authors]

In the book Autism and Personality, Reid (1999) lays out her suggested plan for assessing a child with autism and the child's family. She noted that this may take several months, as there are many phases. The goal is to focus on discovering the nature and location of the distress in the family (rather than on diagnosing) (Reid, 1999). The therapist must pay attention to behaviors, but also the state of mind in which the behaviors are displayed. Reid laments that families who are told that autism is organic in nature then believe that it cannot be treated. While there is no cure for autism, there are certainly treatments that can alleviate the symptoms to improve quality of life. The core feature of autism is the lack of awareness of the realm of personal relationships (Reid, 1999).

First, Reid believed that reports from other professionals should be avoided so as not to have bias before meeting a child. She believed that the therapist should be able to contain the feelings of potentially traumatic impact that autism has had on the family, and carefully observe the patterns between parents and child to find strategies to improve the family's quality of life. After trust has been established, a family history is taken to note areas of health and distress. Only after this has occurred should the therapist meet with the child alone. Meetings with parents are ongoing, and Reid also likes to meet with siblings if they are age appropriate. At some point, she recommended meeting or communicating with other involved professionals to exchange ideas and clarify roles (Reid, 1999).

There are certain components of psychotherapy with children with autism worth considering (Reid, 1999). The setting: regular appointments should be held in a consistent location, which is of utmost importance to children with autism. The feelings of anxiety, despair, and boredom that parents try to avoid on behalf of their children are addressed head on.

The transference is used by the therapist to see how the child views his or her relationship to others. It is often used to make repairs to the parent-child relationship by improving the child's capacity for emotional communication. The countertransference is used via observation on the part of the therapist of how the child reacts, even very small changes, to the therapist, which can then point the way for the therapist to continue on or retreat. The therapist must bring enough energy and imagination for both. There is a strong emphasis on this; the emotional response of the therapist is used as a window into the patient's unconscious. Additionally, if possible, the therapist should watch videos of the earliest interactions in the child's life, which can really illuminate the choice of intervention (Reid, 1999).

\section{Intervention Programs}

In a perfect world, and more and more common in current times, a child with autism will be diagnosed in early childhood. When a child is diagnosed with autism in Ronan's home state, a variety of interventions are put into place. A case manager from a local mental health agency or school system is usually assigned to help parents navigate what services are available. Speech and language therapy, occupational therapy, and physical therapy are commonly recommended for children with autism to target various delays they may have. Further intervention offerings target the child's overall being.

A cursory Google search on autism interventions will bring up a few well-known resources for parents of children with autism. 'Autism Speaks' and 'researchautism.net' were the first two that came up when I searched. Among their categories of interventions and treatments, both mention Applied Behavior Analysis (ABA), medication, and Cognitive Behavior Therapy as means to target behavior. Neither site mentioned relational programs within their list of treatments (though they may be mentioned elsewhere on the sites). I will discuss ABA and less traditional relational programs, as I find understanding both, as well as the distinction between them, to be crucial to the purpose of this paper. 
R.B. Miller et al.

Pragmatic Case Studies in Psychotherapy, http://pcsp.libraries.rutgers.edu/

Volume 17, Module 2, Article 2, pp. 129-209, 08-04-21[copyright by authors]

\section{Behavioral Interventions}

Among the available interventions for children with autism, those with a behavioral focus are the most widely used because of strong research support and because the principles are often implemented in schools (Lindgren \& Doobay, 2011). Much focus is paid to the "ABCs", or the Antecedents, Behaviors, and Consequences, or specifically, how antecedents and consequences lead to certain behaviors and thus can be used to shape or change behavior. Positive behaviors are rewarded to increase their frequency of occurrence. The emphasis of the program is on building skills. There are several other common behavioral strategies that are used for a variety of purposes. Social stories may be used to teach a child what the expectations are in a certain setting. Picture Exchange Communication System (PECS) may be used to offer a non-verbal child a way to communicate using pictures, thus decreasing frustration as the child can make needs and wants clear (Lindgren \& Doobay, 2011).

Behavioral approaches are typically well regarded in academic fields, as there is a plethora of empirical support for them. Trained treatment providers are encouraged to keep tally sheets as children increase language, social skills, and cooperation (accordingly with the child's goals). Tally sheets serve to provide daily support as to whether the current token or reward being used continues to be effective, but also add to the mounting data (Healy, O’Connor, Leader, \& Kenny, 2008).

\section{Relational Interventions}

Relational programs used as interventions for children with autism emphasize learning opportunities through social interaction (Hebert, 2012). As mentioned previously in regards to their omission in well-respected autism resources, these programs are less widely recognized and they do not have as much empirical support as behavior-based programs. The idea is that a child with autism and the adult working with the child each have a mind of their own (Herbert, 2012). Rather than rewarding the child to conform to the adult's expectations for reasons that may not be clear to the child, the adult and child would work together to communicate their needs and wants, their emotions and fears.

The adult is tasked with opening him or herself up to what the child is communicating so that the underlying feelings can be addressed. For example, if a child is fixated on opening and closing a door, a behavioral approach may be to make it so that the opening and closing the door is no longer accessible, or to reward the child for not engaging in this behavior. A more relational approach would be to try to understand if there is some fear or anxiety about the opening and closing of doors (Hebert, 2012).

Additionally, chronological age is not a determinant in developing expectations about when a particular child should meet a developmental milestone. For example, the reasonable goals for a twoyear-old with autism who has no language, no sense of his body, and quickly becomes dysregulated versus a typically developing same-age peer would vary greatly. Thus, a child's developmental age is determined and goals and expectations are built accordingly (Hebert, 2012).

\section{Case Study Literature Review}

During my internship, I was able to see the positive effects of a relational-based therapeutic program on children with varying levels of trauma and on differing levels of the autism spectrum. Children grew in their motivation to connect socially as they learned that it was safe and rewarding to do so. I examined a number of other cases that used a relational model to see if the effects I witnessed were common to this type of program. 
R.B. Miller et al.

Pragmatic Case Studies in Psychotherapy, http://pcsp.libraries.rutgers.edu/

Volume 17, Module 2, Article 2, pp. 129-209, 08-04-21[copyright by authors]

Lydia

A school in New York City called the Rebecca School opened in 2006. Like the Therapeutic Childcare at which I interned, it was designed to meet the various needs of children on the autism spectrum. The ages of the children range from four to twenty-one. The Rebecca School specifically uses the Developmental, Individual-difference, Relationship-based (DIR) model of intervention. Within this model, there is also Floortime, in which the adult follows the child's lead and engages in a rapid back and forth play (Wieder \& Greenspan, 2003).

In the book Respecting Autism: The Rebecca School DIR Casebook for Parents and Professionals (2011), authors Stanley Greenspan and Gil Tippy (also the Rebecca School founder and clinical director) document a variety of cases that have come through the DIR/Floortime program at the school. One such case is that of Lydia. Lydia is four when she makes her first appearance at the Rebecca School. Before this time, her family had a consultation appointment with Dr. Greenspan, the founder of the DIR/Floortime model. The parents recall time with their daughter as being exhausting. If they wanted to get any engagement from her, they needed to pull out all the stops. The parents describe a 20-minute period of time during their consultation with Dr. Greenspan where they worked up a sweat using the amount of enthusiasm it required on their parts, down on the floor, to get their daughter engaged. After this time, they looked up at the doctor, and he said, "That was great! Now you need to do one-hundred percent more!" (Greenspan \& Tippey, 2011, p. 49). At that time, the parents agreed that they could not do the intervention alone.

Lydia was diagnosed at age two, after a period of regression where she lost all the language that she'd been using since age nine months (Greenspan \& Tippey, 2011). Immediately after receiving the diagnosis, Lydia began receiving ABA-based services for 40 hours a week. The parents state that she did "okay", but that there was a lot of crying. They had never seen any fantasy play from their daughter and she did not seem to have any sources of joy. So while she gained a few words and began to point, Lydia's parents were not seeing the kind of progress they hoped for and began to seek alternative forms of treatment. Lydia's mother read about Floortime and tried to implement it within the ABA treatments she was already receiving, but quickly realized it was one or the other - so ABA went, and progress came. Lydia's mother notes that they began to see pretend play and an increase in relatedness.

Lydia began to make connections in thoughts, like singing a song about rain and grabbing an umbrella when she noticed it was raining outside, and asking about people who were not currently present (Greenspan \& Tippey, 2011). She could begin to complete "circles of communication", or back-and-forth question-response cycles, reciprocal and communicative responses that are common in interactions, but was as yet unable to answer "why" questions.

Lydia's father used a game that Lydia enjoyed, called Tickle/Chase where a parent chases and then tickles Lydia, to build on his relationship with Lydia. The game was already fun to Lydia and would draw her in. The next step was to get Lydia to do the chasing, to become the initiator in the game (Greenspan \& Tippey, 2011).

Lydia had been at the Rebecca School for one year at the time of her case study write-up, and her parents had been doing Floortime at home for one year before that. She continued to get dysregulated on a fairly regular basis, but was able to refocus. She engaged with others, but had limited range of 
R.B. Miller et al.

Pragmatic Case Studies in Psychotherapy, http://pcsp.libraries.rutgers.edu/

Volume 17, Module 2, Article 2, pp. 129-209, 08-04-21[copyright by authors]

emotions. Her level of pretend play was stunted and continued to be a goal. She was beginning to use her mind more, and the authors felt her prognosis was good (Greenspan \& Tippey, 2011).

$\underline{\text { Joey }}$

Another case study that uses the DIR Floor Time model documents the case of Joey, age 30 months at diagnosis and beginning in a DIR program at the age of approximately 36 months (Wieder \& Greenspan, 2003). At the time of diagnosis, Joey was non-communicative except when he took a parent's hand to indicate that he wanted a cookie. He spent much of his time fixating on driving a small car back and forth on the floor. His father was able to make his son laugh when he would throw his son around in roughhouse-style play, but the dad felt he really did all the work in the interaction. After six months in the program, Joey and his father have an interaction where the dad acts as the "toy", representing an airplane, and Joey has the keys to make it run. Without eye contact, hand-to-hand contact, and some verbal representation, the plane will not go. As Joey and Dad become more accomplished in their mutual play, additional complexities are added into the mix, such as plane crashes, turbulence, the need to refuel, etcetera. Each of these variations requires that Joey continue to stay in the moment with his father and pay attention to the cues to keep the play on course. Joey learns that play with his father is more fun than playing alone with his cars. In classic DIR-fashion, an activity that was already mutually enjoyed by father and son was taken and complexities were added to require more active engagement from Joey. The mutual pleasure taken in these games deepened their relationship (Wieder \& Greenspan, 2003).

Through the playful barriers set up by Dad in these games, Joey learned to become a better problem-solver (Wieder \& Greenspan, 2003). First, Dad was simply meeting the physical needs of his low-muscle tone son. Over time, the play became more than just meeting a physical need and took on a more symbolic nature. An additional six months later, Joey could play out a similar scene of plane crashes, turbulence, and the need to refuel with small figures. This play then translated to other scenes acted out by Joey and Dad. More months passed and the play moved from somewhat scripted in nature to more symbolic and magical, with themes of emotions emerging. The symbolic play allowed Joey to explore themes that were coming up in real life, with emotions he had once turned off and now felt deeply. By age six, Joey tackled motives of "bad guys" in his play, and discussions with Dad could be abstract and complex. Joey's dad would set up scenarios where Joey had to anticipate his feelings or the feelings of another to help Joey increase his empathy for others. He had learned ample social skills and was actively involved with his peers. He continued to use his Floor time to work through real-life emotional struggles he encountered with his peers, allowing him the opportunity to resolve potential conflicts and work through new and intense emotions (Wieder \& Greenspan, 2003).

What a powerful experience for Joey and his father. When Joey began the DIR program, his father felt that he had had very little by way of meaningful interactions with his son. He felt truly disconnected. Likewise, Joey had not yet seen how delightful these social interactions could be, and had retreated into his own quiet and predictable world. What began as play turned into Joey's way of sorting through his more abstract thoughts (Wieder \& Greenspan, 2003).

\section{ABA Case}

Looking over cases that use a similar relational approach like the one used at the Early Intervention Center has been great for comparison purposes. However, several of the cases mentioned that the child had engaged in ABA services before the child's parents decided to look into other programs. ABA left something to be desired: mainly, the relationship and pretend-play pieces. ABA is the most 


\section{R.B. Miller et al.}

Pragmatic Case Studies in Psychotherapy, http://pcsp.libraries.rutgers.edu/

Volume 17, Module 2, Article 2, pp. 129-209, 08-04-21[copyright by authors]

widely recognized and used program for children on the spectrum, so I wanted to be sure to fully address the program. ABA has the most empirical support, but this is in large part because the way the program is designed makes recording data much simpler than relational programs (Healy et al., 2008).

ABA is considered an effective practice for teaching language, communication, social, and leisure skills, increasing independent functioning, and replacing or eliminating challenging behaviors (Healy et al., 2008). Typical outcome measures for children in ABA programs are IQ scores and ability to be in a typical classroom, and whether the child needs supports to do so. Some ABA-follow up studies have found that gains in IQ and behavior are maintained for at least 10 years (Healy et al., 2008).

In a case study presented by Healy and colleagues (2008), the child (referred to simply as "the participant") studied was two years and two months old at the time of diagnosis. Her diagnosis was based on impairments in social interaction, communication, and imagination, as well as engaging in repetitive behaviors commonly indicated in ASD. When she was two years and four months old, an assessment was conducted to determine an education plan. Some concerns that were noted were "poor attention to tasks and difficulties with compliance, stereotypical patterns and self-stimulatory behaviors, language and social communication difficulties that impacted primarily on her ability to learn." Also noted was that she was not toilet trained, did not use utensils, drank out of a bottle, had few words, and ignores visitors in her home. The participant also walked on tiptoes, disliked loud sounds, and used repetitive hand movements (Healy et al., 2008).

For this case, an early intervention program called the Comprehensive Application of Behavior Analysis to School (CABAS) was used, which is a program that highlights teacher training and teachers as scientists (Healy et al., 2008). Also included at the core of the program is a parent education component. The participant began the 32.5 hours per week intervention when she was two years and ten months old. At the beginning of the intervention, the researchers noted that the participant would not sit in a chair, had no appropriate forms of communication, cried for much of the school day, and displayed a high rate of self-stimulatory behaviors.

Results were displayed in a series of charts (Healy et al., 2008). Some depicted the participant's steady gains on a variety of assessments and psychological tests, such as the British Ability Scales II (test of cognitive abilities), the Vineland Adaptive Behavior Scales (test of day-to-day adaptive functioning) and the Gilliam Autism Rating Scales (tests for four main subareas of autism: Communication, Social Interaction, Developmental Disturbances, and Stereotyped Behaviors). Another chart documented how much time the participant was able to spend in mainstream education setting, and whether or not an ABA instructor was supporting her in the setting. Another chart documented her increasing "basic learner" skills over time (e.g., cooperation, receptive language, requests). Finally, her academic and self-help skills were tracked. In general, steady gains were made in all areas at each interval. By the end, the participant was integrated into a mainstream school for first grade math and English classes for two hours a day. She got a full score on cooperation, receptive language, imitation, and request skills. Her IQ-score was tested using the British Ability Scales and went from 87 one and a half years into the intervention and was 100 three years in. She scored in the "age-appropriate" category in several academic areas as well as self-help areas, such as grooming, eating, and toileting. The case was considered successful (Healy et al., 2008).

This program felt cold to me from the outset by simply choosing not to give "the participant" a name. On several occasions, I felt compelled to give her a name myself, but I believe that the lack of 


\section{R.B. Miller et al.}

Pragmatic Case Studies in Psychotherapy, http://pcsp.libraries.rutgers.edu/

Volume 17, Module 2, Article 2, pp. 129-209, 08-04-21[copyright by authors]

doing so on the part of the researchers was somewhat indicative of the type of program they are a part of. Her personality or likes were not discussed, but rather a series of behaviors that she either engaged in that were not desirable or that she did not engage in that were desirable. I also had to resist the urge to put certain sentiment in quotation marks, such as "no 'appropriate' forms of communication", or to note that it is not unusual for a typical child to lack toilet training at age two years and four months. Indeed, I felt that this child was stripped of her humanness and boiled down to a set of expectations, some of which seemed unreasonable for a typically developing same-age peer. Similarly, in the results and/or discussion, I would have expected the authors to address the child's overall functioning. Did she have friends? What was her relationship with her parents like? Did she have a rich imagination and carry out complex play ideas that she genuinely enjoyed? It seemed the goal of this research was simply to address the participant's compliance and adherence to goals, her academic abilities, and her integration into a mainstream education system. Overall, it had a very different feel than the other case studies presented here.

It is important to note that I did not choose an ABA-based case study at random, nor did I choose one that I disliked solely so that I could "rip it apart". I chose a study that had a child in an intensive early intervention program, that followed the child for a number of years, whose presentation was similar to the other children discussed previously, and that gave detailed descriptions of the intervention. Ultimately, I was disappointed by the lack of richness described in the case.

\section{$\underline{\text { Conor }}$}

The final case I considered was that of three-year-old Conor, who began intensive therapy three days a week shortly after his diagnosis (Hanson, 1999). While Conor's case was written up by his psychotherapist, the similarities in Conor's case and Ronan's are striking.

When psychotherapist Carol first met Conor, she notes being drawn to him by his attractive outward appearance (Hanson, 1999). She described the severity of his withdrawal as being quite great, and that he could be difficult to be with during his somewhat frequent moments of despair. Carol compared Conor to a wild animal, flitting back and forth without seeming to see or take in his surroundings. Carol noted that the way he seemed not to focus on anything was reminiscent of an absence of the firm base that the ordinary link between a mother and child can provide, as the mother's face and eyes act as magnets for the baby to attach to. She compared his flitting around the room to rooting, as if he was searching for something to latch on to. His lack of coordination made it difficult to know how to hold him in the space and help him to feel safe. She articulated, "I felt like I was working with a very small baby driven by a terror of falling into unbounded space," (Hanson, 1999, p. 158).

Carol noted that she had to pull more drama into her voice and gestures to capture Conor at all (Hanson, 1999). She found he was very sensitive to lapses in her attention, and that he would drop into mindlessness if he sensed a shift in her focus.

Conor seemed to lack a sense of a world of mindful figures who could be interested and interesting. This is thought to be essential for the development of a human mind where thoughts can occur, experiences can be remembered, links can be made, and imaginative life can develop. Without such a concept of a containing person, Conor fluctuated between a state of helpless collapse and dizzy mindlessness. As I began to refuse to be smoothed out 
R.B. Miller et al.

Pragmatic Case Studies in Psychotherapy, http://pcsp.libraries.rutgers.edu/

Volume 17, Module 2, Article 2, pp. 129-209, 08-04-21[copyright by authors]

and passed over psychologically, insisting my right to exist in his world, he began to seem interested. (p. 158)

Conor needed a presence strong enough and dedicated enough to push into his world, and to pull him out of his world.

As Carol and Conor continued to meet on a regular basis, Carol noted that Conor was beginning to develop a sense of himself, and that he was becoming increasingly aware of his need for a focused person to help him regulate and provide a sense of safety (Hanson, 1999). He started to think about the world. Unlike in a Floortime session, Carol would often narrate what she believed Conor was experiencing. In a Floortime session, it would not be uncommon for a facilitator to say, "I can see that you're frustrated with that toy," or "I can see that you're mad that I told you 'no'." However, Carol would say things that had a very psychodyanamic feel, such as, "You are testing to see if I'm strong enough to handle your angry feelings, " or "You're letting me know you tried to hold a picture of me in your mind when you weren't here." Carol noted times that Conor seemed very connected to her and times he did not. If she made an interpretation that was incorrect, Conor would quickly retreat into his personal world (Hanson, 1999).

After two years of intensive treatment, Carol felt like Conor was experiencing a "real emergence from his autistic state" (Hanson, 1999, p. 164), using songs and language to communicate about his feelings. He was able to recognize that he was a separate being from Carol and that other children saw Carol, too. At the end of treatment, Carol noted that Conor had significantly reduced the strength of his autism symptoms and had meaningful relationships with his family and peers. He continued to have developmental delays, but was far from "his early undifferentiated mindlessness," (p. 170). Just one year at the Early Intervention Center has pulled Ronan from a similar sounding "undifferentiated mindlessness."

\section{ASSESSMENT OF CLIENT'S PROBLEMS, GOALS, STRENGTHS, AND HISTORY}

Ronan's aunt notes that he "seemed normal" when she saw him in his earliest months for doctor's appointments. Ronan's doctor records up to the age of 18 months do not mention any suspicions that he may be on the spectrum, but doctors must rely heavily on parent report since there are a number of reasons a young child may not make eye contact or speak verbally during a pediatrician visit. Annette believed that Ronan's parents would consistently report that Ronan was meeting all milestones, either because they wanted to look like good parents or because they simply did not know their child well enough to know the answers, which made tracking his progression into his current state even more difficult.

When Ronan came into her care at the age of 20 months, Annette and Ronan's case worker arranged for testing through the local Child Development Clinic for diagnostic support and treatment recommendations. Ronan did not display eye contact and seemed not to hear or understand anything Annette said. Testing occurred and Ronan was given a diagnosis of Autism. When Annette asked the diagnosing doctor where to go from there, the doctor recommended reaching out to the Early Intervention Center. 
R.B. Miller et al.

Pragmatic Case Studies in Psychotherapy, http://pcsp.libraries.rutgers.edu/

Volume 17, Module 2, Article 2, pp. 129-209, 08-04-21[copyright by authors]

The goals for Ronan and the other children at the Center were primarily to build the desire for social connection and to build meaningful life skills. There was a focus on integrating families in the treatment, so that the relationship skills built could transfer beyond the Center's walls. While Ronan had met a number of challenges in his short life, it was a significant strength that he was now in a safe environment, that his aunt was willing to seek the most appropriate treatment for Ronan, and that Ronan was able to get into the center on relatively short notice.

\section{FORMULATION AND TREATMENT PLAN}

The aim of the Early Intervention Center that Ronan attended is to increase a child's intrinsic motivation to become a part of a social world, with staff, family, and other children. The model aims to increase a child's intrinsic motivation to engage with others (as opposed to using behavioral or external motivators, such as giving a reinforcer when a task is accomplished). The model emphasizes the relationship first, as the priority. Once a strong relationship has been established, the adult in the relationship can push the boundaries in small, meaningful ways to help the child master new skills.

Parents are encouraged to be actively involved in their child's experiences at the Center, checking the outside world (to-do lists and other distractions) at the door. Parent coaching and counseling is made available to all parents whose children are in the program. Parents or caregivers are able to gain awareness of how to engage with their child in a positive and dynamic manner. When parents stay in the morning, they are encouraged to follow the child's lead and read their cues. Guidance from Center staff is offered once it seems clear that parents are open to receiving it. Genuine interaction between adults and children is nurtured. Children tend to be good at reading when an adult is bored or only feigning interest; children with autism are no exception. Over time, the goal is that parents will become more attuned, actively engaged, and genuine with their children.

Staff at the Center work to develop a co-regulatory relationship with each child. Co-regulation occurs when two partners move at the same time in close relationship to one another (Fogel \& Garvey, 2007). Verbal and non-verbal communication can be used to fine-tune this relationship. Deeper still, it is a child and mother using each other's cues and non-verbal communications to regulate their emotions. This is typically developed in children as babies, but it is not uncommon for children with autism to have missed this developmental skill because of their lack of social attunement and engagement. Thus, one of the first goals of staff at the Center is to work with each child to develop co-regulation.

The relationship is at the core of the intervention used at the Center, but behavioral strategies are certainly employed. Once a child has demonstrated mastery of a communicative skill, it becomes an expectation. For instance, once a child can say or sign "more" in reference to food, staff would expect that the child say or sign "more" every time he or she wants more of something. The reward in this case would be that the child receives more of whatever they were asking for. It is important to note, however, that the child and his or her abilities continue to be evaluated moment-to-moment. For instance, if the child has previously demonstrated an ability to say or sign "more" but has been having a day fraught with tantrums or meltdowns, staff will evaluate if the child seems to have the capacity on this given day to be pushed. 
R.B. Miller et al.

Pragmatic Case Studies in Psychotherapy, http://pcsp.libraries.rutgers.edu/

Volume 17, Module 2, Article 2, pp. 129-209, 08-04-21[copyright by authors]

\section{COURSE OF TREATMENT}

\section{Winter 2015}

When Ronan first began at the Early Intervention Center, his aunt Annette dropped him off each morning and picked him up each afternoon. When she dropped him off, he showed no signs of distress, including his first days at the Center. When she arrived to pick him up, he showed mild joy, such as a smile crossing his lips but no physical or verbal greeting. This was in direct contrast to many other children at the Center, for whom separations were particularly distressing and difficult.

When Ronan first began at the Early Intervention Center, he seemed like he was not really present in his body. If he got hurt, such as bumping his head, he seemed to barely register the pain, perhaps only pausing briefly before moving on. His sense of where the floor or wall ended and his body began seemed poor, so such accidents occurred with some frequency. He would flit from one activity to another with little focus or motor planning. He often "flopped" on the floor when told no or when a redirection attempt was made to dissuade him from an activity that was unsafe or otherwise unavailable to him at the moment.

Ronan's favorite time of the day was, and still is, mealtime. During meals, Ronan would eat quickly and seem difficult to satiate. He was also very picky - he did not like fruit or foods with a texture his aunt described as "slimy". Ronan made slow but steady progress throughout his earliest months at the Early Intervention Center with respect to his ability to maintain focus on a task, his willingness to engage with others, his communication skills, and his interest in trying new and different foods.

Naptime was difficult for Ronan when he first began at the Early Intervention Center. It was clear that his newly 2-year-old self still needed naps, but it was very difficult for him to settle enough to fall asleep. One staff member began to rock with him in a rocking chair while bottle-feeding. Ronan would struggle to get out of the staff member's arms and then would eventually settle.

When Ronan had been at the Early Intervention Center for three weeks, I had my first experience with him where I felt like I saw a glimmer in him, a desire for connection with others. Ronan was obsessed with doors. He would stand at a door and open and close it repeatedly, in what seemed like a self-stimulatory manner. On a day during his third week, I joined him at the door and began to sing a children's song called "Open, Shut Them", modifying the words that usually go with hand motions to capture what he was doing with the door. "Open, shut it, open shut open, open then shut the door!" I sang, to the time of his movements. Later in the day, I began to sing that song with the hand motions to another child. Ronan stood up and ran to the door. He stood idly while I wondered if he wanted me to join him. I approached and he began to open and close the door as I sang the song. This was a powerful experience for me. Ronan was already beginning to engage more actively in short bursts and understand the expectations at the Center.

Another two weeks went by and Ronan continued to engage more with others. He became increasingly aware of his surroundings and seemed to take pleasure out of highly active games such as chase or tickle. He gave more frequent eye contact and was beginning to babble. In general, he seemed less chaotic and flighty. To my new eye, Ronan seemed to be making such huge strides in such a short amount of time. I was amazed and impressed, leaving me with high hopes for his future. As I have come to learn over time, this is common for new children at the Early Intervention Center. The children who I 


\section{R.B. Miller et al.}

Pragmatic Case Studies in Psychotherapy, http://pcsp.libraries.rutgers.edu/

Volume 17, Module 2, Article 2, pp. 129-209, 08-04-21[copyright by authors]

have seen start there tend to have an experience of making exceptional changes quickly, as they learn how it feels to be accepted unconditionally, to have someone work with them to regulate their emotions, to have sensory play that meets their developmental needs regularly available, and to have a team of people who simultaneously accept their developmental stage and yet push them gently to further their capacities. At some point, the children tend to plateau, and progress creeps along at a pace akin to a typically developing child. Ronan was no exception.

\section{Spring 2015}

In the Spring of 2015, Ronan had made much notable progress. He seemed much less anxious at mealtimes and was increasingly more willing to try new things with different textures. His aunt reported that he did not like fruit, so a staff member tucked some into a Jell-O snack that he was packed from home, and he ate it. The next time, it did not need to be hidden in Jell-O. He continued to be weary of vegetables unless they were pureed into a soup.

At naptime, Ronan no longer needed to be rocked to sleep. He would lay on his mat with a staff person nearby to read a couple of books before he was expected to lay quietly until he fell asleep. The relationship between Ronan and the staff member was utilized to build trust and provide comfort over a period of months. Eventually, the physical touch of the staff member was no longer needed, because her physical presence provided sufficient comfort.

As the weather warmed, the staff and children began to spend more and more time outside. The Center is located on a quiet dirt road and nearby to a river. Many spring walks were taken to the river. This walk is about 15 minutes each way (depending on how much meandering occurs). Ronan went on one such walk on a nice spring day. He did not seem to find the walk pleasurable and sat in the road for some time, refusing to walk. The next day for outside time, Ronan began to fuss and melt down, refusing to put on his outdoor garments. Once it was made clear to him that the group was going to play in the yard that day, he gladly went outside. This was a clear message to the staff that Ronan needed to have some buildup to the long walks to the river. The next time there was a walk, he and a staff person walked slowly along the dirt road for a few minutes before turning back.

Ronan's home was a lengthy drive away at over 30 minutes, and his aunt worked near their home. Taking this time off from work was a hardship for her and she was unable to continue to do so. She arranged for a neighbor to drop Ronan off each morning and continued to pick him up for several months. Parents and guardians are always encouraged to stay at the beginning of the school day for 20-60 minutes to see his or her child interact with others at the Center, as well as to observe strategies that the welltrained staff utilize with the children, but Annette was unable to have this time.

\section{Fall 2015}

The Center holds programming during the school year, and also has a 6-week summer program. They are closed for two weeks in June and most of August. Ronan attended programming during the summer, but I did not observe him during that time.

I met with Annette to discuss Ronan's early history in the late fall. She welcomed me into her home, but was not warm. We sat at the kitchen table immediately inside of the outside door. She answered all of my questions to the best of her recollection, but rarely elaborated. There was not an easy 


\section{R.B. Miller et al.}

Pragmatic Case Studies in Psychotherapy, http://pcsp.libraries.rutgers.edu/

Volume 17, Module 2, Article 2, pp. 129-209, 08-04-21[copyright by authors]

"narrative" feel to the conversation. Towards the end of my visit, Ronan arrived at the home with a family friend, with whom he has a warm connection, according to his aunt. Annette maintained her focus on me, not speaking to her nephew or friend. Ronan did not attempt to get Annette's attention, but did indicate to the family friend that he wanted a snack by lingering in the kitchen area. She asked him if he wanted a snack and he responded by climbing into his chair at the table. She served him some crackers and he was satisfied. At one point while eating his snack, Ronan's older sibling (also in Annette's care) walked by. Ronan quickly raised his hands in a manner that indicated that he felt like he needed to protect his food. Annette commented to me that no one ever takes his food, but that Ronan continues to guard it.

At the Center, Ronan would often find an activity that he enjoys, and would seem perfectly happy to have an adult or peers join him in the activity (unless they took items he intended to use), but he showed little initiation in interactions with adults or peers. Other children at the Center enjoy games of hide and seek or chase. Ronan may have gotten caught up in the joy that other children experienced during such games and laugh along for a moment, but those moments were fleeting.

One area of growth that really struck me was in Ronan's ability to be comforted by a trusted adult. In his earlier days at the Center, Ronan would "melt down" when told no or redirected. A meltdown usually consisted of screaming, flopping onto the floor, kicking his legs, and flailing of his limbs. During meltdowns, Ronan seemed unable to process and might have gotten stuck in this pattern for a number of minutes. In the fall, Ronan began to seek out an adult, even if the adult was the source of his anger (i.e., the person who told him no or attempted to redirect him), and receive physical comfort and regulation from that person.

\section{Winter 2016}

This winter, my relationship with Ronan has grown in some notable ways. Weeks prior, I had remarked to the director that another same-age peer of Ronan's is so much more socially motivated than Ronan is. For instance, this peer would seek out adults for a variety of games he enjoyed playing, such as chase or sword fighting. In contrast, Ronan was happy to have a person playing alongside him, but he would be just as happy to play alone. However, just as I started to sort through why this may be, it began to change. I had a variety of interactions with Ronan where he made it perfectly clear that my engagement was more than just welcome, but wanted. The first example of this was small but powerful: Ronan had just learned the new skill of blowing bubbles through a straw into his water cup. He spent a few minutes playing with his cup of water and straw before I decided to join him. I brought my own cup of water and straw to the table and sat beside him. He was interested in the bubbles in my cup for a moment before he returned to his own. I stopped blowing bubbles and set my cup down. He immediately picked up my cup and handed it back to me. He picked his own cup back up and pointedly waited for me to blow bubbles alongside him. It was clear that Ronan wanted me to participate in the activity with him. It did not seem as highly engaged as a game of chase or something that involved turn taking, but Ronan was enjoying the presence of another. It was a step.

The very next day, Ronan engaged his peers in games of Legos, took turns with peers when jumping into a soft landing pad, and had a very special interaction with me during his naptime. Ronan stopped napping early in the winter, but was still expected to have a meaningful rest. His nap items were set up daily on a beanbag. A staff member would read stories to Ronan for a period of time before he was expected to rest quietly. On this particular day, I was in the nap room with Ronan. Two of his peers had 


\section{R.B. Miller et al.}

Pragmatic Case Studies in Psychotherapy, http://pcsp.libraries.rutgers.edu/

Volume 17, Module 2, Article 2, pp. 129-209, 08-04-21[copyright by authors]

just fallen asleep. While I did not have high expectations that Ronan would fall asleep, he had been rubbing his eyes and I was aware that he might be in need of a nap. He began to get restless and was having difficulty remaining on his rest spot, so I pulled him onto my lap and began to sing a series of songs as I rocked him gently. He relaxed visibly and seemed comfortable, so we continued in this manner for 10-15 minutes. Just as Ronan seemed likely to drift off, he sat up quickly and moved back onto his rest spot. I leaned close onto his beanbag and was deliberately taking loud deep breaths. He looked at me and gently took my face in his hands. He kissed me on the cheek several times and then turned his cheek towards me, indicating that he would like me to kiss him on the cheek as he had done to me. I did so. We repeated this three-to-four more times. While I remained calm on the outside, I was celebrating on the inside. This was big growth for Ronan. In this two-day period, we had had several meaningful interactions, culminating in this very intimate face touching interaction.

Since first meeting Ronan, he has made progress in many notable areas. Perhaps the most important of these areas is in the development of his sense of self. To develop this sense, a child needs to recognize that he or she is an individual separate from other individuals. The person has thoughts and beliefs that may not be that same as those of others. An early example of this development is when a child pushes boundaries of what is and is not acceptable. A child who lacks the awareness that others have their own minds are unlikely to make social references when pushing these boundaries. As this develops, a child might do something that he or she knows is not allowed while anticipating the "no" response from the adult. Eventually, the expectations may become internalized.

On two separate recent occasions, Ronan teased a staff person at the Early Intervention Center. On one occasion, he offered a fork-full of food to an adult. The adult accepted (consider what a big step this was for Ronan, to go from his food obsession to offering another person a bite of his food). Ronan offered another bite and as the person leaned in for it, he smirked and popped it in his own mouth. On another occasion, Ronan held out his foot to me and said "off", to indicate that he wanted his slipper off. When I went to take it off, he said, "no!". I remarked that I must have misunderstood him. He then held his foot out to me again, repeating "off!". When I leaned down a second time, he again said no and hid his foot. He had a smile on his face this second time. Both of these instances of Ronan joking or teasing show that he has begun the development of an intersubjective self. Intersubjectivity refers to shared interpretations of social interactions, or the sharing of subjective states (Stolorow, Brandchaft, \& Atwood, 1995). It can also refer to a shared divergence in meaning, such as with teasing. In this case, Ronan had an idea in his mind and he recognizes that it is an idea the other person does not yet know. What a great development in his theory of mind!

Towards the end of winter, Ronan made another leap in his development. Children with ASD often experience Sensory Processing Disorder, where the senses regularly overloaded the system, leading to anxiety, meltdowns, or restlessness (Grandin, 1992). Most of the children at the Early Intervention Center have an Occupational Therapist who visits weekly and gives tips to the staff on how to help the children with issues such as this. Ronan occasionally enjoys wearing a weighted vest, at times even seeking it out when he begins to feel dysregulated. Another common activity to engage and integrate his senses is to roll him up in a yoga mat and put deep pressure on him. This is typically done in a very playful manner and Ronan enjoys it. Ronan does not typically engage in symbolic play. He likes to build, paint, figure out how things work. Recently, however, Ronan took a baby doll and wrapped the doll up in the yoga mat. Perhaps Ronan is preparing to move into the world of symbolic play, opening countless doors for his growing imagination. 
R.B. Miller et al.

Pragmatic Case Studies in Psychotherapy, http://pcsp.libraries.rutgers.edu/

Volume 17, Module 2, Article 2, pp. 129-209, 08-04-21[copyright by authors]

\section{TREATMENT MONITORING AND USE OF FEEDBACK INFORMATION}

I was able to witness an immense amount of growth in Ronan over a period of 14 months. When I first met him, he was a newly diagnosed two-year-old who had extreme difficulty managing his emotions. He did not seem to have a strong attachment to anyone, including his aunt/primary caregiver. He had difficulty sleeping, spending time in a room with a closed door, and was very obsessive about food. Over time, while in a home that was safe and secure, and while in the day program at the Early Intervention Center, Ronan began to make changes in all of those areas.

Most notably, Ronan began to form meaningful relationships with others. While he remained content spending a great deal of time playing alone, he recognizes the comfort and skill that adults can offer him, and is able to utilize their support appropriately. There is some evidence that his home, while certainly being safe and secure, is not warm and welcoming. Annette and her family decided that Ronan was best off in a gated-off area of the house, for safety and to have him away from what she needed to get done around the house. After recent and new protest from Ronan, who finally wanted to be a part of the family, the gates came down. When I visited Ronan and Annette's home, I was struck by how she did not interact with Ronan at all, and also by how bonded Ronan seemed to be to his family friend. These two elements have led me to think that much of Ronan's growth has come from the endless support provided to him at the Center, though it would have been much more difficult if he did not feel secure and safe at home.

\section{CONCLUDING EVALUATION OF THE TREATMENT'S PROCESS AND OUTCOMES}

When I first approached Ronan's aunt about doing a case study on Ronan, her words to me were, "Ronan is a case where his autism came from his early trauma. There's no history of autism in our family, so I'm sure it's not genetic." While I think Annette's reasoning on the matter was somewhat flawed (autism does run in families, but there are also children for whom there is no familial history), she had an interesting notion. Was Ronan taught that his physical and emotional needs would not be met, and thus retreated into himself? Did Ronan learn that adults could not be counted on, and therefore he was better off in his own world?

It is impossible to know the exact etiology of Ronan's autism, but it is a solid theory that Ronan may have come to his autism by way of his traumatic early history. Whether or not Ronan's case was one of a biological etiology or from a place of trauma, his brain changed in important ways that made typical development more of a challenge for him. The relationalbased therapy that was offered to him at the Center addressed the core deficits of autism by teaching him to regulate his emotions and build relationships. That was an invaluable lesson.

\section{Philosophical Dilemma in the Case of Ronan}

When considering the case of Ronan, I was overcome on many occasions with feelings of relief that he was in an adoption-track home and at the Early Intervention Center. He was clearly doing better because of these drastic changes from his previous life. The local Child Development Clinic diagnosed Ronan. When his aunt posed the "now what" question to the diagnosing physician, she was lucky that the 


\section{R.B. Miller et al.}

Pragmatic Case Studies in Psychotherapy, http://pcsp.libraries.rutgers.edu/

Volume 17, Module 2, Article 2, pp. 129-209, 08-04-21[copyright by authors]

physician knew of the Early Intervention Center. Annette immediately went into action to secure a spot for Ronan. As with all children who are officially in state custody, the Department of Child and Family Services would foot Ronan's childcare bill, so finances were not a deterrent. Luckily for the family, there was an opening at the time and Ronan was able to begin within mere weeks of his diagnosis.

What if the diagnosing physician had not known of the Early Intervention Center? What if she thought that an ABA program was best for children with autism? Most children who are diagnosed with autism are offered a variety of early intervention programming, including speech services, occupation and physical therapy, and often, ABA-based services. Children with autism have been shown to exhibit improvements in IQ and self-help skills with ABA, but what continues to be missing is the lack of meaningful social relationships (Gutstein, 2000). While this is a detriment to any child, it is more than just a detriment to a child with trauma. Even in a very pro-behavioral methods research article on trauma and neglect, authors Prather and Golden (2009) state that children with history of trauma need the trusting relationship with a loving adult first and foremost before any meaningful change will occur.

From my perspective, Ronan was lucky to have secured a spot in a program that was so well suited to meet his emotional needs. The philosophy of the Early Intervention Center was always to meet each child where they were, which could vary on a daily basis. Indeed, Ronan and the other children made great behavioral strides, as they learned the expectations of hand washing, sitting down when eating, communicating needs in the best way that child had, etcetera. The distinction between the behavioral changes these children made and those who are doing so because they are being reinforced with tokens are great: children who learn behavioral expectations using a reward system are learning what to do in that very specific setting in order to get a very specific reward. Greenspan and Weider (2006) noted in their book Engaging Autism that children who use this method of learning often have difficulty carrying the learned behaviors outside of the ABA setting. One parent of a child at the Early Intervention Center had her child receive ABA services for a few months before finding the EI Center. She noted that her child had learned through a reward system to point to things, but failed to understand why she was pointing. The behavior was taught, but the meaning was lost. Ronan was learning social and life skills in a dynamic way that would carry across settings - in fact, his family members consistently reported that gains seen at the Center were also seen at home.

What happens to children who do not live in areas with a relational-based program in place? Or for children who do live in a place where it is an option, but the cost is insurmountable? As long as ABA gathers the data and can show increases in IQ scores and in compliance behaviors, there will be funding. What comes next is taking a long, hard look at quality of life. Children who have received relationshipbased programming have been shown to have an overall higher level of life satisfaction and more meaningful relationships than those who received ABA (Greenspan \& Weider, 2006). There is more to life than IQ and the ability to be integrated into a typical classroom. Ronan is doing as well as he is because of receiving an intervention that truly met his needs for security and safety and allowed him to explore in a meaningful way. I expect his current gains would look drastically different if his circumstances were otherwise. The data are there to support relational-based programs, as well, but as long as well-respected autism resources such as Autism Speaks are not recognizing them, they will hardly have the opportunity to become mainstream. 


\section{R.B. Miller et al.}

Pragmatic Case Studies in Psychotherapy, http://pcsp.libraries.rutgers.edu/

Volume 17, Module 2, Article 2, pp. 129-209, 08-04-21[copyright by authors]

\section{Final Discussion}

The case of Ronan is one in which it is difficult to pinpoint the etiology of his disorder. His aunt feels certain that he would not have autism if not for his traumatic and neglectful beginning. Whether or not she is correct, his traumatic history likely at least compounded the symptoms Ronan displayed. As mentioned previously, however, some amount of trauma may be common in cases of young children with autism as the parents wrestle with feelings of inadequacy from the lack of warmth and social relatedness that his or her child displays. As parents feel rebuffed, they may in turn come to reject the child and his or her needs. Regardless of the etiology, it was clear that Ronan had experienced some amount of neglect and trauma in his earliest months. To best reach Ronan, the play and relationship needed to be the focus of his treatment.

Throughout this project, I have been disappointed in what I have learned about ABA. When the common phrase "play is a child's work" is stated, perhaps that was not necessarily meaning to include children with autism. The ABA domain has a focus on shaping one behavior after another until the child can conform to mainstream society. Behavioral methods certainly have a place in the autism world, but we, as humans, are not simply a pile of behaviors. We are also our emotions, our social connections, and our histories. Play is how children learn to connect and relate. Children with autism are no different in this respect, but they may differ in how motivated they seem to be to play, or how innately playful they are. Children with autism tend to struggle with play, which to some may signal that play is not necessary for them to engage with others. On the contrary, play is just as crucial. Play cannot be taught as a chain of behaviors (i.e., Step one: pick up a baby doll; Step two: put the bottle in the baby's mouth; Step three: rock and sing to the baby). It is not for an adult to dictate what the child should do and then judge whether the child did it correctly. Play is only meaningful when it is the result of the child's imagination and desire to act out a personally meaningful experience.

Ronan made extraordinary gains in his ability to relate to others, his differentiation of self, and his curiosity in the world. Through the relationships at the Early Intervention Center, Ronan began his development into a person; an individual with needs and desires that were his alone. I have high hopes that his family and future schools will continue helping him toward a path of great gains. The future is bright for this happy three-year-old boy.

\section{REFERENCES}

American Psychiatric Association (2013). Diagnostic and Statistical Manual of Mental Disorders (5th ed.). Washington, DC: American Psychiatric Association.

Beebe, B., Lachmann, F.M., Markese, S., Buck, K.A., Bahrick, L.E., Chen, H., Cohen, P., Andrews, H., Feldstein, S., Jaffe, J. (2012). On the origins of disorganized attachment and internal working models: Paper II. An empirical microanalysis of 4-month mother-infant interaction. Psychoanalytic Dialogues, 22(3), 352-374.

Champagne, F. A. (2015). Epigenetics of the Developing Brain. Zero To Three, 35(3), 2-8.

Fogel, A., \& Garvey, A. (2007). Alive communication. Infant Behavior and Development, 30, 251-257.

Grandin, T. (1992), Calming effects of deep touch pressure in patients with Autistic Disorder, Journal of Child and Adolescent Psychopharmacology, 2 (1).

Greenspan, S. I., \& Wieder, S. (2006). Engaging autism: Using the floortime approach to 
Further Developments in the Panel of Psychological Inquiry

Method of Case Study Research: The Case of "Ronan"

R.B. Miller et al.

Pragmatic Case Studies in Psychotherapy, http://pcsp.libraries.rutgers.edu/

Volume 17, Module 2, Article 2, pp. 129-209, 08-04-21[copyright by authors]

help children relate, communicate, and think. Cambridge, MA: Da Capo Lifelong Books.

Gutstein, Steven E. (2000). Autism Aspergers: Solving the relationship puzzle. Arlington, TX: Future Horizons, Inc.

Healy, O., O'Connor, J., Leader, G., \& Kenny, N. (2008). Three years of intensive applied behavior analysis: a case study. The Journal Of Early And Intensive Behavioral Intervention, (1), 4.

Kaufman, B. (1994). Son-rise: The miracle continues. Tiburon, Calif.: H.J. Kramer.

Kerig, P., Ludlow, A., \& Wenar, C. (2012). Developmental Psychopathology (6th ed.). New York: McGraw Hill.

Klauber, T. (1999). The significance of trauma and other factors. In A. Alvarez \& S. Reid (Eds.), Autism and personality: Findings from the Tavistock Autism Workshop (pp. 33-48). New York, NY: Routledge.

Levine, P.A., \& Kline, M. (2007). Trauma through a child's eyes: Awakening the ordinary miracle of healing. Berkeley, CA: North Atlantic Books. 15(5), 563-577.

Perry, B.D. Child maltreatment: the role of abuse and neglect in developmental psychopathology. In Textbook of Child and Adolescent Psychopathology (Eds., Theodore P. Beauchaine \& Stephen P. Hinshaw) Wiley, New York, pp. 93-128, 2008.

Prather, W., \& Golden, J. A. (2009). A behavioral perspective of childhood trauma and attachment issues: toward alternative treatment approaches for children with a history of abuse. The International Journal Of Behavioral Consultation And Therapy, (2), 222.

Reid, S. (1999).The assessment of the child with autism: A family perspective. In A. Alvarez \& S. Reid (Autism and personality: Findings from the Tavistock Autism Workshop (pp. 33-48). New York, NY: Routledge.

Rhode, M. (2004). Different responses to trauma in two children with autistic spectrum disorder: the mouth as crossroads for the sense of self. Journal of Child Psychotherapy, 30 (1), 3-20.

Roberts, A.L., Koenen, K.C., Lyall, K., Robinson, E.B., Weisskopf, M.G. (2015). Association of autistic traits in adulthood with childhood abuse, interpersonal victimization, and posttraumatic stress. Child Abuse and Neglect, 45, 135-142.

Rutter M. (2005). Incidence of autism spectrum disorders: changes over time and their meaning. Acta Paediatrica, 94 (1), 2-15.

Schore, A.N. (1994). Affect regulation and the origin of the self: The Neurobiology of Emotional Development. Mahwah, NJ: Erlbaum.

Schore, A.N. (2013). Regulation theory and the early assessment of attachment and Autism Spectrum Disorders: a response to Voran's clinical case. Journal of Infant, Child, and Adolescent Psychotherapy, 12, 164-189.

Schore, A. N. (2014). Early interpersonal neurobiolical assessment of attachment and autistic spectrum disorders. Frontiers in Psychology, 5, 1-13.

Siegel, D.J. (2006). An interpersonal neurobiology approach to psychotherapy. Psychiatric Annals, 36(4), 248-256.

Siegel, D.J. The developing mind: How relationships and the brain interact to shape who we are. New York: Guilford Press, 2012.

van der Kolk, B. (2005). Developmental Trauma Disorder: Towards a rational diagnosis 
Further Developments in the Panel of Psychological Inquiry

Method of Case Study Research: The Case of "Ronan"

R.B. Miller et al.

Pragmatic Case Studies in Psychotherapy, http://pcsp.libraries.rutgers.edu/

Volume 17, Module 2, Article 2, pp. 129-209, 08-04-21[copyright by authors]

for children with complex trauma histories. Psychiatric Annals, 401-408.

van Ijzendoorn, M. (1995). Adult attachment representations, parental responsiveness, and infant attachment: A meta-analysis on the predictive validity of the adult attachment interview. Psychological Bulletin, 117(3), 387-403.

Voran, M. (2013). The protest of a 6-month-old girl: Is this a prodrome of autism? Journal of Infant, Child, and Adolescent Psychotherapy, 12, 139-155.

Wieder, S. \& Greenspan, S.I. (2003). Climbing the Symbolic Ladder in the DIR Model Through Floor Time/Interactive Play, Autism, 7 (425-435). 